Illinois State University

ISU ReD: Research and eData

Theses and Dissertations

6-2-2014

\title{
Essentially Point-Less: The Influence Of Alternative, Non Points- Based Grading On Teachers' Instructional Practices
}

Jay C. Percell

Illinois State University, jpercel@ilstu.edu

Follow this and additional works at: https://ir.library.illinoisstate.edu/etd

Part of the Educational Assessment, Evaluation, and Research Commons, and the Social and Philosophical Foundations of Education Commons

\section{Recommended Citation}

Percell, Jay C., "Essentially Point-Less: The Influence Of Alternative, Non Points-Based Grading On Teachers' Instructional Practices" (2014). Theses and Dissertations. 196.

https://ir.library.illinoisstate.edu/etd/196

This Dissertation is brought to you for free and open access by ISU ReD: Research and eData. It has been accepted for inclusion in Theses and Dissertations by an authorized administrator of ISU ReD: Research and eData. For more information, please contact ISUReD@ilstu.edu. 


\section{ESSENTIALLY POINT-LESS: THE INFLUENCE OF ALTERNATIVE, NON POINTS-BASED GRADING ON TEACHERS' \\ INSTRUCTIONAL PRACTICES}

Jay C. Percell

192 pages

August 2014

Grading is often a time-consuming, laborious task for teachers continuously required to document student performance. Simultaneously, among students there is intense competition for grades, which determine class ranks, college entrances, scholarship opportunities, as well as satisfy parental and societal expectations (Campbell, 2012; Wood, 1994). Due to the importance of grades, some educators have sought to determine whether or not traditional grading systems are truly indicative of students' abilities (Brookhart, 1991, 1993; Guskey, Swan \& Jung, 2011).

This study investigated alternative grading systems, especially those that were non points-based, and the influence alternative grading had upon teachers' instructional practices. This study also examined teachers' motivations for implementing alternative grading systems, how they aligned with teachers' educational philosophies, and how they affected the feedback teachers provided their students.

Utilizing a blended methodology of multi-case phenomenology, case study provided structure in the data collection procedures, while Moustakas' (1994) transcendental phenomenology provided the methodological framework for the data 
analysis, aimed at identifying the essences of teachers' experiences with alternative grading. After bracketing my own experience with alternative grading in the Epoche, and horizonalizing the data along the subsidiary research questions to find invariant qualities, I employed the transcendental-phenomenological reduction (Moustakas, 1994), synthesizing textural and structural descriptions, to arrive at the essences of the experience.

Ultimately, the essences of alternative grading were determined to be built upon strong administrative support with a focus on increasing student learning. While teachers reported that alternative grading did not have much influence over their instructional practices - possibly due to teaching in a style that was conducive to alternative grading so as not to perceive a change, it was apparent that alternative grading forced these teachers to adjust their planning, and to reflect on the nature and purpose of each assignment in order to maximize student learning. 
ESSENTIALLY POINT-LESS: THE INFLUENCE OF ALTERNATIVE, NON POINTS-BASED GRADING ON TEACHERS'

INSTRUCTIONAL PRACTICES

JAY C. PERCELL

A Dissertation Submitted in Partial Fulfillment of the Requirements for the Degree of

DOCTOR OF EDUCATION

School of Teaching and Learning

ILLINOIS STATE UNIVERSITY 
(C) 2014 Jay C. Percell 
ESSENTIALLY POINT-LESS: THE INFLUENCE OF ALTERNATIVE, NON POINTS-BASED GRADING ON TEACHERS'

INSTRUCTIONAL PRACTICES

JAY C. PERCELL

COMMITTEE MEMBERS:

Robyn L. Seglem, Chair

Roland K. Schendel

Rena A. Shifflet 


\section{ACKNOWLEDGMENTS}

I am indebted to so many people whose unyielding support has made the accomplishment of this remarkable endeavor possible. While the list is lengthy, it is important that I recognize each of the individuals who have helped me along the way. I will begin with those who have supported me here in academia, as well as within the classroom itself, and then acknowledge the vast support that I have received from my family members.

I must first send a huge thank you to my dissertation committee: Dr. Robyn Seglem, my dissertation committee chair; Dr. Roland Schendel, my methodologist; and Dr. Rena Shifflet, my inspirational guru. Together, I affectionately referred to them as "RS3" and I am so grateful for their insight, their dedication to this project, and for pushing me to continually produce a better, stronger version of this work.

Dr. Seglem, my chair, has been instrumental to the success of this study. Not only did she admirably coordinate the entire committee and keep everyone on the same page, she also kept me on pace to complete this dissertation in a very fixed and swift time frame. I greatly appreciated her guidance in working to make my writing stronger and more succinct, as well as tolerating and eliminating my occasional inclinations towards fanciful verbosity. Possibly her most challenging task was keeping me grounded and focused on the task at hand. I am indebted to her for knowing exactly what kind of chair 
to be at exactly the right time - the encouraging chair, the no-nonsense chair, the enthusiastic chair, the crack-the-whip chair, and the satisfyingly pleased chair. Thank you so much, Robyn! I literally could not have done this without your support every step of the way.

Dr. Schendel served as my qualitative methodologist, and his guidance was essential to this work. Not only did he model a positive approach, he patiently provided me with a space for self-discovery - the realization of how my own thinking was quantitatively shackled, and he allowed me to liberate myself from that mindset towards a more qualitative and distinctly phenomenological leaning. Thank you, Rolly! I am so grateful for your tutelage and your endless positivity and goodness.

Dr. Shifflet was a source of inspiration for me from the very beginning. At the very outset, she encouraged me to pursue what I was most passionate about—alternative grading — and emphatically embraced that passion along with me in her unquenchable thirst for ever more learning. Not only that, but she also provided me with extremely detailed and thorough feedback, which has made my work far stronger. I greatly appreciate all of your support and encouragement, Rena. Thank you!

Furthermore, my colleagues within the School of Teaching and Learning at Illinois State University have been extremely helpful as they have shared of their own experiences and given me tips and pointers. I am also grateful for my fellow doctoral candidates in this program. We have served as a web of support for each other and I am so fortunate to have worked alongside such quality, inspiring individuals with whom I have formed lasting friendships. Thank you all! 
Additionally, I must thank my former colleagues from my career in the secondary classroom, most especially Lance Huffman, who took me under his wing as an emergent teacher and modeled a professionalism and passion for teaching and students that is second-to-none. His mentorship was vital to the initial implementation of the No Points Grading System, and I am grateful for his professional guidance, but most of all for his friendship. I am also very grateful to many other former colleagues who endured me talking about grading day after day, especially: Michael Sliwa, Greg Rivers, Justin Sauble, and C.J. Mehall. Thanks, boys! When are we getting the band back together?

Of course, I would not be here at all without the love and support from my family. First and foremost, my parents, Jerry and Faith Percell, have shown me an amazing amount of love and have maintained a relentless and fervent faith in me throughout my entire life. They raised me with a belief in the power and importance of education, a notion that was passed down from my grandparents, Paul and Beulah Baker and Wayne and Carolyn Percell. In a time when many families are referred to as "broken" (Fagan, 1999, para. 1), mine has continually provided me with a model of stability, love, and support. There is no way that I would be here today without them. Thank you, Mom and Dad. I love you!

My in-laws have also been incredibly supportive throughout this program and the writing of this dissertation. Specifically, my mother-in-law, Maribeth Kolb, who has never once refused to drop everything on her agenda to be there for me, for Renée, and for the boys; my father-in-law, Gary Alwan, who has also shown a huge amount of personal support in this endeavor; and my sister-in-law, Carolyn Noel, who was 
especially helpful in rehearsing my dissertation defense. Thank you all so much! I am so grateful to be part of such a wonderful family.

While my sons, Micah and Ezra James, may be too young to have a recollection of this project in the future, they have felt it in the steady absence of their father for these past four years. All of this has been for you, boys, as is everything that I do. I am so blessed to be your dad and I look forward to being present and invested in each of you. I love you boys so much, and I am so very proud of both of you!

Ultimately, absolutely none of this would be possible without the tireless support of my beautiful wife, Renée Alwan Percell. No amount of words can entirely capture the amount of resilience and selfless dedication that she has shown throughout this journeyto me, to our family, and to this program. Not only has she carried our family on her back to make this possible, but she has made innumerable sacrifices along the way, especially giving up precious time with her two baby boys - moments that she will never be able to recapture. Thank you, Renée, for loving and supporting me through this, and for being the rock of our family. I am so excited to ease your burden and look forward to carrying you from here on out. I love you so much, Honey!

This is also for my good friend, Jason Wenger, who was tragically and senselessly murdered in 2007 while in pursuit of his own graduate degree. This is for all of the books he will never get the chance to write. 


\section{CONTENTS}

Page

ACKNOWLEDGMENTS $\quad$ i

CONTENTS $\quad$ V

FIGURES $\quad$ x

CHAPTER

I. PERSPECTIVE 1

Statement of the Problem $\quad 4$

Purpose of the Study $\quad 5$

$\begin{array}{ll}\text { Research Questions } & 6\end{array}$

Primary Research Question 6

Subsidiary Research Questions 6

Definition of Terms $\quad 6$

$\begin{array}{ll}\text { Description of Study } & 10\end{array}$

$\begin{array}{ll}\text { Significance of Study } & 10\end{array}$

$\begin{array}{ll}\text { Limitations } & 11\end{array}$

$\begin{array}{ll}\text { Chapter Overview } & 13\end{array}$

$\begin{array}{ll}\text { II. LITERATURE REVIEW } & 15\end{array}$

$\begin{array}{lr}\text { Theoretical Framework } & 16\end{array}$

$\begin{array}{ll}\text { Grading and Assessment } & 18\end{array}$

Historical Perspectives 19

Grading Practices in the Classroom 23

The Purpose of Grades 24

The Meaning of Grades 25

Examination of Grading Practices 29

Traditional Grading Practices 30 
Alternative Grading Systems

Points-Based Alternatives

to Traditional Grading

Criterion-Referenced Alternatives

to Traditional Grading

No Grading

Grades as a Measurement of Learning

The Heart of the Matter

Chapter Overview

III. METHODOLOGY

Methodology in Answering Research Questions

Primary Research Question

Subsidiary Research Questions

Methodology in Data Collection Procedures

Initial Semi-Structured Interviews

Focus Group Interview

Debriefing Interview

Teacher Participants' Feedback Self-Analysis

Methodology in Data Analysis Procedures

Transcription and Analysis for Common Themes

Transcendental Phenomenological Reduction

Synthesis of Meaning: The Essence of Alternative Grading

Research Design

Phenomenology

Case Study

Multi-case Phenomenology

Research Setting and Participant/Case Profiles

Case 1: Christine 
Case 2: Brandi $\quad 64$

Case 3: Simon 64

Case 4: Titus and Everett $\quad 65$

$\begin{array}{ll}\text { Ethical Considerations } & 66\end{array}$

Subjectivity 66

The Nature of the Researcher-Participant $\begin{array}{ll}\text { Relationship(s) } & 67\end{array}$

$\begin{array}{ll}\text { Chapter Overview } & 68\end{array}$

$\begin{array}{ll}\text { IV. THE EPOCHE } & 69\end{array}$

My Experience with Alternative, Non Points-Based Grading $\quad 70$

The Influence of Alternative Grading

on my own Instructional Practices $\quad 72$

The Influence of Alternative, Non Points-Based
Grading on my own Feedback

Alternative, Non Points-Based Grading

in Relation to my Philosophy of Education 77

My own Curiosity, Excitement and Passion

$\begin{array}{ll}\text { Chapter Overview } & 81\end{array}$

V. PRESENTATION OF DATA 83

Phenomenological Reduction and Horizonalization 85

Delineated Horizons or Meaning Units 85

Motivation $\quad 86$

$\begin{array}{ll}\text { Feedback } & 90\end{array}$

$\begin{array}{ll}\text { Philosophy of Education } & 97\end{array}$

Invariant Qualities, Horizon Clusters, or Themes 105

Revision or Resubmission of Assignments 106

Student Learning $\quad 110$ Students' Perceptions of "Being Done"
$\quad$ or Being Satisfied with "Good Enough"

Practice 115

The Nature of Success 116

The Nature or Purpose of Grading 119

Individual Textual Descriptions 122 
Case 1: Christine

Case 2: Brandi

Case 3: Simon

127

Case 4: Titus and Everett

Individual Structural Descriptions

Case 1: Christine

Case 2: Brandi

Case 3: Simon

Composite Textual Descriptions

Composite Structural Descriptions

Synthesis of Meaning:

The Essence of Alternative Grading

Chapter Overview

Primary Research Question

How Does the Use of an Alternative, Non Points-Based Grading System Influence Teachers' Instructional Practices in their Classrooms?

What Are the Motivating Factors Behind Teachers' Decisions to Implement an Alternative, Non Points-Based Grading System?

How Does the Use of an Alternative, Non Points-Based Grading System Influence the Type of Feedback that Teachers Provide to their Students?

How Does the Use of an Alternative, Non Points-Based Grading System Relate to a Teacher's Educational Philosophy Regarding Student Assessment and Grading? 
Implications for Teachers $\quad 157$

Implications for Administrators $\quad 158$

Implications for Students

159

Implications for Teacher Preparation $\quad 160$

Implications for Parents or

Community Members

Findings in Relation to the Literature 162

Future Studies $\quad 165$

$\begin{array}{ll}\text { In Closing } & 166\end{array}$

$\begin{array}{ll}\text { VII. AFTERWARD } & 169\end{array}$

Return to the Epoche 169

$\begin{array}{ll}\text { REFERENCES } & 173\end{array}$

APPENDIX A: $\quad$ Teacher Participant Interview Protocol 183

APPENDIX B: $\quad$ Focus Group Interview Protocol 187

APPENDIX C: $\quad$ Debrief Interview Protocol 190 


\section{FIGURES}

Figure

Page

1. No Points Grading Checklist-Rubric_-High School

2. No Points Grading Checklist-Rubric_-Higher Education 


\section{CHAPTER I}

\section{PERSPECTIVE}

Teachers have long endured deflating questions from students related to classroom assignments that seem to undermine the value of learning: questions like, "Why do we need to learn this?" "Will this be on a test?" "When will I ever have to use this in real life?" "How many points is this worth?” (Brookhart, 1991; Sen, 1994). Oftentimes, it seems, this is done out of students' desires for a quicker and easier means to a better grade, even at the expense of actual learning (Brilleslyper et al., 2012; Huhn, 1995). In my own experience as a classroom teacher for nearly a decade, I, too, encountered this same phenomenon. It was this discrepancy between my desire for students' to become adamant learners and my perception of their motive to grub for points, what De Leonibus and Thompson (1977) described as "grade glut," which propelled me to higher education in search of further study and investigation of grading systems and their meaning and implications for teachers, students, and the climate of schools (p. 2).

It is difficult to quantify how many other teachers have found themselves in a similar position, but practitioner-researchers have concurred that point values ascribed to assignments, among other things, contribute to hindering true, authentic leaning among students (Huhn, 2005; Kohn, 2011; Wood, 1994). 
According to Tocci (2008), "grades are a vital place where the theories of schooling, practices of schooling, and experiences of schooling come into contact and result in a tiny inked marking, one which represents the schooling process in terms of student performance. Tocci (2008) goes on to pontificate on exactly how this process of assigning such a powerful letter came to be, and it is a wonder how such a seemingly small character can have such a powerful impact upon students' futures, their current self-perceptions (Wood, 1994), societal views of how they will function in society, and the lengths that students will go to get them.

This extreme value placed on students' grades is especially baffling, especially when considering that for all of the cut-throat competition students engage in to post the highest GPA for Valedictorianships or for college scholarships, there is only marginal internal consistency behind grades and what they mean from district to district, school to school, and even teacher to teacher (Guskey, 2000). Researchers note that not only do teachers vary considerably in how they grade, but also that grades as a whole do not reflect what students know, and inconsistencies across schools, classrooms, and even within departments can lead to gross inequities for students (Campbell, 2012; Guskey, Swan \& Jung, 2011).

Some classroom teachers may feel they have little choice in the matter. After all, educational researchers have also noted that grades are here to stay (Wiggins, 2012), despite the leanings of some to abolish them (Bower, 2010; Kohn, 2011). Tocci (2008) described grading as an immanent machine, inevitable and unyielding, with many teachers never questioning the implication of grading before succumbing to what Dewey referred to as the "mechanics of instruction" (Dewey, 1904, p. 22). 
Building off of Dewey's mechanics of instruction, Tocci (2008) envisioned that rather than being a letter a student receives at the top of his or her homework, grades, and the process of grading are an "immanent machine" (p. 768) that works to aggregate the both the student body, and even the body of students. He stated:

Over the course of time, the body of a student produces streams of grades which are in turn aggregated. The student, as found in grade books, transcripts, and the documentation of schooling, is a composite of grades. (p. 785)

Tocci (2008) described grades as both the outward product of schooling, as well as the internal mechanical process. He said that, "once deployed, grade-machines ran of their own accord through schooling, rearranging the subject positions of schooling and education through categorical designations" (p. 775).

The dystopian picture Tocci (2008) paints of grade-machines seems to alludes to a scene from the Matrix, where the machines of the future, equipped with artificial intelligence, have begun harvesting humans in vast fields of row upon row of lifesustaining pods, solely for the purposes of being used as a source of energy (Silver, Wachowski, A., \& Wachowski, L., 1999). Perhaps just as the machines used the Matrix to keep people dependently unaware, so too "grade-machines" (Tocci, 2008) serve to blind students and teachers alike, preventing them from maximizing the full potential of student learning in their classes.

The analogy may not be too far off. Just as Tocci (2008) described students as being a literal amalgamation of their grades, Wood (1994) asserted that students' own self-perception is determined by the grades they receive in school. This thinking can quickly become you are what your grade is. As noted above by Campbell (2012) the 
marginal consistency between what grades actually mean from teacher to teacher is problematic when such high stakes, even students' own self-worth, are riding on them.

\section{Statement of the Problem}

In recent times, much attention and scrutiny has been paid to American students' poor performance on both international and national examinations like the PISA and NAEP (Brown and Brown, 2007; Stedman, 2010a), and educational leaders and politicians have challenged schools to produce students capable of being more globally competitive. Besides improved test scores, these policy makers have called for schools to equip students with the skills needed to become world leaders in areas like innovation and technological advancement (Stiggins, 2002; Shepard, 2010). Unfortunately, business leaders have found the crop of students our schools have been producing to be "woefully ill-prepared for the demands of today's (and tomorrow's) workplace" (Casner-Lotto \& Barrington, 2006, p. 1). Specifically, Caner-Lotto and Barrington cite massive deficiencies in critical thinking skills, problem solving, and innovation among US graduates who are preparing to enter the workforce.

Admittedly, some select schools are actively engaged in fostering higher order thinking skills among their students (Robertson, 2012), but regrettably, the vast majority of American schools are becoming increasingly more standardized (Steadman, 2010b). The Standards Movement has taken root and become the ruling order of education in the nation, and now that federal school monies are tied to student performance on standardized tests, many doubt that change will happen anytime soon, if at all (Shepard, 2010; Wiggins, 2012). 
It is paradoxical at best, at worst oxymoronic, for educational leaders to expect schools that operate on standardized patterns of minimized achievement levels to generate students who exhibit innovative, dynamic thinking skills and possess exemplary creative abilities. Research dictates that the way we assess students is a good indicator of what we want them to learn (Briscoe, 1994; Stiggins, 2002). Wood (1994) went further to assert that it is the grading practices of a classroom that directly impact student learning.

If educators truly desire creative, innovative students, then why are schools assessing and grading students in menial, standardized ways? Instead, students should be assessed and graded using the same innovative and creative methods we want them to demonstrate as polished, refined graduates of our educational institutions.

\section{Purpose of the Study}

The purpose of this study is to examine the essential qualities of alternative grading as opposed to the traditional, points-based grading system that is typically used in secondary classrooms $(90 \%=\mathrm{A}, 80 \%=\mathrm{B}$, etc. $)$. Furthermore, teachers who employ alternative grading devoid of a points structure of any kind will be examined in order to ascertain how those alternative grading systems inform — or are informed by — their instructional practices, their educational philosophies, and the way in which they ascribe student feedback. Through this study, educators and curriculum specialists can be briefed about different alternative grading options and can choose if one might fit their curricular aims for their students and teachers. 


\section{Research Questions}

The following research questions were shaped through extensive review and

feedback from my committee and have undergone several iterations. They were used to inform the interview protocol and guide the data analysis:

\section{Primary Research Question}

1. How does the use of an alternative, non points-based grading system influence teachers' instructional practices in their classrooms?

\section{Subsidiary Research Questions}

a. What are the motivating factors behind teachers' decisions to implement an alternative, non points-based grading system?

b. How does the use of an alternative, non points-based grading system influence the type of feedback that teachers provide to their students?

c. How does the use of an alternative, non points-based grading system relate to a teacher's educational philosophy regarding student assessment and grading?

\section{Definition of Terms}

Traditional grading systems: will be defined as point-based systems of marking and scoring students and averaging all work to arrive at a final percentage which translates to a given letter grade (Marzano \& Heflebower, 2011). In the most common 5- 
point system, A-F, will serve as the default understanding of traditional grading systems, although there are other types (Kirschenbaum, Napier \& Simon, 1971).

Alternative, non points-based grading: alternative grading owes much to the concept of alternative assessment. According to Anderson (1998), alternative assessment is rooted in performance-based, authentic, real-world oriented forms of evaluating the skills or knowledge a student is able to demonstrate. Alternative assessment is often used interchangeably with the term "authentic assessment," which is a form of assessment advocated by many educational reformers like Wiggins (1989) and Eisner (1994). Either way, alternative assessment is roundly conceived of as more holistic than traditional forms of assessment, with an emphasis on the inquiry process as opposed to solely being concerned with the product (Anderson, 1998).

Alternative grading, then, being the central focus of this study, will refer to any system of grading that differs from traditional grading. Many times, alternative grading may be thought of as relegated to specialized curricula or solely directed towards exceptional students (Hendrickson \& Gable 1997). However, Malehorn (1994) encouraged all teachers to develop alternatives to traditional systems - multi-faceted grading procedures that more completely reflect the variety of their interaction with students and differences in educational objectives. De Leonibus and Thompson (1977) identified an array of grading options, and placed these grading practices along a continuum from "traditional" to "non-traditional," everything from: "ABC" grading to "Pass/Fail" to "Checklists" and "Written Evaluations," to "Self-Evaluations" and finally "No Grading." They stated that "the 'non-traditional' arm of the scale tends to focus upon 
individual rates of progress and affective criteria, while the 'traditional' tends to be cognitive and normative" (p. 6).

For the purposes of this study, any type of grading system other than traditional grading will be considered alternative grading, and alternative, non points-based grading will specify those alternative grading systems that do not use any sort of points ascribed to assignments or calculated for students' final grades.

Instructional practices: for the purpose of this study, the concept of instructional practices will be inclusive of any processes the teachers participants employ to impart instruction to their students, including, but not limited to: planning, preparation, presentation, implementation, providing of feedback, and assessing and grading student work. The conceptual framework for this notion will be rooted in Gagné's (1965) instructional design theory, where he identified nine events of instruction: gaining attention; identifying objectives; stimulating recall of prior knowledge, presenting content, providing "learner guidance," eliciting performance (practice), providing feedback, assessing performance, and finally solidifying retention and transfer of skills (p. 313.). Gagné and Briggs (1974) then outlined an individual lesson design based on the events of instruction. They arranged their lesson by first identifying performance objectives, modeling the performance, guiding the learners, providing examples, presenting stimuli to elicit student performance, providing feedback, and finally assessing the attainment of the objective.

Much of Gagné's (1965) instructional design model was intended to foster mastery learning, the instructional strategy promulgated by Benjamin Bloom (1968) wherein educators predetermine certain identifiable performance-oriented skills or 
objectives for students to demonstrate after a given unit of time. In mastery learning, these objectives are prerequisites and students must demonstrate their mastery of said skills before advancing to the next topic; these objectives are assessed formatively and students are given "correctives" based upon timely thorough feedback before being given additional opportunities to demonstrate their skills until they have mastered them.

Providing students with correctives allows them opportunities to expand, organize, apply, and teach their newly acquired skills and knowledge and develop a sense of selfawareness as it pertains to their own learning (Lalley and Gentile, 2009; Guskey, 2010).

A precursor to backwards design (Wiggins and McTighe, 1995) and the gradual release of responsibility (Pearson \& Gallagher, 1983), Gagné and Briggs (1974) stated the importance of knowing the objective before designing the instructional activities; they also highlighted the importance of the "learning conditions," a conceptual framework to move students from basic recall to conceptual understanding to higher order thinking ( $\mathrm{p}$. 149).

Feedback will be regarded as the process of revising or commenting upon student work for the sake of guiding it toward the achievement of a certain goal or objective. Merely indicating that work is "good," that students have done a "nice job," or other similar menial validations are not good examples of what feedback should truly be. As Wiggins (2012) mentions, feedback is often falsely conceptualized as a value judgments or recommendations on how to improve. Instead, Wiggins describes it as simply information given in order to achieve a predetermined goal. By keeping feedback goaloriented and timely, teachers can seamlessly engender learning in more authentic and tangible means. 


\section{Description of the Study}

This qualitative study investigated current high school teachers' motivations and philosophies behind implementing an alternative grading system, and how such a grading system influenced the feedback they provided to students. The primary goals for this study were: to examine how alternative grading influenced teachers' instructional practices, to understand their motivation for implementing alternative grading and how such alternative grading influences the type of feedback these teachers provide their students. Additionally, this study seeks to shed light upon the philosophic considerations behind the role of student assessment and grading in the classroom through a methodological lens of phenomenology and case study, a multi-case phenomenology.

This study highlighted five current high school teachers who employ an alternative grading system at four different sites, which comprise the four separate cases. The essences of their grading systems are investigated, as well as how those systems influence or inform their instructional practices and feedback. The alternative grading systems each teacher practices are: the 3P Grading system (Peha, 1995), standards-based grading (Guskey, 2010; Cox 2011), and the No Points Grading System (Percell, 2013), and an independently-designed, summative-driven grading system.

\section{Significance of the Study}

This study aims to make a significant contribution to the field, especially from a practitioner's standpoint, as it examined different types of alternative grading systems and reflected upon how those systems informed teachers' instructional practices and their 
feedback provided to students. This work is intended to shed some light on the meanings teachers ascribe to scholastic grades and how educators can utilize the function of grades and grading systems to maximize the relevance of student learning and refine instructional strategies within the classroom.

Previous research in this field has focused almost exclusively on standards-based grading, an assessment strategy designed to negotiate the current tides of standardized assessment while still championing criterion-based assessment that is honest, fair, and accurate (Guskey, 2001). A notable few researchers and practitioners have taken issue exclusively with points being the hindering factor in traditional grading systems' shortcomings (Brilleslyper et al, 2013; Huhn, 2005), but what has yet to be explicitly examined is how employing an alternative non-points based grading systems influence teachers' instructional practices and inform the ways in which they provide feedback to their students.

\section{Limitations}

There are several limitations to this study, the biggest of which is time, and an especially fixed time span. As Andrew Marvell (1992) wrote, "Time's winged chariot" is always against us, and it is no different with this project (p.229). This limitation potentially cut into the number of visits I was able to have with each participant, and possibly reduced some of the depth and breadth of data that I was able to obtain from each one.

The limited timeframe may have also impacted the number of teacher participants I was able to include in this study, as my time to spend with each one was somewhat 
minimal. However, another limitation which may have influenced the number of teacher participants in this study was that in this educational climate, teachers who actually employ alternative, non points-based grading systems are few and far between. Even some potential participants that I initially had in mind were either no longer grading alternatively, or else left the field entirely, or were prevented from participating in the study by their administrations. Gaining permissions from school districts to conduct this research at all, even for those teachers who participated, was very challenging. More work needs to be done to foster relationships with local schools and districts as partners and co-beneficiaries in the research process.

Once identified and secured, the hectic schedules of the teacher participants themselves was another limitation. Two participants, in particular, were also coaches of winter sports teams, the busiest of times overlapping right with the heart of the data collection, and they were unable to participate in the online focus group, as well as to complete feedback self-analyses. In lieu of the focus group, these two participants did meet together for a joint-interview or mini-focus group to give some collective insight into the support and further challenges of their grading system. However, the data could have been even richer were they able to participate in conjunction with the other teacher participants, and I believe the others would have benefitted greatly from their experiences, and vice versa.

Another limitation was that different types of alternative grading systems were examined, and as such they lacked a certain consistency one to another. While three of the grading systems were not points-based, one grading system, that of Titus and Everett, 
still maintained a points-based structure. As such, their results may not be indicative of a truly non points-based grading system.

Furthermore, most of the teachers taught subject areas that were either primarily electives, or else subjects that were very indicative of performance-based assignments, such as art, graphics design, and family consumer sciences. Even Simon, a social studies teacher, primarily taught sociology courses, which had more of an electoral leaning, and Titus, an English teacher, mainly taught speech, although he did have some co-taught English sections. There were no participants who taught core content areas, like math, science, or literature.

One final limitation is that Titus and Everett are regarded as the same case, while the other three cases were each comprised of an individual teacher participant. They are considered together due to the fact that the cases are bound by the grading system in place, as opposed to the individual teachers themselves. Since Titus and Everett employ the same grading system, one which they designed together, they represent a single case. This could potentially make them seem like a single individual, despite the fact that they each have their own individual experiences employing a shared alternative grading system.

\section{Chapter Overview}

This chapter has introduced my research study investigating the ways in which employing alternative grading systems influence teachers' instructional practices. The statement of the problem, the purpose of the study and my investigative research questions have been documented, along with the description and significance of the 
study, as well as working definitions of some key terms. The subsequent chapter will investigate the historic and current literature and relevant empirical studies related to assessment and grading practices in the secondary classroom, before moving on to my methodological framework as outlined in chapter three. 


\section{CHAPTER II}

\section{LITERATURE REVIEW}

Teachers have been awarding grades to students for hundreds of years (Kirschenbaum, Napier \& Simon, 1971; Marzano, 2000; Tocci, 2008), and for just as long, there has existed controversy regarding the manner in which teachers have awarded these grades (Cross \& Frary, 1999; Guskey, 1994). The earliest incantations of grading systems in this country stemmed from the one-room schoolhouses of the $18^{\text {th }}$ century when teachers would simply narrate the progress of students (Kirschenbaum et al., 1971). Yale is credited with awarding the first "grades" to higher education students in 1785 , and maintained distinction as the only institution to do so for the next several decades, until Harvard followed suit in the 1830s (Tocci, 2008, p.764). In public schools, the first recorded instances of formalized grades occurred in the Boston Public school system in 1845 (Tocci, 2008).

Since then, grading in schools has undergone multiple overhauls and various attempts to create a more reliable system to determine the best way to document student achievement. Despite these efforts, the world of grading is currently a murky, multifaceted domain that is seldom overtly discussed but is simultaneously rife with importance and consequence. 
In order to gain a more complete perspective of the issue of grading practices in schools, an issue that is admittedly enormous in scope and influence, it is essential to first investigate the literature that addresses the issue of both historical and modern grading practices, as well as the related topic of student assessment in so far as it informs grading practices as they currently exist in American schools. It is also important to consider the governing theological framework that informs this investigation of literature as well as the overall study itself.

\section{Theoretical Framework}

The theoretical and conceptual framework for this study is based in a constructivist view of educational practices, especially one that privileges a critical perspective related to literacy skills such as reading, writing, and thinking. This work has been informed by the present work of several notable researchers who have been invested in studying grading and assessment practices, especially Brookhart (1993, 1994), Guskey (1999, 2006), Marzano (2000), Popham (1993), Stiggins (2002), and Wormeli (2006). Additionally it has also been meaningfully impacted by more progressive researchers such as Kohn $(1999,2011)$, as well as modern, forward-thinking practitioners like Huhn (2005), Bower (2010), and Spenser (2010). The work of these specialists, and others, has given rise to a growing number of teachers who have begun to reexamine their grading practices, and has been instrumental in the growing acceptance of some alternative grading practices, especially standards-based grading, which seeks to report a more accurate account of students' abilities (Brookhart, 1993; De Leonibus \& Thompson, 
1977; Guskey et al., 2011; Hendrickson \& Gable, 1997; Jung \& Guskey, 2011; Marzano, 2000; O’Connor, 1999).

Furthermore, this study is predicated on mastery learning, as promulgated by Benjamin Bloom (1968), wherein educators predetermine certain identifiable performance-oriented skills or objectives for students to demonstrate after a given unit of time, which are prerequisites students must demonstrate before advancing to the next topic; these objectives are assessed formatively and students are given "correctives" and provided additional opportunities to demonstrate their skills until they have mastered them. Through this process, students are given opportunities to expand, organize, apply, and teach their newly acquired skills and knowledge and develop a sense of selfawareness as it pertains to their own learning (Lalley and Gentile, 2009; Guskey, 2010).

The foundational principles of mastery learning are not new. Precursory concepts of mastery learning predate even Bloom (1968), as he himself examined a wealth of practitioners including Morrison (1926), Carroll (1963), Bruner (1966), and Skinner's (1954) ideas of behavioristic objectives, wherein students are able to demonstrate an observable skill. Nonetheless, the fundamental principles for mastery learning were clearly identified and conveyed through Bloom's $(1968 ; 1982)$ research into human development, student learning, and exceptional teaching.

Presently, Anderson and Krathwohl's (2001) revision of Bloom et al.'s (1956) taxonomy of learning is worthy of note, having placed a higher importance on students' ability to produce and create in an academic context. Additionally, all good mastery learning is objective-oriented and begins with the end result in mind. To that end, Wiggins and McTighe's (2005) understanding by design and backwards planning has 
been instrumental to this process by providing a framework for advancing mastery learning and objective-oriented instruction.

Furthermore, this study is also framed within the contextual hope of creating a heightened sense of intrinsic motivation among students, and ultimately a strong personal teaching efficacy among educators. Pink's $(2009,2011)$ work with motivation and what motivates us informs the perspective of the research, as does Dweck's (2006) work with brain research and her theories regarding fixed mindsets verse growth mindsets. By standing on the shoulders of these giants in educational research and current forwardthinkers in the field, this study has been given a firm positionality and a foundation for illuminating current pedagogical practices in the hope of imparting change for the future.

\section{Grading and Assessment}

The practice of grading is closely tied to assessment; they could possibly be thought of as two different sides to the same coin, and while assessment informs grading practices, oftentimes grading policies will influence how assessment is carried out (Stiggins, 2004).

Assessment is an essential component in the field of education, and although assessment practices have evolved and changed throughout history, they remain one of the most widely researched, roundly discussed and hotly debated topics to this present day. Even though there is general consensus among educators and educational researchers as to the elements that comprise quality assessment, our country's current standardized assessment practices, especially the high stakes placed upon the backs of students, exist largely in direct contrast to prevailing research (Shepard, 2010). 
Regardless, there is more to assessment than just testing, at least theoretically, and any investigation of grading practices would be remiss without also addressing the elements that comprise student assessment, such as formative and summative assessments, and grading and reporting practices, as well as the historical foundations upon which the current model of traditional and alternative assessments have been derived.

\section{Historical Perspectives}

According to Guskey (1994), grading is a relatively new phenomenon. While assessment has existed in civilizations dating back to the ancient Greeks, the actual practice of assigning grades in public schools did not until the early 1800s (Guskey, 1994; Tocci, 2008). Even then, most schools in the United States used narrative systems where classroom teachers would literally write down the skills and performances that each student was capable of demonstrating or had learned throughout the given term (Guskey, 1994; Kirschenbaum et al., 1971).

Since the turn of the twentieth century, grading in the United States has traveled along a circuitous path of change and evolution. Controversies in grading practices can be traced back to the early 1900s, when the practice of assigning narrative grades slowly gave way to numeric percentages as a representation of achievement and ability levels. This shift which went relatively unquestioned as merely a rational progression or accommodation to the changing nature of schools themselves, which were increasingly accommodating much more numerous and diverse students due to school attendance being newly mandated by state law (Guskey, 1994). 
However, two researchers did take an issue early on with the widely adopted 100point grading system. Starch and Elliott (1912) investigated the reliability of the new percentage grading system as it played out in an English class. They studied the grades different teachers gave to the same students' final essay, only to find that the scores varied widely for numerous reasons. Some teachers focused more on spelling and punctuation; others graded for neatness and appearance; and still others focused more on meaning and content (Starch \& Elliott, 1912). Sadly, the vast majority of the teachers scored the essay far higher than the student's actual teacher. Starch and Elliott (1912) deduced that the percentage grading system was unreliable and too prone to teachers' own subjectivity.

Proponents of percentage grading easily dismissed the work, claiming that essays in English lead themselves to subjective assessment by nature (Kirschenbaum et al., 1971). Therefore, the researchers conducted the study two more times using the exact same methods, but changing the subject matter, once examining the reliability of grading at the high school level in mathematics (Starch \& Elliott, 1913a) and once in history (Starch \& Elliott, 1913b). In both cases their findings mirrored those of their initial study. There were wild discrepancies between the grades teachers awarded the exact same assignment. Again, Starch and Elliott (1913b) found percentage based grading unreliable and called for "the development and general use of standard tests and scales for measuring efficiency in all subjects" (p. 681).

Another review of early $19^{\text {th }}$ century grading practices by Rugg (1918) also criticized grading for being highly unreliable. He was especially troubled at the high percentage of students failing, noting that it was common for "teachers to fail upwards of 
30 per cent of their students" (p. 701), and while he allotted that some of that might be ascribed to students' inabilities, he placed most of the blame on "bad administration of the grading system" (p. 701). His was one of the earliest investigations into the meaning of grades, as Rugg found that the symbols and marks held little or varying meaning for students, parents, and teachers. He called for grades to fulfill two purposes: to represent students' abilities and to rank them in order according to those abilities.

Proliferation of traditional grading. In light of the findings from early research efforts regarding the validity of grades, grading in schools changed several notable ways. Instead of relying solely on a 100-point grading scale, many schools began adopting fewer, but larger, categories. One early incantation of this in 1918 was a three point grading system with the categories defined as: Excellent, Average, and Poor (Guskey, 1994). Another was a five point system with the defining attributes being: Excellent, Above Average, Average, Below Average, and Failing. In this five point system, each attribute was assigned a letter: A, B, C, D, and F (Kirschenbaum et al., 1971). In both instances, percentages were still the prevailing measurements of distinction between different levels, but the cut-off level of failure had been set at $50 \%$ of the whole (Kirschenbaum et al., 1971). This system soon began to gain widespread acceptance among schools in the 1920s and 1930s.

Even as the five-point, A-F grading system began to take root as the normative grading scale across the country, grading practices continued to be debated throughout he first half of the twentieth century. Some educators called for a return to grades being comprised once again by narrative, written descriptions of students' abilities (Chapman \& Ashbaugh, 1925), while others called for pass/fail systems of grading or the elimination 
of grades entirely (Good, 1937). Despite the debate, and despite empirical research across subject areas that exposed the A-F system as unreliable, the overwhelming acceptance of this system would soon become the prevailing grading scale gold standard upon which all other forms of grading are conceptualized nearly a century later.

Standardized testing. Any review of the relationship between grading and assessment, particularly as it operates currently would be remiss to neglect the phenomena of standardized tests. Perhaps called upon as early as 1913 (Starch \& Elliott, 1913b), the practice of standardized testing grew of out the social efficiency movement in education, and educational philosophy forwarded by Franklin Bobbitt (1918) which viewed schools as a vehicle to equip communities with knowledgeable citizens who were capable of contributing to the overall societal efficiency (Kliebard, 2004). Naturally, this theory resonated with the budding industrial American society at-large, one that was focused on progress and affluence. However, one drawback to the social efficiency movement was that it was rooted in Fredrick Taylor's social-class views, which were implicitly (or otherwise) given to classism, hereditary-based intelligences and eugenics (Kliebard, 2004; Wiggins, 1989).

Whatever the origin, standards-based testing was in place, at least in some form, as early as the 1920s, and began to gain prominence from that point forward. Even modern day detractors of standards-based testing agree that at one time, standards-based testing held a relevant purpose within the school systems as reasonable indicators of student learning (Shepherd, 1989). However, the clamor for more testing intensified throughout the 1970s, and with the US Department of Education's publication of the bipartisan commissioned report $A$ Nation at Risk in 1983, standardized testing was given 
central prominence as a way to not only determine the amount of student learning, but also as a way for American students to demonstrate academic achievement on a globally competitive scale (Steadman, 2010a).

Currently, the fervor surrounding assessment policies regarding standardized testing in public education is particularly contentious given the mandated, high stakes nature in which the tests are being implemented, which has very real and concrete impact upon how assessment operates at the school and district level, and how it influences student learning and achievement (Hout, Elliott, \& Frueh, 2012). For better or worse, the federal government has enacted institutional-level assessment through the No Child Left Behind Act (NCLB), which had resounding impacts filtering down to the district, school and even classroom levels (Au, 2011). Schools, once considered to be home for inquiry and learning, are now being held to impossibly high standards aimed at mandated, timesensitive acquisition of skills and threatened with disastrous consequences for failure. Public schools have become veiled test prep factories relying on incentivized methods to attempt to boost student achievement and save what little funding they received (Hout et al., 2012; Kohn, 2004).

\section{Grading Practices in the Classroom}

Grading is closely tied to assessment; however, they are not one and the same. The practice of marking and scoring students' work and reporting that progress to students, parents, and school administrators is an enigma all its own. Hence, the reason grading practices have been discussed for over a century. O'Conner (2009) does an admirable job distinguishing between the commonly associated terms: grading, scoring 
and marking. According to O'Conner, scoring or marking is any number, letter, or combination of words placed on an individual student assignment to indicate overall quality. Grades or grading are any numbers or letters a teacher assigns at the end of a unit or term that indicate or act as a summary statement of student performance ( $\mathrm{O}^{\prime} \mathrm{Conner}$, 2009). These definitional distinctions are nicely succinct, and will be similarly used throughout this study unless otherwise indicated; however, beyond working definitions, multiple educational researchers have questioned just exactly what grades mean (Brookhart, 1991, 1993; Marzano \& Heflebower, 2011; Rugg, 1918). With such a great lack of internal validity, the same grade of a B may indicate entirely different things based on different classes, teachers, schools, or districts (Campbell, 2012; Guskey, 1994; Wiggins, 1989). Throughout the past few decades, researchers have been attempting to identify exactly what scholastic grades mean, or what should mean at any rate (Guskey et al., 2011).

\section{The Purpose of Grades}

Regardless, grading practices serve three essential functions in schools: they inform teachers in regards to student performance, they are indicators for students as to their performance, and they give teachers a platform to discuss students' progress with parents (Kohn, 2011). While seemingly benign in nature, scholastic grades have taken on an elevated sense of importance, especially as multiple levels of external motivators have been placed upon them. Everything from gold stars to weekend privileges, from academic distinction to college scholarships, make grades highly competitive (Cox, 2011). From an early age, students are encouraged to "make the grade," a mantra which reinforces a 
subconscious belief that getting "good grades" in school is all that matters (Huhn, 2005, pg. 81). The importance of good grades above all else has been equally adopted and fostered by many parents and teachers, many of whom were once students themselvesand successful ones — operating under the notion that grades are all that matter. Research suggests that many teachers revert to the same grading practices that govern their teaching as the ones they themselves were subjected to as students (Reeves, 2004).

Regrettably, this notion has been disseminated by society throughout the past several decades and the burden of grades have been carried like a yoke around the necks of countless students. Much like Tocci's (2008) description of grades as being an aggregate machine that work together to create students' very identities, Wood (1994) notes how students' perceptions of themselves are based on this construction- that students' grades determine their own self-worth.

\section{The Meaning of Grades}

Although standard A-F grades seem to have a concrete and pervading meaning throughout our culture, i.e., $\mathrm{A}=$ excellent, $\mathrm{B}=$ above average, $\mathrm{C}=$ average, etc., just exactly what grades mean regarding a students' academic ability seems to vary wildly (Campbell, 2012; Cizek, Fitzgerald \& Rachor, 1995). There is an open debate as to whether scholastic grades should be comprised of intangible or "non-achievement factors" (Brookhart, 1991, pg. 35) such as student behavior, attendance, effort and academic integrity, or whether they should solely be relegated to reflect the skills that a student possesses or the abilities they are able to demonstrate (Erickson, 2011a; Jung \& Guskey, 2011; Reeves, 2008; Wormeli, 2006). 
Perhaps the seminal work attempting to decipher the exact meaning behind the grades teachers assign their students was conducted by Stiggins, Griswold and Frisbee (1989), which established the commonly accepted best practices of assessment and grading. The researchers constructed a framework of 34 aspects of grading. For each aspect, they examined the prevailing thought among assessment leaders and strategists as to what constituted best practices and matched it with the practices that were actually occurring in the schools and the perspective held by current teachers. The majority of these grading issues (26 out of 34) revealed a discrepancy between best practices and actual classroom practices. Most notably, teachers considered students' attitudes, motivation and effort in their final grades, a tactic that is not recommended by assessment experts because "the message to students may be that if you show a positive attitude" or "if you appear to try hard, you don't have to learn as much" (Stiggins et al., p. 10). Additionally this study exposed current practices related to giving a good deal of weight to daily exercises and assignments in students' final grades. Stiggins et al. found that by doing so "grades may reflect amount of work completed more accurately than amount learned" (p. 12).

This study was of premier importance for several reasons, one being that it brought to light the stark disconnect between what assessment experts identified as best practices and what practices were actually taking place in the classrooms. Furthermore, Stiggins et al. (1989) documented these discrepancies in very specific ways in identifying specific components of best assessment practices and how they should ideally translate to the grading process. Ultimately, Stiggins et al. postulated three scenarios that might account for this disconnect: that perhaps best practices are merely a matter of opinion; 
that best practices are unrealistic given the constrains of the classroom; or that there is general inadequate knowledge of best practices among teachers and administrators. They called for further research into the matter of grade reporting.

Researchers answered that call and undertook to discover the reason behind the massive discrepancies between best practices and teachers' actual grading practices that Stiggins et al. (1989) identified. One such study conducted by Cizek et al. (1995) investigated the grading practices of 143 classroom teachers as to what factors they considered when giving students grades, what their final grades represented, and whether or not their grading practices were consistent with their colleagues' grading systems or district grading policies. The study found that nearly $90 \%$ of the respondents reported using formal assessment measures in their grading. However, the second largest category was that of informal measures such as effort, conduct, and teamwork, with $67 \%$ of teachers identifying it as part of their grading system. Cizek et al. speculated that there may be a "success bias" (p. 175) among teachers whereby teachers use informal achievement factors as a way to positively influence students grades due to a "success orientation" (p. 170) many teachers proclaimed to have, noting their desire to see "every student succeed" (p. 170). McMillian's (2001) study of secondary teachers' grading practices reflected the same notion, which he described as teachers' tendency to "pull for a student" (p. 30) whereby they rely on non-achievement factors in order to do so.

Other notable findings from Cizek et al.'s (1995) effort were that the majority of teachers were unsure of whether or not their grading practices were similar to those of their immediate colleagues (53\%), and several were unsure whether or not their school districts employed a formal grading policy (11\%). Ultimately, Cizek et al. were forced to 
surmise that "it is not at all clear that any interested group - administrators, teachers, and parents, or even students and teachers themselves - can confidently glean the meaning of students' grades" (p. 175) and that the practice of assigning grades is "taking into account various sources of information and combining that information in unknown but varying ways" (p. 175).

Another foundational work, Brookhart's (1993) study of the grading practices of 84 teachers, examined grading through a lens of validity based on Messick's (1989) theory of validity which includes two overarching facets: interpretation and use. Brookhart asserted, "in grading, the distinction between interpretation and use is more blurred than for most other educational measures" (p. 125). Although many of her participants readily agreed that grades should largely be performance-based measures of skills students can demonstrate, she found that the vast majority of teachers insisted on including non-academic behaviors in their grades despite the fact that assessment specialists recognize it as the least important factor that grades should measure. Teachers' themselves largely agreed that non-achievement factors should not be included in students' grades, but defended their reasons to include it as being that the perceived meaning of grades and social stigmas from others — students, parents administrators was beyond their control. These perceptions and connotations of students' grades, i.e. what it means to be a $C$-student verses an A-student, are alluded to by Wood (1994) when investigating students' perceptions of self-worth. The teachers in Brookhart's study stated that were they able to control the perceived meaning of grades as being strictly a measure of performance and learning, then they would not include non-achievement factors in 
their grades. However, they felt unable to control such societal perceptions (Brookhart, 1993).

Again, McMillian (2001) corroborated this view as his study of secondary teachers' grading practices revealed the same phenomenon: teachers' use of intangible measures in their grading system despite their own knowledge of recommended best practices in grading. He called these intangible measures "academic enablers" (p. 13) and questioned whether teachers believed their students' effort and improvement to be valid indicators of student performance from constructivist perspectives, regardless of the recommendations of measurements specialists. Furthermore, McMillian (2001) indicated that while some teachers included academic enablers in their factoring of student grades, other teachers did not. He noted that this inconsistency was the root for sending "mixed messages" (p. 31) to students and teachers alike regarding the ability of students as measured by academic grades.

\section{Examination of Grading Practices}

Regardless of teachers' beliefs about education, no single factor has greater importance and influence than the course grading system upon curricular aims like teachers' instructional practices, student progress, and performance, and on the way classes function and operate (McMillian, 2001; Campbell, 2012). The grading system is the skeletal framework that provides a class its structure and informs its procedures and processes (Cox, 2011). While some schools have mandated grading policies, most teachers do have some autonomy to select their own system of grading. Indeed, in an educational climate that is growing increasingly more standardized in terms of 
curriculum, instruction, and assessment, many teachers view their grading system as the last measure of actual power or autonomy that they possess (Guskey, 2004; Reeves, 2008). For whatever reason, possibly due to their own educational upbringings, the vast majority of teachers typically selected a traditional A-F grading scale (Cox, 2011). Even among pre-service teachers in my own experience, many teacher candidates cannot even conceptualize scholastic grades outside of the traditional framework: $A=90 \%-100 \%$, etc.

\section{Traditional Grading Practices}

Traditional grading systems have been in place for decades (Kirschenbaum et al., 1971). An investigation of their practices can date back to the early part of the $20^{\text {th }}$ century, and as Kohn (2011) notes, it is remarkable how little they have changed even a century later. In traditional grading systems, each student is scored with a percentile or ranking that can be used for comparison among all members of the group or class (Lalley \& Gentile, 2009; Guskey, 2010). As such, traditional grading systems provide a readily available means by which to make comparisons among students, to analyze student achievement, and recognize excellence in education. On the surface, traditional grading systems seem harmless, as they are very much ingrained into the status quo of what school is all about.

Indeed, teachers who employ traditional grading systems, especially those who employ points-based systems have strong emotional attachments to them. Feldman, Kropf and Alibrandi (1996) examined the grading practices of 91 high school science teachers and found that the overwhelming majority favored using points-based grading systems. These teachers noted many benefits that in using a points-based grading system 
with many expressing that points based systems are more "quantitative, objective and scientific" than alternative grading systems (p. 10). They also felt that points-based systems are less biased, more straightforward and easy to comprehend, and allow students to quickly and easily determine exactly where they stand in relation to their course grade. Feldman et al. went on to note that the decision to grade using points-based systems arose in these teachers organically as opposed to a reliance on any formal grading training through professional development or university professors. Some pointed to computer based grading systems, other teachers, and colleagues who use such systems as being motivational for them. One teacher even commented that he "dreamed it up himself” (p. 10).

\section{Drawbacks of Traditional Grading}

The shortcomings of traditional grading systems have been lauded for nearly a century, but some of the most common drawbacks are discussed in depth: grade inflation; the use of zeroes, which create statistical deficits; an overall diminished love of learning due to a formulaic accountability system; and the creation and implementation of a token economy system that subverts the learning process (Feldman et al., 1996).

Grade inflation. Despite these perceived benefits among practitioners, many researchers have documented several problematic issues with traditional grading systems. One issue that has been widely investigated since the 1970 s is the idea of grade inflation, the notion that students may be receiving grades which are not indicative of the actual amount of learning they have attained throughout a class (Hunt, 2008). Conley (2000) conducted a study which compared students' grades received in school with their 
proficiency levels as determined by a performance-based admissions scoring system (PASS). Through statistical analysis, Conley (2000) indicated that the distributions of proficiency scores and grades were statistically different. The regression analyses found little relationship between the grading system a teacher used and whether or not a student was proficient, thus making a case for the existence of grade inflation, in that students' grades and students' proficiencies are measuring statistically different things (Conley, 2000).

Use of zeroes. One traditional grading practice which has been hotly contested in recent decades is the use of zeros in the grade book. Researchers have shown the statistical imbalance in relation to students' final grades that is produced by giving them zeroes on assignments, especially on a 100 point grading scale, as many of them are. More often than not, zeroes are given for non-achievement factors, like lack of attendance, missed assignments, or incomplete homework (Guskey, 2004; Reeves, 2004).

Guskey (2004) investigated alternatives to assigning zeros and identified several practices teachers could easily employ in place of assigning zeros for non-academic achievement, such as: awarding incompletes, at least until such time as the student was able to complete the desired academic work; removing non-achievement factors from academic grades; or re-envisioning teachers' grading systems in general (Guskey, 2004).

According to Reeves $(2004,2008)$, another leading voice against the use of zeros in grading practice, many teachers employ tactics that he labels as "toxic to the process of education" (2008, p. 85). Namely, Reeves (2004) cited the teachers' use of grades as a punitive measure to redress undesirable classroom behaviors, assigning a zero for missed work or absenteeism. While this is a common grading practice, Reeves questioned 
whether students' final grades will truly reflect what they know about a subject when this is the case. He also contested the averaging of all scores into the final grade, another common "toxic" practice, according to Reeves (2008, p. 85).

Both Guskey (2004) and Reeves (2008) have called for teachers to rethink their grading processes. If teachers' intentions are to assign grades that accurately reflect what students know and are able to demonstrate at the end of a term, then they should do so regardless of any momentary struggles students might have incurred along the way (Reeves, 2008).

Loss of a love for learning. It's no secret that scholastic grades can sometimes unwittingly cause anxiety and adverse effects among students (Campbell, 2012; Kohn, 2011; Cox, 2011). Some report elevated levels of stress among students due to a competitive drive to achieve more than their peers (Becker and Rosen, 1992). However, Kohn (2011) goes further, asserting that traditional grades sap the joy of out of the learning process for students, and not only diminish students' interest in whatever they're learning, but they also reduce the quality of student's thinking. He coins a slogan from the 1960's when he claims that "grading for learning" is akin to "bombing for peace" (p. 31). He cites a pseudonymous student, "Claire" who said:

I remember the first time that a grading rubric was attached to a piece of my writing. ... Suddenly all the joy was taken away. I was writing for a grade-I was no longer exploring for me. I want to get that back. Will I ever get that back? (p. 28) 
Based on these statements, traditional grading systems seem to counteract one of the primary goals of well-meaning teachers: to foster a love of learning among students (Kohn, 2011; Cox, 2011).

Token economy. A final drawback to traditional grading systems, and possibly the most problematic, is their unintended —or intended — creation and implementation of a token economy. Originally designed for corrective facilities of the mentally unstable, a token economy is a behavioristic mechanism in a controlled environment whereby normative conduct is encouraged and reinforced through a system of rewards and punishments (Ayllon \& Azrin, 1968). In a token economy, a certain value is ascribed to a commodity and participants are encouraged to gain capital and become functional productive members of the system, which is designed to reflect society—especially a capitalistic one. Beyond psychology, this notion of a token economy has been generalized to the field of education (Kazdin, 1982).

In classroom token economies inspired by traditional grading systems, points become a type of currency and students are in a race to acquire as much capital as possible. Feldman et al. (1996) discovered as much when investigating grading practices of science teachers. Some of the teachers felt students were beginning to "grub for points" (p. 11). One teacher remarked, "Kids will do anything for points. If I told them they would get 10 points by running to the parking lot and back, they would do it" (p. 14).

This is problematic on several levels — most notably that, as Feldman et al. (1996) iterated, "As part of a token economy, points become devoid of information about the relative worth or importance of specific assignments or assessment techniques. For 
example, a student may accumulate a larger percentage of points through the completion of homework or classwork than for performance on tests or quizzes, thereby reducing the effect of the latter on the report card grade" (p. 14).

Not only does the accumulation of points begin to supersede the act of learning in terms of importance, but the points themselves disguise the actual ability of students, especially if students are able to earn extra credit points, which can disguise a lack of achievement simply by "buying a grade" (Feldman et al., 1996, p. 14).

The token economies created by point-based grading systems are further perplexing because many teachers feel that the practice is justified. While there were some conflicting sentiments regarding the nature of points-based grading systems, the vast majority of Feldman et al.’s (1996) teachers supported such systems. Said one:

Grades are the currency that we use, the medium of exchange by which [students] feel good about and can say, "I did this work, I did this test, I did this lab and I got paid 50 points." And that's a natural part of human behavior. We all like to receive something for what we do. And I think grading is a piece of that." (p. 11) Regardless of the fact that all teachers interviewed stated that points were not a means of rewarding proper classroom behavior, one teacher reported that, "When I don't use points, especially with a hard-to motivate group, I don't get anywhere near the level of class participation" (Feldman et al., p. 11).

These results are telling in many ways. Point-based grading systems are turning school classrooms into micro-token economies where students are invested in the pursuit of earning class capital, i.e. points, rather than being invested in gaining new knowledge, obtaining new skills, and fostering an overall love of learning (Feldman et al., 1996; 
Hahn, 1995; Kohn, 2011). Furthermore, the vast majority of teachers in these studies saw no problem with the traditional grading system and were actively engaged in employing it despite some of their conflicting statements to the contrary (Feldman et al., 1996). Perhaps this is why Wormeli (2006) referred to our grading practices as "the elephant in the room," and called for educator to "question assumptions" and "embrace alternatives" to traditional grading (p. 89-90).

\section{Alternative Grading Systems \\ Points-Based Alternatives to Traditional Grading}

In an effort to combat this "toxic" residue left by traditional grading practiceseven if unintentional — educators and researchers have advocated a litany of alternative grading practices attempting to rectify the situation in order to assess what their students actually know and can demonstrate, and to ensure consistency between students' performance and the grade they receive in class. The initial grading systems detailed below are variations of traditional grading systems that are still points-based. They are representative of attempts to address the inconsistencies of traditional grading without having to completely overhaul a deeply entrenched system of reporting and evaluation.

Point by point grading. Denise Marchionda (2010), a community college instructor in Wisconsin, was tired of the "watchdog" (p. 409) atmosphere she had unintentionally created in her classroom. She was continually battling excuses for missed classes, missed assignments, and was fed up with students begging for exemptions semester after semester. She was similarly tired of the rubrics she used in class, and the 
heavy-handed nature she felt it employed in the grading. Therefore, she implemented a new system she deemed "point-by-point" grading (Marchionda, 2010, p. 408).

Essentially, her system broke all projects down into smaller, formatively assessed tasks, each one worth a certain level of points, a 2-point assignment, or a 5-point assignment, or a 10-point assignment. Giving her assignments levels or point categories allowed her students to take a more active role in managing both their grade and participation in her class, and she credits the grading system with making her assessments more objective, and giving her students a greater sense of responsibility (p. 416).

While this system certainly served an important purpose for Marchionda (2010), it was still points-based at its core, and still rooted very much in extrinsic motivation. It was an attempt to break away from the "toxic" practices of tradition (Reeves, 2008, p. 85), but didn't escape very far.

Self-reflective grading. Another attempt to break away from traditional grading was the self-reflective grading that Cherepinsky (2011) employed. Also at the postsecondary level at a private Jesuit institution, Cherepinsky (2011) essentially implemented what Bloom (1968) described as "correctives" for his students" exams (Guskey, 2010). Exams would be returned with no feedback, except the terms "right" or "wrong" for each question (Cherepinsky, 2011, p. 294). Students were then given a period of time, if they so chose, to investigate the problem further, develop a better solution, and try to arrive at a different answer. Students could resubmit their exams in an effort to recoup a percentage of the points they had initially lost with their original incorrect answers. 
Cox and Bloom (1980) would certainly approve of this accommodation, as he said that correctives were instrumental to students making students more attuned to their own needs and giving them the ability to diagnose their own learning styles. However, while Cherepinsky (2011) lauded this system as increasing students' motivation and allowing inquiry-driven exploration, which it most certainly did, the system itself was still rooted in points-based framework and the motivation that drew upon was still entirely extrinsic.

Minimum grading. One grading system gaining much credence thanks to the work of several researchers, especially Guskey (2004) and Reeves (2008), is minimum grading, which is specifically designed to alleviate the statistical deficits created by traditional grading systems, particularly 100-point grading systems (Carey \& Carifio, 2012; O’Connor, 2009). This system sets a minimum grade that a student could possibly receive, usually set at 50 in a 100-point scale. The thinking is to prevent students who might receive a zero on an assignment — be it missed homework or poor attendance or anything else - from completely ruining their grade, as it may be an unfair representation of their academic ability.

O’Conner (2009) makes this case by recalling a student he observed in Phoenix: her scores of 90, 0,82, 72, and 76, gave her a mean average 64 percent. Unfortunately, the passing score for the class was 70 percent, so this student received an F, despite the fact that all of her scores were above the passing line save one, the zero. The zero this student received disproportionately affected her overall score to the degree that it was no longer a valid representation of her overall ability. 
O'Conner (2009) constructed an analogy between grading practices and recording weather temperatures. Hypothetically, he imagined recording the temperature in Phoenix each day for one week in November-a week in which the temperature never dipped below $80^{\circ} \mathrm{F}$. If, for some reason, we forgot to record the score on one day, but still averaged it with all of the other scores, we might derive a weekly average temperature of $64^{\circ} \mathrm{F}$, which would be entirely inaccurate to say the least. In the same way, averaging zeroes for missed assignments is an inaccurate assessment of their abilities (Guskey, 2004; O'Conner, 1999; Reeves, 2008). Minimum grading systems provide an elevated basement to prevent scenarios like this from happening.

Carifio and Carey (2009) investigated minimum grading and its effects on students in classes deemed "high-risk" (p. 34), as well as peripheral factors such as student motivation and engagement. One of the common complaints from detractors of minimum grading is the assertion that it unfairly awards students a percentage of points that they have not earned and is akin to a type of social promotion (Carey\& Carifio, 2012). While their study did find that minimum grading has a positive effect on both the academic performance as well as the motivation of students in "high-risk" classes (p. 34), Carifio and Carey (2009) noted that minimum grading has little benefit to students who continually score below 50 percent. Rather, the students that stand to gain the most are the ones who have scant few scores that are disproportionately low which has impacted their overall grade negatively. Therefore, Carifio and Carey recommend further research into minimum grading as it could be potentially beneficial to all students, not just those in high-risk situations, and they encouraged teachers to consider minimum grading systems within their classrooms. 


\section{Criterion-Referenced Alternatives to Traditional Grading}

The following grading systems have also been presented as alternatives to traditional A-F grading systems, but these have been successful in freeing themselves from the shackles of norm-referenced comparisons and have focused more on criterionbased evidence. Guskey and Bailey (2001) detailed several types of grading systems which might operate in a given classroom, many of which have been attempted throughout history. Pass/Fail systems, for instance- those that award students a passing score for successful documentation of the requirements, or failure if they don't (Guskey \& Bailey, 2001)—were identified in the 1930s when some researchers were reacting against the perceived subjective nature of the A-F grading system (Kirschenbaum et al., 1971). Additionally, Guskey and Bailey (2001) identified Narrative grading as an acceptable alternative grading system, a practice which was common place in the $1800 \mathrm{~s}$ (Kirschenbaum et al., 1971). They also described Blanket grading, whereby students begin the term with a certain grade, usually an A or $100 \%$, and all course work is done in an effort to retain their top score (Guskey \& Bailey, 2001). While these options are certainly worthy considerations for teachers to employ, the following systems will be discussed in greater detail from multiple sources in the existing literature: Minimum Grading, Standards-Based Grading, 3Ps Grading, Mastery Grading, and No Grading.

Standards-Based Grading. The criterion-referenced grading system that is currently gaining the greatest acceptance in schools throughout the nation is standardsbased grading (Cox, 2011; Guskey, 2000, 2001; Marzano, 2000). This grading system is far and away the most preferred grading style by specialists in assessment and grading 
(Brookhart 2011; Cox 2011; Erickson, 2011a; Guskey 2000, 2001; Marzano, 2000; Reeves, 2008; Wiggins, 1991). Built entirely on mastery learning concepts, standardsbased grading predetermines a learning outcome for students—a "standard" — and then aligns all corresponding activities so that the student will be able to achieve that standard. Although there are a few variations of standards-based grading, the scoring system is a stark break from traditional points-based grading systems, wholly divergent from traditional A-F letter grades. Scores, themselves nominal numbers containing no ordinal value, are distributed based on a 5-point (or sometimes 4-point) rubric, where "5" indicates that a student has mastered the standard or objective, " 4 " indicates that they have achieved an acceptable level of competency for that objective, " 3 " is developing towards competency, and " $2 \mathrm{~s}$ " and " $1 \mathrm{~s}$ " indicate an emergent or limited level of mastery, or a lack of mastery, respectively, neither of which are passing scores (Marzano, 2000). In most cases, correctives and retakes are allowed so that students will not move on until they can demonstrate at least a developing or competent level of mastery for each objective (Guskey, 2001).

Currently, many schools are moving towards standards-based grading, and some entire school districts, such as the Adams County School District (CO) and the Excelsior Springs School District (MO) are adopting standards-based grading and implementing district-wide, standards-based report cards, much like the one created by Marzano (2000) (Adams 12 Five Star Schools, n.d.; Excelsior Springs School District 40, 2011; Feyerick \& Garrett, 2011). The entire state of New Hampshire has also adopted the standardsbased grading system exclusively (Gewertz, 2012; Leather \& Yocum, 2012). Erickson (2011a) put forward a "call to action" (p. 46) for administrators to consider implementing 
standards-based grading across the board, as he outlined his perspective that doing so contributed to saving his school (Erickson, 2011b).

Much research has been, and continues to be done regarding standards-based grading, but essentially, this grading system forces educators to examine what they believe grades truly mean (Scriffiny, 2008). Proponents of standards-based grading, like Brookhart (2011), advocate that grades should be a reflection of what students learn. However, she allotted that this is something not all educators believe. She said, "I know plenty of teachers who firmly believe that grades should reflect what students "earn" in the classroom by doing their work, following instructions, and behaving" (p. 13). Still, in order to reach a consensus for improving student achievement and the way teachers teach, Brookhart outlined strategies to at least begin the discussion about grading systems, grades, and what they mean among school faculty and administrators. Some strategies she mentioned are Vote-Compare-Discuss, where all faculty get to mark an $\mathrm{X}$ in a voting square and then results are discussed using supported ideas; Expert Panel Boards, where certain teachers are assigned to an issue or topic (standards-based grading, traditional grading, etc.) to investigate, become an expert on the subject, and then report back to the group; and Fishbowl, where a large group discussion can ensue with a portion of the group observing outside. One seat is vacant in a Fishbowl so that a member of the audience can join the discussion at important junctures when so moved. Brookhart maintained that through actual conversation and discussion, educators can root out the purpose behind grading.

Another advantage that standards-based grading advocates have used to gain a certain amount of prominence has been the standards movement itself. With the 
implementation of NCLB in 2001, individual states have been required to create standards of achievement for all students to attain (Yell \& Drasgow, 2005). Presently, over ten years later, the standards movement is in full swing, and has ballooned to see the majority of states adopting Common Core standards - a set of standards that provide a measureable requirement of what students should be able to demonstrate that have been disseminated at a national level (Zhao, 2009). It is into this educational climate, one inundated with standards, objectives and performance assessments, where standardsbased grading has attempted to carve out its niche. The standards-based grading movement has been very effective at showing how national or state standards can be used to directly inform students' grades in classes, and even on individual assignments (Tierney, Simon, \& Charland, 2011).

However, despite all of these potential benefits, standards-based grading is not without some inherent challenges. For one, it seems to fly in the face of deeply entrenched perceptions of grading that have been established by traditional norms, and that can be confusing to many stakeholders: administrators, parents, students and teachers alike. Just as some school districts have begun to adopt standards-based practices, others are just as quickly beginning to abandon it (Erickson, 2011b; Gewertz, 2012). For instance, the Osseo Area School District (MN) is now reconsidering their district-wide move to standards-based grading. Implemented in 2011, strong parental and student opposition to the new grading system, coupled with confusion from Osseo Area teachers has led some district administrators to abandon their support for the grading system (Young, 2012). 
3-P's Grading. Another alternative, non points, criterion-based grading system is the 3-P's grading system developed by Steve Peha (2005), which focuses on three categories: Participation, Progress, and Performance. Each category is weighted with a certain final percentage, $25 \%, 25 \%, 50 \%$, respectively, but within each category there are only three marks a student will receive: a check $(\checkmark)$ meaning sufficient, a check plus $(\checkmark+)$ meaning outstanding, or a minus (-) meaning unsatisfactory. Just as in other mastery-based systems, correctives are used to ensure that students revise any minuses until they reach a level of demonstrated proficiency.

One interesting aspect in the 3-P's Grading System is that it involves an element of collaboration. As traditional letter grades are difficult to ascertain with the 3-P system, teachers and students will conference about where the students stands in the class, coursework will be examined, and the student will be able to offer insight into what they feel their grade should be based on their quality of work. These aren't just empty words, either; the students' self-assessment accounts for $50 \%$ of the final grade (Peha, 2005).

Mastery grading. Guskey and Bailey (2001) outlined yet another alternative, non-points, criterion-based grading system known as mastery grading. This system shares much in common with standards-based grading in that both systems use performance standards that students must demonstrate in order to gain proficiency or, in this system, mastery. However, in mastery grading there is a definitive cut-off between mastery and "non-mastery" (p.96). Another difference is that students in mastery grading systems are given multiple opportunities to achieve mastery if their initial attempts fall short.

This system is based very specifically upon Bloom's (1968) iteration of mastery learning. Teachers using mastery grading organize their content into learning units, 
identify essential curricular objectives, and administer regular and timely formative assessments to assess whether or not students have met the aforementioned objectives (Guskey, 2010; Guskey \& Bailey, 2001). While many of Bloom's educational theories have become mainstream practices in today's classrooms, mastery learning among them (Diegelman-Parente, 2011, Greenstein, 2012, Guskey, 2006), mastery grading is a system that is entirely governed by his principles.

One emerging mastery grading system is the No Points Grading System (Percell, 2013). In this system, a cut-off line between mastery and non-mastery has been established that is regulated by a checklist rubric of minimum requirements, as well as two other achievement level indicators. However, in this system all points have been removed from the grading system. As a result, there are no percentages, and students' grades are determined by predefined achievement levels, or "tiers" that students must achieve, which are based on the overall quality of a student's work (para. 12).

\section{No Grading}

Finally, beyond the talk of norm-referenced and criterion-based grading systems, there is a contingent of educators actively advocating for no grades at all. Among them, Kohn (1999), along with several practitioners (Hunt, 2008; Bower, 2010, Malehorn, 1994; Spenser, 2010), assert that assigning grades only serves to create a sense of apathy in students and instill in them a preference for the easiest task possible (Kohn, 1999; 2011). This camp is receiving converts from former standards-based grading advocates, like Jason Beddell, a middle school teacher from New Jersey who said: 
"I had been advocating standards-based grading, which is a very important movement in its own right, but it took a push from some great educators to make me realize that if I wanted to focus my assessment around authentic feedback, then I should just abandon grades altogether" (as cited in Kohn, 2011, p. 28) Another such teacher, Joe Bower (2010) from Alberta, Canada has "de-graded" all of his classes, and is using social media to encourage others to follow suit in his online blog, The Love of Learning. He even has a "Grading Detox Guide" where he walks uncertain teachers through the painful but necessary withdrawal process of ridding themselves of "grade-use" forever (Bower, 2010 March 10). For his own practice, Bower (2010) gives what he calls "replacement grades" in his efforts to "abolish grading" (Bower, 2010 February 16, para. 28). Instead of giving grades, Bower (2010) focuses instead on providing formative feedback to his students on a regular basis. While he does enter a final letter grade on students' final report cards as required by law, he does so through a collaborate meeting where students defend why they feel they deserve the letter grade of their choice, although Bower makes it clear that the grade is in no way an average of cumulative scores, as there aren't any, and he intentionally keeps the entire process as low-stakes as possible (Bower, 2010 February, 16).

\section{Grades as a Measurement of Learning}

Do grades measure learning? Admittedly, this is the question that researchers have been attempting to answer, and resoundingly the answer has been a definitive no (Brookhart, 1994; Conley, 2000; K. Cox, 2011; Stiggins et al., 1989). However, the research has also demonstrated that teachers value grades for purposes beyond just a 
measurement of how much a student has learned (Brookhart, 1993; Cizek et al., 1995;

Feldman et al., 2006; Guskey, 2004). Despite assessment specialists' recommendations of best practices, teachers still feel that non-achievement factors are important aspects of students' grades (Brookhart, 1993, McMillian, 2001).

\section{The Heart of the Matter}

At some point, the question becomes: does it even matter? In their study of district-wide grading practices, Cross \& Frary (1999) specifically investigated the phenomenon of "hodgepodge grading" coined by Brookhart (1991, p. 36), which is the intentional inclusion of non-achievement factors such as effort, motivation and progress as an attempt on behalf of teachers to purposely keep student's grades invalid. Cross and Frary (1999) postulated that hodgepodge grading existed as a defense mechanism to protect both students and teachers against negative consequences. Were grades a strict representation of student achievement, teachers may lose a certain element of control to temper potentially arising external pressures.

Ultimately, like others before them (Brookhart, 1991, 1993; Stiggins et al., 1989), Cross and Frary (1999) found inconsistencies between teachers stated ideals in grading and their actual practices. Students also seemed unsure as to exactly the extent that effort and progress should factor into grades. The researchers questioned: if there was such a prevalence of hodgepodge grading practice at work among teachers in the district they studied, why wasn't there a greater outcry from teachers and parents, to say nothing of administrator and district officials? Their conclusion was that there is a common understanding among stakeholders that grades are, in fact, expected to be a hodgepodge 
accumulation of various factors, and that teachers' subjectivity in determining students grades are "less of a concern than discounting effort, ability, attitudes, conduct, and growth" among students (p. 70).

\section{Chapter Overview}

Chapter Two has thoroughly investigated the literature relating to grading practices both historic and current and the best practices that have been identified by assessment strategists through research, namely: that grades should be relegated to solely reflect students' academic abilities and proficiencies, independent of any nonachievement factors such as behavior, effort or attendance (Stiggins et al., 1989). Additionally, several alternative grading strategies have been investigated, as well as literature that attempts to decipher the meaning and purpose of grades. In the next chapter, I will detail my presiding methodology for this study, and explain my data collection and analysis procedures, as well as detail the research setting, participants, and ethical considerations. 


\section{CHAPTER III}

\section{METHODOLOGY}

In exploring the methodology that is best suited for this study, I investigated several types of qualitative methodologies. Based on my research topic, my participants, my research parameters, and the intentionality of my study, I have determined to use a combination of two methodologies: case study and phenomenology, what I am referring to as a multi-case phenomenology. In the following chapter I will discuss my research design, the historical relevance of both phenomenology and case study, and how blending the two methodologies will benefit my own research study. I will then speak to how this blended methodology will assist in answering my research questions, informing my data collection and guiding my data analysis procedures. Finally, I will introduce my research setting, provide participant and case profiles and identify some ethical considerations at work.

\section{Methodology in Answering Research Questions}

Leaning on the methodological framework of case study in my blended design gave my study an appropriate route through which to go about answering my research questions. These questions were developed with a semi-structured nature, and although my data collection procedures allowed for some flexibility, the questions were far more structured than they might be in a pure phenomenology. This structured nature of 
questioning was partly due to the case study elements of the research design, and partly due to the genre of the dissertation itself (Hawley, 1993). Either way, this structure aspect aided me, as Stake (1995) asserted, "Good research questions are especially important...because case and context are infinitely complex and phenomena are fluid and elusive" (p. 33). The questions are few in number, as one would expect from a phenomenology, with just one primary question, but three additional subsidiary questions.

\section{Primary Research Question}

1. How does the use of an alternative, non points-based grading system influence teachers' instructional practices in their classrooms?

\section{Subsidiary Research Questions}

a. What are the motivating factors behind teachers' decisions to implement an alternative, non points-based grading system?

b. How does the use of an alternative, non points-based grading system influence the type of feedback that teachers provide to their students?

c. How does the use of an alternative, non points-based grading system relate to a teacher's educational philosophy regarding student assessment and grading?

My questioning and implementation of the interview protocols will reflect ideas related to how the phenomenon of grading and providing feedback in alternative systems 
influences, informs, and relates to these teachers' lived experiences and instructional practices.

\section{Methodology in Data Collection Procedures}

Incorporating a blended design of case study and phenomenology will be nicely suited to my data collection as both designs are largely dependent on interviews, but will also include documents used throughout the teacher's assessment process of providing students feedback. The data collection will be comprised of four main elements: initial semi-structured interviews of each teacher, a focus group interview of all participating teachers, a follow-up interview with each teacher debriefing the focus group, as well as a self-analysis of the teacher participants' feedback.

\section{Initial Semi-Structured Interviews}

Data collection began with an initial interview of each teacher participant conducted at the teacher's school site, or a mutually agreed upon location (see: Appendix A: Semi-Structured Interview Protocol). All interviews were audio recorded on the researcher's iPad using the Voice Memos application in order to ensure trustworthiness. The interview protocol was semi structured in nature so as to specifically address the elements of the research questions, especially: gauging the motivation for employing an alternative grading system, the ways in which this grading system influenced the teachers' instructional practices, as well as how grading in this fashion aligned with their educational philosophy and beliefs about teaching. Each interview was designed to take no more than 60 minutes, although most interviews took less time. 


\section{Focus Group Interview}

Once individual interviews had been completed, transcribed, and analyzed, I conducted an online focus group interview utilizing using the video conferencing software program Blackboard Collaborate. The focus group was recorded, both audio and video, so as to ensure trustworthiness, and to capture any important physical nuances. Once again, a semi-structured focus group interview protocol was generated to guide the session structurally (see: Appendix B: Focus Group Interview Protocol), although I remained open to pursue additional topics of conversation that naturally arose from the participants. The focus group interview protocol was designed to: support the research questions - how teachers' grading systems informed their instructional practices, their initial motivations for employing this system, how their grading system influenced the nature of feedback they provide to their students; but also to allow the teacher participants a collegial environment of solidarity among other practitioners who are also pursuing alternative grading, and to document their recommendations of how to sustain such support systems moving forward.

The focus group was designed to last roughly one hour, which it did, despite certain minor technical difficulties incurred along the way.

\section{Debriefing Interview}

Following the online focus group interview, each teacher who participated gave a second individual face-to-face interview, this time specifically to debrief the focus group. Once again, this interview was audio recorded on the researcher's iPad using the Audio 
Memos application in order to ensure trustworthiness, and once again a semi-structured interview protocol was created to give the session a baseline structure, although I was still open to the possibility of unexpected topics of relevance. The protocol sought to explore any epiphanies arising from the online focus group, any ways in which the other participants' experiences may have influenced their own grading practices, especially in so far as they relate to the nature of feedback they provide their students, and any feelings of solidarity they experienced with teachers using alternative grading systems (see Appendix C: Debriefing Interview Protocol).

\section{Teacher Participants' Feedback Self-Analysis}

At the time of the initial interview, each teacher participant was requested to provide a self-analysis of their own feedback they provide to their students. Prior to the data collection, all participants were provided with two examples from the researchers of their own feedback which had been coded into themes for the purposes of analysis. They were also provided with literature related the effectiveness of feedback (Wiggins, 2012). Teachers were asked to select samples of student work upon which they provided feedback in a triangulated manner, three assignments from three separate students, to then code their feedback for emergent themes, and then write a brief self-analysis of their own feedback in an objective manner.

This activity was designed to provide a third data point for the study, but also to benefit the teacher participants, as it allowed them to analyze their feedback objectively and to see if their feedback really was being administered in the way that they thought it was, and if it was actually as effective as they imagined it to be. Due to time constraints 
of some of the teacher participants who coached, only three of the five teachers were able to complete this feedback self-analysis.

\section{Methodology in Data Analysis Procedures}

Employing a multi-case phenomenology was essential to my data analysis procedures, as a cross-case analysis of the data occurred through the transcendental reduction of textural and structural elements to arrive at the philosophic essence of the lived experience of teachers who use alternative grading systems. This blended methodology achieved a qualitative positionality: to speak power from a marginalized perspective (Merriam 2009), to identify a "particularity" of the experiences within the cases rather than to hunt for generalizability (Stake, 1995, p.8), and to recreate a sense of authenticity and "enhancement of former meaning" (Crotty, 1998, p. 78).

\section{Transcription and Analysis for Common Themes}

Once recorded, all interviews and focus group data were directly transcribed using the transcription software program, Express Scribe. Each transcription underwent a member checking process to determine accuracy and ensure trustworthiness and interrated reliability. The focus group interview was video recorded through the Blackboard Collaborate online video conferencing software, and in the same manner, the session was transcribed using Express Scribe. Again, all transcriptions were member checked to ensure accuracy and increase trustworthiness. Textural and structural descriptions were synthesized in order to arrive at the essence of a shared or collective experience of teachers grading through alternative methods. 


\section{Transcendental Phenomenological Reduction}

Once all data was collected, transcribed, and member checked, it was analyzed for significant statements and clusters of meaning, per Moustakas' (1994) framework of transcendental phenomenology. After first providing an auto-biographical account of my own experience with the phenomenon of alternative, non points-based grading - the Epoche (Husserl, 1931) - I then analyzed the data using a process known as the Transcendental-Phenomenological Reduction, specifically following the StevickColaizzi-Keen method as outlined by Moustakas (1994). The Stevick-Colaizzi-Keen method relies upon employing the process of horizonalization, a method of analysis where the researcher makes him or herself receptive to all statements and comments from each participant as having an equal weight. The data is combed for delineated horizons or meaning units which appear to be essential to the nature of the experience. Through the analysis of these horizons, horizon clusters or themes, also known as invariant qualities of the experience, typically arise and are grouped. This clustering process allows the researcher insight to generate individual and composite textural descriptions of the phenomenon, the "what" of the experience, as well as individual and composite structural descriptions of the phenomenon, the "how" of the experience (Moustakas, 1994, p. 74). The final step in the Transcendental-Phenomenological Reduction is to integrate the textural and structural experiences to arrive at a "synthesis of the meanings and essences of experience" (Moustakas, 1994, p. 144) of teaching a class that utilizes an alternative grading system, and the extent to which these grading systems inform their instructional practices and the feedback they provide to their students. 


\section{Synthesis of Meaning: The Essence of Alternative Grading}

By analyzing the clusters of meaning — or invariant qualities — through textural and structural elements of the data, and reflecting back upon a sound philosophical foundation, this process of transcendental phenomenological reduction (Moustakas, 1994) will allow me to synthesize the essence of the experience of employing an alternative grading system in a high school classroom, and how such an implementation informs classroom practices and feedback provided to students.

\section{Research Design}

I was initially drawn to phenomenology, investigating the essence of a phenomenon or lived experience by a group of individuals, as a way to research individual high school teachers living out their experiences of incorporating an alternative, non points-based grading system within their classes. Regarded as its own phenomenon, alternative grading systems are scarce, particularly at the secondary level, and it is worth investigating the essence of operating within this type of a system. Furthermore, the nature of phenomenology being so richly steeped in philosophy would afford my study a certain level of credence within the realm of educational philosophy, especially as alternative grading systems stand opposed to the dominant thought processes that have governed education in this country for decades (Anderson, 1998).

However, I was surprised to find the seamless consistency with other designs, especially that of case study. Merriam (2009) describes how case study is able to bring to light complex social units consisting of multiple variables, especially those anchored within a real-life context, which provide a rich, holistic account of phenomenon. 
Furthermore, Stake's (1995) conception of case study lent my research a desirable element of particularity, and after further reflection, I began to see the real value of how my study might present as a collective case study. Still, I was loath to lose the value of elucidating the philosophical essential that a phenomenology would afford. Reading Merriam's (2009) description of different types of case studies_-historical, organizational, and observational, I began to envision a different type of case study: phenomenological.

\section{Phenomenology}

Possibly one of the more complicated qualitative methodologies, phenomenology is rooted in the underpinning philosophies that informed the fields of psychology and sociology in the early $20^{\text {th }}$ century. Founded in the philosophical works of Edmond Husserl and Martin Heidegger, phenomenology aims to investigate the central importance or essence of a given phenomenon. Phenomenology originated in response to the European depression surrounding WWI as a philosophical "system" to describe the essence of a lived experience or a singular phenomenon by several individuals (Moran, 2005, p.35).

It is impossible to remove the philosophic origins from phenomenology, but viewed strictly as a research design, phenomenology has become quite popular in the scientific community, especially in the fields of nursing, health, psychology, and education. Contributors have sought to describe commonalities among participants who experience a phenomenon and derive a universal essence (Willis, 1999). Creswell (2007) identifies two main strands of phenomenological research: one is hermeneutic 
phenomenology, purported by Van Manen (1990), in which phenomenology is viewed not only as a descriptive process, but also an interpretive process for the researcher who "mediates" the lived experience (p. 26). The other is transcendental phenomenology, as described by Moustakas (1994), which aligns itself more closely back to Husserlian philosophy, particularly in the use of Epoche or "bracketing," a structure for researchers to "put out of play" their own prior knowledge (Husserl, 1931, p. 98). Transcendental phenomenology also incorporates a reductive process Husserl (1931) called "transcendence" (p. 78) - a way to bring to light that which was hidden in order to perceive objects in a fresh new way, "as if for the first time" (Moustakas, 1994, p. 34).

Transcendental phenomenology utilizes an analytical process Moustakas (1994) dubbed "horizonalization" (p. 122). Horizonalization is analyzing the data for "significant themes" and clusters of meaning, also called invariant qualities, and then analyzing both the textural description of the experience (what participants experienced) and a structural description (the experience described within a given context) and then comparing both to ultimately arrive at the essence of the experience and convey it in the findings (Creswell, 2007, p. 67).

Certainly, phenomenology is challenging as a research design. To use it, researchers must feel comfortable and knowledgeable with the prevailing philosophy from which phenomenology is derived. Indeed, Creswell (2007) notes that any researcher attempting to do phenomenology would be remiss to ignore the underlying philosophy, and several more recent studies, especially in the nursing field, have been criticized for just that (Crotty, 1996; Norlyk \& Harder, 2010). Furthermore, phenomenology can present challenges dealing with the concept of bracketing and the Epoche, as researchers 
must decide how their own personal understandings will be involved in the study (Creswell, 2007).

Despite the challenges, I feel that my study stands to benefit far more from phenomenology than from other qualitative designs. First and foremost, describing a lived experience of several individuals incorporating a system that is alternative to the normative majority structure will provide the study with a voice and power to speak from a marginalized position, and it will do so in a way that is reliant upon its inseparable and deeply rooted underlying philosophical essence.

\section{Case Study}

Just as it sounds, a case study explores an issue through one or more cases within a given context or system. Through this design, individual issues can be examined in great detail, and case study has been very popular in the fields of psychology, medicine, and law (Creswell, 2007).

My research study presents nicely as a case study, with the four cases being four alternative grading systems employed in the secondary classrooms of five different teacher participants: one who implements the 3-P grading system as conceived of by Peha (1995), another who uses standards-based grading, as promoted by Guskey (2001), Reeves (2001), and others (Brookhart, 2011; Cox, 2011; Erickson, 2011b, Marzano 2000; O'Connor, 2009; Stake, 2004); the third who uses a mastery grading system that is pointless and assesses student work purely qualitatively, as envisioned by Percell (2013); and the fourth being a minimum grading system which is self-designed and focused on summative assessments. Each case was bound within the spring semester of the 2013-14 
school year, at which time I conducted all data collection, analysis, and reported my findings. Through cross-case analysis and transcendental phenomenological reduction, I documented the essence of these teacher participants' experiences using alternative, nonpoints based grading systems and analyzed the affect these systems have on teachers' instructional practices, their relations to the teachers' educational philosophies, and the nature of the feedback they provide.

For these purposes, I have drawn extensively on the work of Creswell (2007), Lichtman (2013), Merriam (2009), and Stake (1995), who identify multiple types of case studies including a collective case study, which investigates more than one case, and aims to present thoughtful reflection through cross-case analysis. Merriam (2009) has been instrumental in not only situating case study as a distinctly qualitative design, but also one that is particularly effective within the field of education (Merriam, 2009). No matter the type of case study, Merriam (2009) offers other characteristics of this research design: that they are concrete and tend to rely on vivid, straightforward reasoning as opposed to abstract logic; they are rooted in context, as each case is investigated within bounded parameters; and they are more developed in that they invite readers to be active participants, allowing readers the space to apply their own generalizations to whatever specific populations they have in mind, a process Stake (1995) calls naturalized generalization" (p. 85). Indeed, regarded as the final process in case study research (Merriam, 2009), the reader's generalizations may prove important to this study for other educators who are also investigating alternative grading systems.

All of these factors were instrumental for me to envision a case study as being phenomenological in nature, but also as a way to increase the trustworthiness of my study 
insofar as it focuses on particularity, but still naturalizes generalizability for the readers and potential teachers and administrators in the field (Stake, 1995). Despite the limited number of participants for this study, it does not diminish the essence of their experiences employing alternative grading systems, or the levels of importance their experiences offer other educators.

\section{Multi-case Phenomenology}

By combining the two qualitative designs of phenomenology and case study, it afforded my study just enough of an element of structure through the elements of case study, as well as a strong sense of particularity to examine each case (Stake, 1995) and a "naturalistic generalizability" that is left to the reader (p. 85). However, by directing the study according to the principles of phenomenology, I still maintained a philosophic insistence and the transcendent nature that Moustakas (1994) advocated, incorporating a reduction of textural and structural descriptions to arrive at the essence of the phenomenon of alternative, non points-based grading.

It is my hope that through this multi-case phenomenology, in which I documented lived phenomenon of incorporating an alternative, non points-based grading system in four separate cases, and the experiences of five separate secondary teachers, their pedagogical epistemologies, and the nature of their feedback provided to students. Incorporating a blended methodology allowed me to richly describe the essence of the experience that these alternative grading systems as experienced by these five teachers from a distinctly philosophical stance, especially from a marginalized corner of the educational field. 


\section{Research Setting and Participant/Case Profiles}

My study included five teacher participants who were selected based on convenience and the stipulation that they employ a version of alternative grading in their high school classrooms. They were identified either through their administrators or through members of my dissertation committee. Each case of this study is bound by the specific alternative grading system that is employed, and as such two teacher participants, Titus and Everett, are considered together in the same case because they both use the same grading system, which they designed together. In order to endear each individual teacher more personally, I will present personal profiles of each teacher/case in further detail. Please note that all proper names are pseudonymous and all identifiable information has been removed.

\section{Case 1: Christine}

Christine is technology teacher at Easton High School, which is located in a large suburban area. Easton has a student population of 1,803, $42 \%$ of whom come from low socioeconomic situations (SES) and $12 \%$ of whom have Individualized Education Plans (IEPs). Easton has an ethnically diverse student body, 64\% of whom are non white, and a large Hispanic population, $46 \%$. Students at Easton routinely score at or near the state average on statewide, standardized tests. Christine teaches several different elective courses throughout the year, most of which have to do with industrial design and industrial technology. She is a veteran teacher who always strives to get the most from her students. In preparing for the 2013-14, she realized that she was dissatisfied with 
traditional grading models, and wished to employ an alternative grading system in the hopes of increasing the quality of her students' work.

The No Points Grading System. After growing dissatisfied with the points system in her graphic design courses, Christine was actively searching for a different way to not only assess her students, but a different way to grade them entirely. Through one of my committee members, she was put in contact with me and I introduced her to an alternative, non points-based grading system, which I designed and have used in the past, the No Points Grading System. This system removes all points and percentages from students' grades as well as the scores that they receive on assignments. Instead, each assignment is assessed according to a checklist-rubric for all required elements, the satisfactory completion of which would give them a score of Meets. If they fail to complete all required elements, they would receive a score of Approaches, which is not a passing score. The highest score students may receive is an Exceeds, which means that they have met all requirements, as well as added something extra, gone above and beyond the required elements in a novel and creative way. The No Points Grading system is designed to encourage creative and critical thought among students.

All course activities are broken down into categories, which for Christine are: Assignments, Milestones, Reflections, and Projects. Each category has three levels or tiers of achievement, and based on whatever levels students attain in each category (which is directly related to their performance) determines students' final letter grade that appears on their school transcripts: an A, B, C, or F (there is no D) on a traditional 4.0 scale. 


\section{Case 2: Brandi}

Brandi is a veteran teacher of Family Consumer Science at Weston High School. She has been teaching for over 20 years and is nearing retirement. Weston is located in a rural-fringe location with a student population of $1,640,29 \%$ of which come from low SES, and $15 \%$ of which have IEPs. Weston is considered to be diverse in nature, with $1 \%$ of the population being English language learners (ELLs).

Standards-based grading. After attending a district assessment orientation, Brandi has decided to adopt a standards-based grading system which is regulated by a proficiency scale and guided by learning targets that she has specifically established for her classes. In conjunction with another colleague in her district, she is also piloting a standards-based online gradebook for her entire district.

\section{Case 3: Simon}

Simon is a social sciences teacher at Middleton High School in a mid-size ruralfringe location that is diverse in nature. $22 \%$ of Middleton's 1,942 students come from low SES and 10\% have IEPs. Simon is a socially conscious individual and feels strongly about issues of justice, diversity, and equality and fairness. Outside of school, he is an active member in several community organizations that promote advocating for issues of justice and community awareness. As you will see in chapter five, the presentation of data, Simon incorporates these sentiments into his teaching in efforts to make his classes more democratic and more free. 
The 3-P grading system. Simon is in his second year of teaching, and even in this challenging time in a teacher's career, he is employing the 3-Ps grading system (Peha, 2005) in his history and sociology courses for the 2013-14 school year.

\section{Case 4: Titus and Everett}

Titus and Everett both teach at Downton High School and both employ a minimum grading system of their own design, one which is rooted in the importance of summative assessment. They are being considered together as a single case, as they both use the same grading system, although I have collected data from them both individually and collectively, like the other participants. Both Titus and Everett are veteran teachers, with nearly 40 years of teaching experience between them. They also both coach athletic programs: Titus is a basketball coach, and Everett is the head wrestling coach at Downton. Downton is a diverse school; $45 \%$ of its student population of 1,490 is nonwhite. The percentage of students from low SES at Downton has more than doubled in the last five years, with $24.1 \%$ low SES in 2003, to 52.6\% reported in 2013. Meanwhile, their graduation rate has steadily declined, down from $89.2 \%$ in 2003 to $75.5 \%$ in 2013 .

Minimum grading. Both Titus and Everett spoke about observing an increase of students in their classrooms who were dealing with poverty related issues that were negatively affecting their academic performance, and both teachers cited it as one of the motivations to switch to their minimum grading system. Minimum grading systems set the minimum grade that a student could possibly receive at 50, and Titus and Everett are no exception. In this manner, it prevents students who might receive a zero on an assignment — be it missed homework or poor attendance or anything else - from 
disproportionately ruining their grade, as it may be an unfair representation of their academic ability.

\section{Ethical Considerations}

There are several ethical considerations that are at work throughout this study which need to be identified and claimed in order to enhance the trustworthiness of the study.

\section{Subjectivity}

The first ethical consideration is my own position as one who is highly invested alternative grading systems. Indeed, as the creator of one of the grading systems at play, my beliefs about the shortcomings of traditional grading systems are hard to ignore. Additionally, as a former high school teacher myself, and one who also experimented with alternative non-points based grading systems while in the classroom, I am an educator who believes firmly in the power of authentic assessment as opposed to more traditional and standardized forms of assessment.

Therefore, I have undergone a process outlined by Husserl (1931) as being instrumental to phenomenology, The Epoche (chapter 4), in which I offer an account of my own experience with this phenomenon of alternative, non points based grading. It is through The Epoche that I "bracket" or "put out of play" (Husserl, 1931, p. 98) my own prior experiences and carve out a space from which to examine each of these cases in a fresh light, "as if for the first time" (Moustakas, 1994, p. 34). 
Regardless, should aspects of my own prior experiences cause some to question my subjectivity in this research, I side with Peshkin (1988) who is not only unafraid of subjectivity, but rather embraces it calling on researchers to claim their own subjectivities and allow it to frame their studies. Peshkin (1988) compares one's subjective perspectives to the garments one wears, and while he does not endorse regarding one's individual perspective as "holier than thou" (p. 20), he affirms:

The point is this: by monitoring myself, I can create an illuminating, empowering personal statement that attunes me to where self and subject are intertwined. I do not thereby exorcise my subjectivity. I do, rather, enable myself to manage it— to preclude it from being unwittingly burdensome — as I progress through collecting, analyzing, and writing up my data. (p. 20)

I shall employ this same perspective to self-monitor my own admitted subjectivity derived through my own unique personal experiences, as well as to bracket my own prior experience with alternative, non points-based grading in the Epoche in chapter four and the afterward.

\section{The Nature of the Researcher-Participant Relationship(s)}

An additional ethical consideration to note is the relational proximity of the researcher to the participants. Although none of them are personal acquaintances of mine, I do have some pre-existing knowledge of them, mostly due in large part to the process of attempting to identify high school teachers who employ alternative grading systems in their classrooms. Teachers who grade in these ways are few and far between. 
One of the teacher participants, Simon, is a former student of my dissertation committee chair in her PDS program at Middleton High School, where he is now employed. Furthermore, he is also a former student of mine from an introductory educational course taken several years ago, when he first began his undergraduate degree in secondary education. Another teacher, Christine, was identified by one of my committee members with whom she is closely related. It was through my committee member that I was made aware of Christine's desire to initiate an alternative grading system in her classroom, and throughout the school year I continued to communicate with her and mentor her related to her grading and the implementation of the No Points Grading System.

\section{Chapter Overview}

This chapter has documented the qualitative methodology that will govern my study, a blended design of phenomenology and case study. Furthermore, I have explained how this methodology manifests itself in the research questions, the data collection, and the data analysis procedures. I have also explained the research design itself, and given a brief background of each methodological design. In the upcoming Chapter 4, I will detail The Epoche and "bracket" my own personal experience with the phenomenon of alternative grading before presenting the data. 


\section{CHAPTER IV}

\section{THE EPOCHE}

In this methodological framework, it is important for phenomenological researchers to enter into the process of Epoche, a preparation for experiencing a phenomenon by first undergoing an intense self-reflection of their own prior knowledge, experiences and biases of a given experience. The researchers' stated prior history and experiences are then set aside, or "bracketed," allowing the researcher to clearly investigate the phenomenon in an unbiased fashion, as if seeing it for the first time (Moustakas, 1994, p. 85). This process of clearing the mind allows the researcher to authentically encounter the phenomenon in a fresh way, seeking new knowledge of an experience, and through reflective meditation they are able to experience the true essence of a phenomenon. Sartre (1967) noted that objects studied and described in this manner will ultimately reveal themselves to be indicative of their true essence.

Therefore, in keeping with my stance as a phenomenological researcher, I will first describe my own history with the phenomenon of alternative, non points-based grading as I have experienced it, and how it relates to the questions I am seeking to answer, as a means of clearing my mind before I analyze the accounts of my participants in their own experiences with this phenomenon. It is my goal to arrive at a place of clarity to encounter this phenomenon as it exists for each of my participants in a way that is new 
and fresh, so that I can be reflectively critical, but open to understanding these objects as they actually are.

\section{My Experience with Alternative, Non Points-Based Grading}

My own experience with alternative grading began almost five years into my career in the high school classroom. I vividly remember my first encounter with this phenomenon, when a question raised by a student in one of my classes prompted an epiphanic moment of clarity, one which would spur my decision to embrace and implement alternative, non points-based grading in my own classes, and ultimately lead me to pursue it as a research interest in higher education. It was spring, and I was teaching American Literature to juniors in a southwestern suburban high school. The semester was waning and summer's promise of freedom and excitement was tangible. But at that present moment, we still had some work to do. I was rolling out one of our few remaining assignments to the class, and after I finished speaking and the class sat through an unenthusiastic silence, one student raised his hand and asked, "Mr. Percell, how many points is this worth?”

It wasn't an incredibly novel question by any means. It was one I had heard many times before. But at that moment, given the academic and seasonal context, the question sounded new to me. It was plain to me that this student wasn't concerned with the total value of the assignment at hand. As I watched him mentally calculating percentages in his head, I heard what he was really asking: "Do I have to do this assignment at all?" “Will my grade be 'okay' even if I take a zero on this one?" This was the precise moment when teaching changed for me and I began to overtly question the value of the 
assignments in my classroom, the manner in which they were graded, what that grade meant, and even the purpose of education and our educational system as a whole. I questioned the true motivations of students in their academic pursuits, and I wondered if I could design a grading system that would motivate students to learn course material primarily for the sake of enrichment and edification as opposed to just receiving an arbitrary letter grade to go on their transcripts.

I speculated that what hindered true, authentic leaning among my students were the point values ascribed to assignments, and so I sought to eliminate them by all means. Researchers and practitioners have concurred with this notion. Huhn (2005) stated that points-based grading systems shift students' focus away from demonstrating what they have learned and toward accumulating as many points as possible. Weimer (2011) also noted that points contribute to the crippling value of learning in our collective school culture. I had noticed this same phenomenon play out among my students in class. By assigning a point value — any point value — to an assignment, teachers by nature nullify the assignment's specific worth as an opportunity for skill development and growth. Instead, it merely becomes a means to accumulate points in the overarching importance of gaining capital towards a desired percentage (Cizek et al., 1995).

Certainly students' grades are valuable. Students openly engage in cutthroat competition to post the highest GPA for Valedictorianships, for college scholarships, and to fulfill outside pressures from parents, teachers, and society at large. Indeed, there is a manifested belief that students' own perceptions of their self-worth are conditional upon how good their grades are (Wood, 1994). However, for all of this competition and pressure, there is only marginal internal consistency behind the meaning of grades from 
district to district, school to school, and even teacher to teacher. According to Campbell (2012) not only do teachers vary considerably in how they grade, but she notes that grades as a whole do not reflect what students know, and inconsistencies across schools, classrooms, and even within departments can lead to gross inequities for students.

Like Brookhart (1993), I began to question exactly what the grades I was giving to students actually meant. I determined that answer to be: not much, at least in the traditional sense. Therefore, I set out to design a system of grading that more authentically reflected what students were able to do, without any of the commonly associated external stimuli and false motivators (rank, status, and rewards). I sought a grading system that would inherently work to foster — to the largest degree possible - a sense of intrinsic motivation among students toward inquiry-based learning for their own edification. Just as my student had asked me, "How many points is this worth?" I asked myself, what if the answer to that question was: "None. Just like every other assignment."?

\section{The Influence of Alternative Grading on my own Instructional Practices}

In the summer following that spring epiphany, I set about in earnest to redesign

the structure of my courses from the ground up - the course objectives, the unit assessments, the class activities, and the way in which they all were graded. At the time, I based this course overhaul largely on the Understanding by Design framework of Wiggins and McTighe (2005), and identified a certain number of major performance objectives (four, throughout the course of one semester) that I ultimately wanted the students to master, and I designed all course activities in such a way that would lead to 
the successful accomplishment of those tasks. In this way, as my school administration pointed out, I had simultaneously built my course redesign upon the foundation of mastery learning as outlined by Bloom (1968), which was an entry point for me into the further study of mastery learning principles and curriculum and instruction in general.

Additionally, my course overhaul also aligned with Gagné's (1965) theory of instructional design and what he referred to as "objective-based assessment" (Gagné \& Briggs, 1974, p. 160). Similarly built of the foundation of mastery learning, Gagné's (1965) theory of instructional design sets forth a clear path to aligning instructional objectives with activities and their corresponding assessments, what he referred to as “tests” or "examinations" (Gagné \& Briggs, 1974, p. 163). Assessing students based on objectives places a greater importance upon mastering the skills used to perform a task as opposed to completing a series of activities in order to cover a subject, thereby providing students with a deeper connection to the content material.

Through my implementation and redesign of instruction that was planned from backwards to front, I discovered that it allotted a certain measure of internal validity to everything that we did in class. By aligning my assessments and culminating activities very closely to the objectives set forth in my lesson plans, as recommended by Gagné and Briggs (1974), I was able to achieve a very rigid consistency in my teaching. My instruction felt airtight.

While many aspects of backwards design and effective lesson alignment are simply good teaching and best practices (Stiggins, Frisbie, \& Griswold, 1989), it was also true that the very way I intended to grade the students on formative and summative assessments affected the way instruction had been designed. Since I had routinely 
experienced students playing the game of school in the past (Fried, 2005). Therefore, I intentionally designed the minimum requirements for each assignment as a checklist rubric in an attempt to foster critical and creative thinking, genuine engagement with the material, and deeper levels of thinking and operational levels. These checklist rubrics evolved dramatically from some of their first iterations (see Figure 1).

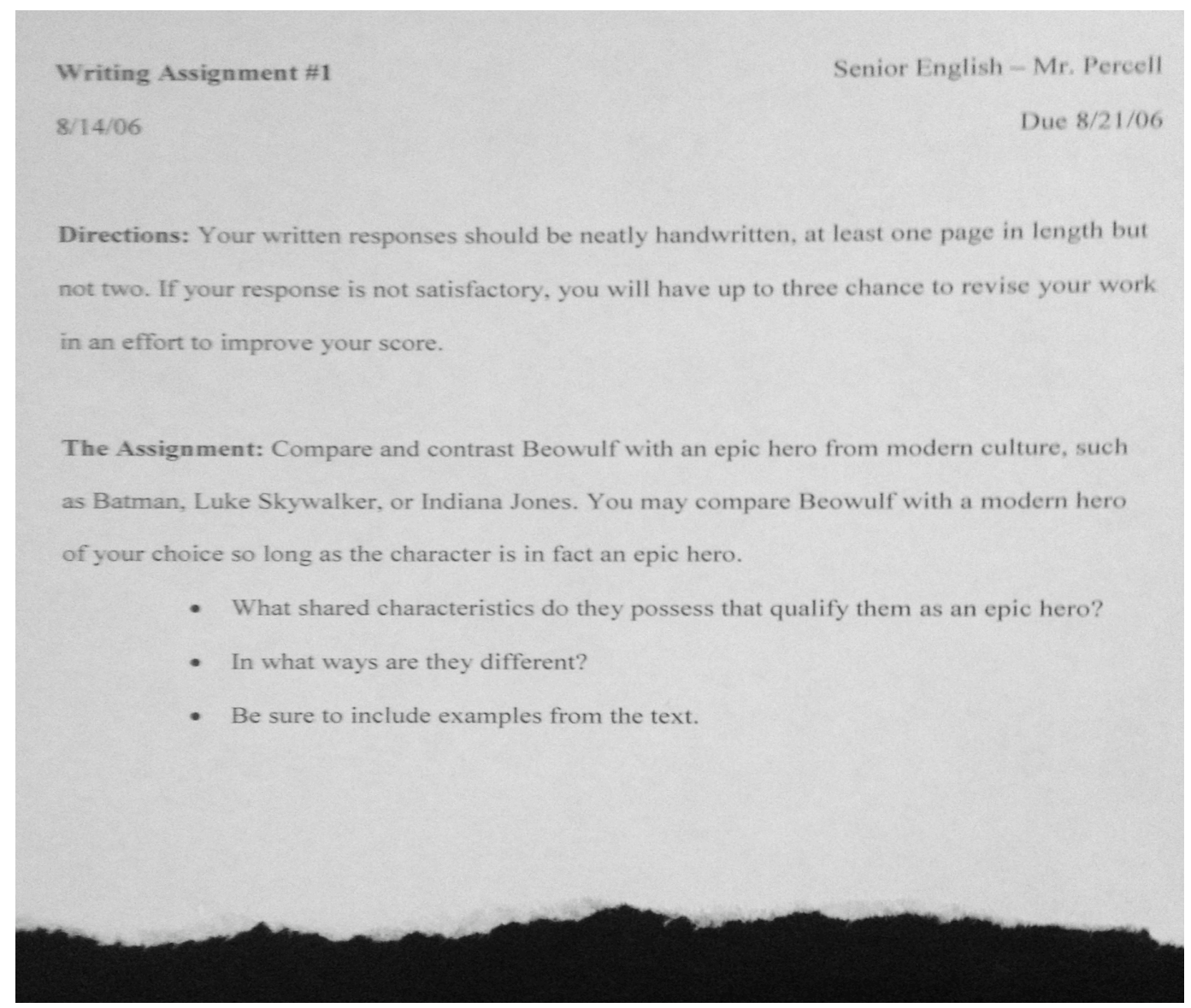

Figure 1. No Points Grading Checklist-Rubric-High School. This is an early iteration of the checklist rubrics which mostly focused on directions and suggestions.

Over the past eight years, they have seen several revisions in form and purpose.

The checklist rubrics currently exist today with the requirements much more clearly defined as to how to Meet the minimum requirements, as well as leaving space to document how students might Exceed (see Figure 2). 


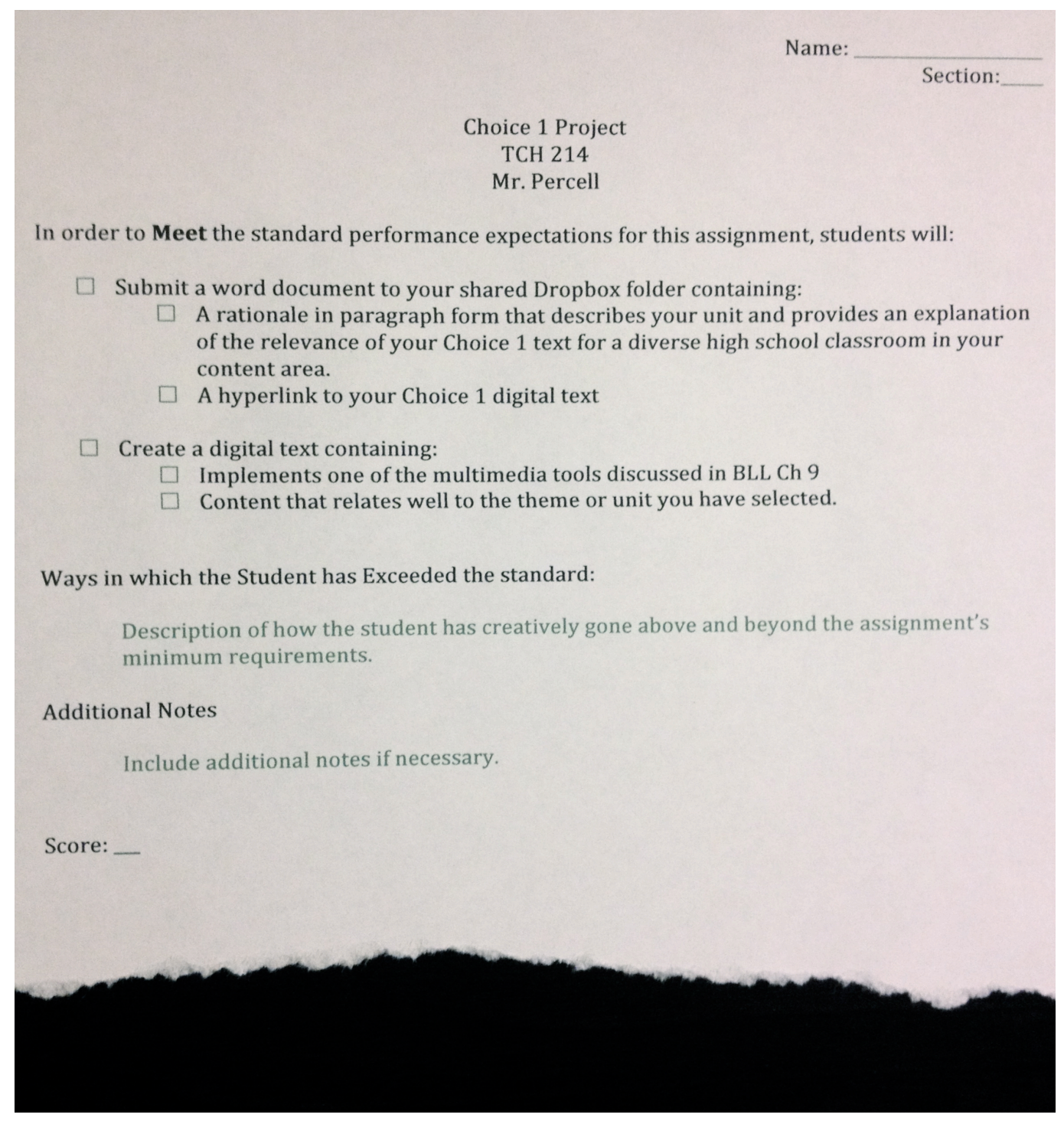

Figure 2. No Points Grading Checklist-Rubric-Higher Education. Over time, the checklist-rubrics evolved to more clearly define how to Meet the minimum requirements.

While it is still feasible to those students with a resolutely determined mindset, I sought a grading system that would inherently minimize students' ability to circumvent learning while still receiving tops scores. As the teacher, I felt a discernable relationship 
between the grading system and the design of every formative classroom assignment and all summative performance assessments.

\section{The Influence of Alternative, Non Points-Based Grading on my own Feedback}

Once I changed my grading system to an alternative, non points-based model and redesigned the entire structure of my classes, it had a profound impact on the type of feedback I provided to my students. Previously, when I was grading in a points-based, traditional grading system, I rarely thought about feedback at all, or if I did, it was not thoroughly analyzed. I used to grade solely for completion — whether or not the student had turned something in, and while there may have been elements of the work that I hoped would be displayed, I was mostly looking for ways to assign students points in order to enter into the gradebook.

Once those points were completely removed, the feedback that I had to provide my students seemed to stand alone. It was suddenly the most critically important facet of the assessment process. I went about providing this feedback through various means: initially, students would receive written feedback as to how their work matched up with the guiding checklist rubric for each specific assignment, at which point they had the option either to be satisfied with their score, or to revise and resubmit their work for further consideration. Students were allowed to revise each assignment up to three times in order to improve the quality of work and/or the score that they received on it. In addition to the written feedback, weekly or bi-weekly conferences were held with individual students in order to provide them verbal feedback on recent assignments, as well as to determine their plan for potential revisions going forward. In most instances, 
these conferences were student led and student directed; the students were the ones conferencing with me, the teacher, and my primary role was to offer them feedback on how best to accomplish the tasks they had laid out for themselves.

Based on my experience, this reliance on feedback above awarding a certain amount of points had a noticeable effect on my students' understanding of their assignments and the quality of their work. I was able to converse with them much more personally, and they were able to work towards continually improving the quality of their work through the process of collaborative revision, as opposed to simply receiving a lump sum of points and being finished with the process. This made each assignment a much more fluid endeavor.

\section{Alternative, Non Points-Based Grading in Relation to my Philosophy of Education}

Throughout my life, my own philosophical perspective has always been an integral and motivating force for the reasons behind why I attempt anything. It is no different with my foray into alternative, non points-based grading. My belief is that the function of teaching and education in general should be to foster critical thinking in students, to expose them to information and multiple perspectives, to equip them with skills and then to allow them a space so that they can make meaning for themselves from an informed perspective and ultimately derive their own worldview. This is the core of my educational philosophy, which has been in place from the outset of my career in the classroom.

However, despite my attempt to develop critical thinking within my students, what I witnessed in the classroom was mainly students attempting to circumvent 
learning — and especially thinking — in favor of accumulating points, getting grades, and moving on with their schooling. This was not necessarily the students' fault. I felt that the educational system as a whole lent itself to being "gamed" in this way. Certainly, a student could engage with course content and critically analyze the material and learn for the sake of his or her own edification, were he or she so motivated, but it certainly was not a necessity. It was possible, and probably far easier, not to engage so completely with the curriculum, to submit work that may or may not be the highest quality for classes (like mine) that were just scored for completion, and move on, without actually internalizing the content or making it meaningful and relevant.

I was dissatisfied with this system; it seemed contrary to how I truly believed the nature of education should be. What's more, it seemed that many around me (colleagues, administrators, parents, etc.) were content to perpetuate this system, or at least were unwilling to disrupt it. They passively allowed school and education to be merely a game that students could play, a hollow series of hoops to jump through, all while simultaneously promoting a standardized testing agenda in earnest that prizes rote, momentary knowledge over deeper levels of thinking and grappling with ideas and content (Shepard, 1989). I actually had fellow teachers tell me that they would never give an essay test, or any other test which they could not run through a Scantron, because it was just too much work to grade.

I completely disagreed with that mentality. Gagné and Briggs (1974) stated that any objective-oriented assessment where students are using any cognitive skill beyond merely choosing, selecting or recalling cannot be accomplished through a multiple choice testing format. In order to get students producing and performing at higher cognitive 
levels, teachers must assess them more authentically. Despite the extra effort and energy this requires, I felt compelled create this type of learning environment within my own classrooms, if nowhere else, where I felt at least a small measure of autonomy.

The beauty of alternative, non points-based grading, for me, is that it brought my beliefs about education and philosophy of teaching into a very clear and harmonious alignment with my actual practices in the classroom. I believe this overlapping of belief and practice to be rare - rare and wonderful. Many times what teachers believe about teaching and learning and what we actually do in our classes are two different things (Stiggins et al., 1989). Despite what we hold to be true, I feel that we, as teachers, tend to make concessions about our prevailing philosophies and beliefs regarding teaching and learning for a myriad of reasons: for expediency and time, or for regulation of large class sizes, or systematic acquiescence, or economic rationalization; we say that we believe one thing and admit that is how we would choose to operate in a perfect world, but we recognize that the educational system is not a perfect world, and so we operate in a style that is contrary to our beliefs. I wonder if perhaps some teachers have operated in this way for so long - a way that is completely contrary to their own beliefs - that they have forgotten what those beliefs are. Having personally experienced a harmony between belief and practice in the classroom, I have found it to be intoxicatingly rewarding, and I am determined to do whatever is necessary to maintain the agreement of belief and practice within my own teaching. 


\section{My own Curiosity, Excitement and Passion Related to Alternative Assessment}

According to Moustakas (1994), phenomenological studies are derived from the researcher's intense interest in a particular problem, and they rely on the researcher's own passion and curiosity to fuel the search, using the researcher's own personal history of the phenomenon as the study's core. To this end, I am well suited to this research.

To say that I am passionate about alternative, non points-based grading would be very accurate. Redesigning my secondary level courses to eliminate all points and traditional forms of grading was not easy. Fielding questions and soothing confusion from students, parents, administrators, and fellow colleagues every semester is a recursive battle. Explaining the purposes behind my grading is a continual processdemonstrating that I am assessing the quality of the work students produce authentically in order to foster more creative and critical thinking as opposed to assumptions that I am haphazardly assigning grades and scores based on personal bias or merely disrupting normative grading practices just for the sake of being different.

And yet, for some reason I enjoy this struggle. I believe it is because of my passion for alternative assessment that I am able to continually defend, implement and recommend an alternative, non points-based grading style; I believe in the results I have seen. I believe in the quality of work I have seen students achieve once points and completion were taken away, and students were left solely to produce assignments to the best of their ability.

Completing the Epoche-a self-reflective process to identify and state my own personal connection with the phenomenon of alternative non points-based grading-has allowed me a space from which to study others' encounters and lived experiences with 
the same or similar phenomenon. I have gained a sense of my own understanding related to my own history with alternative non points-based grading related to the research questions at hand, and I am able to lay down that prior knowledge, to bracket it, and clearly examine how others' lived experiences with alternative, non points-based grading presents themselves.

\section{Chapter Overview}

Chapter Four has detailed the Epoche, the deep self-reflection on the part of the researcher to identify and declare one's own prior experience with the specific phenomenon at hand (Moustakas, 1994). This is done for the purposes of "bracketing" or stating and then setting aside one's own biases so that the phenomenon may be examined and studied in a fresh light, as if for the first time (Moustakas, 1994, p. 85), allowing it to exist as it is and to accept it however the phenomenon presents itself. I have detailed my own experience with the phenomenon at hand, alternative non points-based grading in relation to the research questions that will guide this study: my own experience with it, how it relates to my instructional practices, how it affects the type of feedback I give, and how it relates to my own educational philosophy. Furthermore, in keeping with principles of qualitative research and phenomenology, I have detailed my own passion and excitement regarding this subject, which will generate the core structure of this research and fuel the study to its completion (Moustakas, 1994).

In the next chapter, I will use this fresh perspective that I have gained through the Epoche to clearly report and analyze the data that I have gathered from the study's participants. Through an analysis of the textural and structural elements of their 
experiences, I will seek to arrive at the essence of phenomenon, the lived experience of employing an alternative, non points-based grading system in the classroom. 


\section{CHAPTER V}

\section{PRESENTATION OF DATA}

During the data collection process, I conducted semi-structured initial interviews of each teacher participant. Initial interview questions that were drafted in order to examine the primary and subsidiary research questions of the study (see Appendix A), however I allowed for follow up questions as they arose. Primarily, these initial interviews centered around how the implementation of an alternative, non points-based grading system influenced their instructional practices in their classrooms, how their prevailing philosophies of teaching and learning related to their motivation for grading in this fashion, and how their grading systems affected the nature of the feedback they provided to their students. Once the initial interviews were completed, all sessions were transcribed and the trustworthiness was verified through a member checking process.

Following the initial interviews, I conducted a focus group with three of the five teacher participants using an online meeting place software program, Blackboard Collaborate, to account for those in disparate locations. Two of the study's participants were unable to take part in the online focus group due to their coaching schedules, which conflicted with all possible times for the focus group. However, those individuals elected to participate in their own mini-focus group that, while unable to offer the same comprehensive feeling of camaraderie, could at least allow them to collectively think 
through some of the issues related to the support that they receive in their grading. The content of the focus group(s) revolved around the types of support each teacher received in relation to their grading system. It also offered the teachers a sense of camaraderie and solidarity with others who grade in similar alternative - and potentially marginalizedfashions. Similarly, the focus group and the mini focus group sessions were also transcribed and member checked for trustworthiness.

Throughout the duration of the study, I also asked participants to analyze the nature of the feedback that they provide to their students. The teacher participants completed a self-analysis of their own feedback and shared the results with me for a third point of data upon which to draw. Participants were provided with examples of coded feedback from the primary and co-primary investigators, as well as a peer reviewed article detailing seven essential features of effective feedback (Wiggins, 2012). Participants were asked to select three assignments from at least three students and code their own feedback based on criteria of their own choosing. They then briefly summarized the results of their feedback analysis, and shared with me their reflections of the insight they gained from examining their own feedback practices. Two of the teacher participants provided this analysis before the focus group was conducted, and a third provided his prior to the completion of the data analysis. The two participants who coached were similarly unable to complete a feedback analysis due to time constraints.

Finally, once the focus and mini-focus groups had been completed, and once I had received the feedback analyses, I again conducted individual "debrief interviews" with each teacher participant. The nature of these interviews was to gain insight related to their perceptions of the focus group, to reflect on their participation in the study as a whole and 
how they have benefited in their instruction-especially related to how their grading practices influenced their instructional practices and the nature of their feedback. Just as before, all debrief interviews were transcribed and member checked for trustworthiness and accuracy.

\section{Phenomenological Reduction and Horizonalization}

Having transcribed all interview and focus group data, I began to analyze the data through a phenomenological lens intentionally ascribing an equal weight and value to all comments and statements. To begin the phenomenological reduction, I first "horizonalized" (Moustakas, 1994, p.125) the data along delineated horizons of: Motivation, Feedback, and Philosophy of Education. I selected these horizons as units of meaning because they directly related back to my subsidiary research questions, which were:

a. What are the motivating factors behind teachers' decisions to implement an alternative, non points-based grading system?

b. How does the use of an alternative, non points-based grading system influence the type of feedback that teachers provide to their students?

c. How does the use of an alternative, non points-based grading system relate to a teacher's educational philosophy regarding student assessment and grading?

\section{Delineated Horizons or Meaning Units}

The delineated horizons that appeared in the statements and comments from the teacher participants were tied primarily to my subsidiary research questions: Motivation, 
Feedback, and Philosophy of Education. I will examine each of these horizons independently before presenting the clusters or themes - the invariant qualities of the experience — and then provide textural and structural descriptions of both individual and composite experiences with alternative grading.

\section{Motivation}

In an effort to address the subsidiary research questions about teachers' motivations in switching to an alternative, non points-based grading system, the teacher participants were asked about their motivations in the initial interview protocol: "What is your motivation for grading in this manner?" (see Appendix A, 1.b.). Regarding her switch to a grading system based on proficiency scales and learning targets, Brandi stated, "I felt like it was a better representation of the knowledge and skills that the students were able to demonstrate." She also elaborated that this style of grading assists in student engagement, "It's a more accurate measure of what students know and what they're able to do, and I've just seen students be a lot more engaged with this type of system." Titus mentioned a very similar motivation for his switch to alternative grading as he described his system as, "trying to give grades to all students that most accurately reflect where they are academically within the class."

Everett echoed these remarks when describing his own motivation for alternative grading, first being a more accurate depiction of what students can demonstrate, but then also presenting information in a way that fosters enjoyment and lifelong learning. "I'd like to make it something that they can continue to enjoy for the rest of their lives," he said, "Not just that they learn it, but that they enjoy doing it, and it's fun, and it's 
something that they can continue doing on their own for years and years throughout their whole lives."

For Christine, the motivation behind this change in grading styles was more about getting away from points-based grading and challenging her students to learn more for purposes of edification. She said:

In the past ... I did everything with points and I feel that so much of it was a game with them, just trying to calculate: "Do I need to do this assignment in order to pass this class?" I'd rather have them focused on what they're learning and what they're taking away from the class rather as to, "I got an A, I got a B, I got a C," and really focus on mastering skills.

Christine also mentioned that one of her motivations for grading in an alternative way was to foster a sense of self-regulation among her students:

At the end of the day, I really wanted these kids to be more self-regulated in their designing and in their troubleshooting when things go wrong. When they leave me and...they're doing this on their own...they're not going to have a teacher there all the time to tell them how to fix something or to give them that feedback. So my end goal is to have them be more self-regulated, have them be more reflective without me.

It was clear that Christine presented her coursework along the lines of real-world application that her students may benefit from should they find themselves needing the use of graphic design skills in a professional setting or otherwise.

Simon's motivations for employing an alternative grading system are closely tied to his own personal ideology and prevailing philosophical principles by which he lives 
his life. However, he admitted to being initially resistant to changing his style of grading for fear of ruffling feathers of his colleagues or making waves within his school. He said: Last year I didn't do this-I played by the rules of the game because I was new to the institutions and the system and I didn't want to rock the boat. Otherwise I would have started it last year.

After settling in, Simon did elect to change his grading system to the 3-Ps system, but he stated his desire to subtly implement change:

There's a lot of things I'm trying to do, but I'm very new in the district and in this institution, so I'm not trying to do it all at once because I don't want to make myself a sore thumb of the district and then get nixed, and then not be able to do anything.

Still, Simon stated how implementing an alternative grading system is vitally important, especially in keeping with his motivations for becoming a teacher and pursuing education in the first place — his desire to affect change and encourage critical thinking among students. He stated, "I think we can do things different and better if we think a little more critically. So in that sense, the grading system works toward [my] ultimate goals."

Simon also stated that he viewed his classes as a "mechanism to chip away at the socialization that has boxed these young people in and killed their creativity." $\mathrm{He}$ elaborated upon that chipping away process by saying:

If you actually want to inspire change in people's consciousness through education, you have to, sort of, do education in a way that will allow for that, and 
I don't think that traditional, hierarchical, point-based, ranked, competitive education models allow for that...

He cited the forward to one of the editions of Pedagogy of the Oppressed (Frere, 1972) where Richard Shawl writes, (paraphrasing) "Education can either be a means to... indoctrinating young people into the way things already work, the mechanisms of the current institutions and systems, or it can be a way to practice freedom."

According to Simon, that is his view of education. He said, "If we want to truly practice freedom, we have to try to structure the process to be as free as possible."

Besides philosophical leanings, some motivations for adopting alternative grading systems were along the lines of equality and fairness. Everett and Titus shared their motivations as being derived more from the inequalities that they had been witnessing over several years of teaching in the classroom. They saw a move to an alternative grading system as a more equitable system for all students in their classes, regardless of individual differences, but especially differences related to socioeconomic status. Titus stated:

Some of our kids from traditionally underserved groups in school were suffering from some of our practices that really were more recording and antiquated policies and practices that didn't really have anything to do with student learning, and so we wanted to make sure that students weren't impacted based on their address.

Everett concurred with this sentiment and related his experience in the previous school year of working directly with "traditionally underserved" students as a tutor after school. He noted that these students had "no support at home." He noticed that the 
underserved students, whom he also referred to as "poverty kids" were having more academic difficulty, especially with their grades, as compared with other students. "I started realizing that most of the stuff they were having problems with were the responsibility-based things," he said. "No one has ever taught these kids responsibility. And these teachers were grading responsibility... How are you grading them on something that you haven't taught them? I mean, you're basically penalizing [students] for not having it when they walk in."

Ultimately, all of these teacher participants were united in their motivations for turning away from traditional grading. Whether those motivations were along the lines of being more closely aligned to their personal philosophies or notions of fairness or equality, or whether it was just that they saw alternatives to traditional grading as a more accurate representation of what their students actually knew and what they were able to demonstrate, they all acted on those motivations to make substantial changes to the ways in which they grade their students. According to Christine:

Grading didn't really make sense before this. I had a really hard time assigning point values to things, you know, [giving] a 4 for this, and a 4 for that, or a -10 for using the wrong color. It just didn't make sense. It didn't feel like teaching.

\section{Feedback}

In order to address the nature of feedback, all teachers were asked about their feedback directly in the initial interview with the question: "In your grading system, what types of feedback do you typically provide to your students?" (see Appendix A, 6), and most of them provided a detailed self-analysis of their own feedback. During the 
interviews, most of the teachers described their feedback as being largely formative and usually informal and conversational. Titus stated that his informal feedback usually happens in the form of conferences, "We'll do a lot of conversation. It might just be two minutes for each one, but the rest of the room [is] working on their [assignments]."

Both Everett and Brandi also spoke to the informal nature of their formative feedback. Everett said that he walks around the room to make suggestions and to "give them some constructive criticism." He said that he "may do six or eight laps around the class by the end of the class period."

Brandi's description of her feedback was similar. She said, "It's a daily process. As they're working I'm walking around the room, and I can see what they're doing. If I see they're on the wrong track, I stop and ask questions, have a discussion about that."

She also made an important distinction here regarding the learning process as being fluid, as opposed to regulated by units of time. This is a major difference between alternative grading and more traditional grading systems, which typically operate with very fixed units and timelines. Brandi said, "It's an ongoing process; it's not finished until the end of the semester."

Christine clearly distinguished between her informal feedback: "walking around the class" and formal of feedback "in a Google Doc," but mostly her feedback was comprised of face-to-face conferences. "We have a lot of student conferences," she said. "I have a lot of conferences with them where we just talk."

Simon described his feedback as more informal and conversational as well, but he provided a recent example of an instance of whole class feedback that is similar in nature to the type he routinely provides his students: 
I'm always giving verbal feedback. Like the other day we were working on the research project that they're doing as a group, and at the end of the class I made a point to tell them, "You guys did a great job today. This is very hard material."-I just made a point to say something to the whole class and give them feedback. The teachers who submitted feedback analyses for this study gained even more insight into their own process of providing feedback. Even though not all participants were able to submit an analysis due to time constraints, those that did gained from the activity. Simon reflected about the feedback analysis in his debrief interview, "I have made a more conscious effort to be more thorough with my feedback as a result of this study, because it has made me more self-conscious about my feedback, which has been good."

In his feedback analysis, Simon said that mostly his feedback is focused on how students can improve the development of their ideas within their writing, and to strengthen the support behind their arguments. "The feedback that I tend to give is toward...trying to be encouraging - to try to encourage my students to think more critically and to keep exploring and keep opening their minds." Simon divided his feedback into three categories: encouragement, asking questions, and "half-joking" negative verbal comments, which he stated that he uses only rarely and only to prod his student to put more thought and time into their work. He stated that:

The bulk of my feedback is encouragement. I frequently write things like, "Please think more about this," "Don't stop here," "You've only scratched the surface; there's way more," and "You need to explain yourself better." I find myself writing the same things over and over again. 
Simon also noted in his analysis that, "I don't seem to care much about grammar, spelling, or punctuation within my students' writings, as I found no examples of me making any comment about such things in the texts I analyzed." This is in keeping with his initial statements regarding his feedback when he stated that although he recognizes that constructing "coherent, grammatically sound paragraphs" is important insofar as "playing the game of school and getting somewhere in this system," but he viewed that as secondary in nature to "developing a critical consciousness" and "being able to express yourself in some way critically." He said, "I would be a terrible English teacher."

Brandi also submitted a feedback analysis where she detailed and categorized the type of feedback she provides. As her grading system was built upon proficiency scales and learning targets that were built into her rubrics for each assignment, most of her feedback indicated what level of proficiency students had achieved. However, she categorized her feedback coding as: Circling where they Meet the Rubric Criteria, Positive Reinforcement, and Questioning and Clarifying Comments.

Most of Brandi's comments were geared toward having students relate their skills to real life events or for personal growth and development. For instance, she made comments like, "Tell me a story of how you used these traits in real life," and encouraged her students to revise their assignments for "a greater understanding of yourself." Brandi's feedback was instructional, but she placed an emphasis on process over product. In the initial interview, she stated, "Knowing why is just as important as knowing how."

Christine provided a detailed feedback analysis with coding that was very thorough and deep analysis, and it was apparent that she gained a great deal from being so intensely self-reflective. She also coded her examples of feedback into three 
categories: Assignment Rating (Approaches, Meets or Exceeds), Suggestions for Improvement, and Subjective Comments. In her feedback analysis she stated:

My main purpose when providing feedback to students, whether verbal or written, is to help them grow. It's not always easy for my students, being graphic designers, to see everything that I see... I try to make my feedback transparent so that my students can develop a clear understanding of my expectations from the beginning. At the same time, I try not to stifle their creativity. I always tell them: I don't want 30 copies of the same thing. They should strive to be original in their thought and in the designs.

Christine detailed her own change process as a grader throughout her analysis, clearly portraying how she dealt with feelings of guilt, maintaining high expectations, and how they related to what was ultimately in her students' best interests:

Through this whole No Points process, my feedback and the way I approach grading has definitely changed. At the beginning of the process, I found myself feeling a lot of guilt when I would assign anything less than meeting expectations. This was especially the case when I knew a student put a lot of effort into an assignment. I realized that I'm really not helping my students by telling them something meets expectations when really is does not. This does not promote growth.

Through this study, and as a result of incorporating an alternative, non pointsbased grading system, Christine experienced both frustrations and epiphanies. One frustration which she documented in her feedback analysis, which she related in both the focus group and her debrief interview, was her shock at her students' response to her 
feedback. On her analysis, Christine wrote, "After I grade a round of assignments, I send out an email to the class to let them know they can view their comments. A lot of times, my students do not check the comments I write on their documents." She echoed this in her debrief interview describing being shocked to learn that her students had not even bothered to view her electronic feedback. In her face-to-face student conferences she would ask:

"Hey, did you see my comment?" "What did you think about that?" "Have you thought about how to make it better?" And they were like, "No, I haven't." Some of them hadn't seen the comments or hadn't taken that initiative. I wish there was a way that I could get them more feedback.

In both instances, Christine noted the importance of following up her written feedback, which was delivered electronically through Google Drive, with individual conferences. In her feedback analysis, Christine stated that, "I've found that personal conversations are far more effective than written comments. I really enjoy the personal conversations with students as it really allows me to see into their thought process." In her debrief interview she concluded that feedback is different having "a human sitting in front of them telling them that it needs to be better."

Finally, in her feedback analysis she included some comments related to a survey she had conducted among her students as to their perceptions of her no points grading, the results of which were pleasantly unexpected:

One surprising thing I learned from my student evaluations is that they prefer the No Points System to actual points. I sent out an anonymous survey to my students because I wanted the truth. This is a direct quote from a student, "I liked the 
grading system. I think it was fair, and gave us more of an opportunity to grow with our work." Another student said, "I think it's a different way of doing it. I feel like you grade upon what we are capable of instead of the amount we do, which is why I like it." This came as a shock to me, because they did spend a bit of time complaining about it. So it is nice to see that they really do understand the system and why I use it.

This same sentiment was echoed by Simon in the focus group when he mentioned, "I've had countless students tell me that they like how this is sort of compelling them to not think about points and to just do the work for the sake of learning." He even related a specific example in his initial interview about a student grappling with this new paradigm of being graded in an alternative, non points-based fashion:

I had a kid who was very cynical at the beginning of the semester... and very suspicious of me, who — just the other day—when we held a democratic assembly so that they could decide what they were going to do for this project, made some comment about how: "I feel like we're doing this just to learn" (Laughs). And I was like, "Yeah. Yes." And now, only a week and a half later, he's already told me, "I really like how you do things." ... So the grading procedure is affecting things, for sure. But for me, it's freeing it up. It's making it more free.

The nature of providing feedback to students is an important element for any teacher, regardless of how they grade. However, according to these teacher participants, in alternative, no points-based grading systems, feedback becomes critically important. Perhaps especially because the grading system is largely or entirely different than that to 
which students have become accustomed, teachers in alternative grading system must provide continual feedback to let students know how they are doing and how they can improve and grow. While all of these teachers spent some time thinking about their own feedback and the specific purposes behind it, those who completed the detailed feedback analysis demonstrated visible personal growth related to their own instruction and grading practices.

\section{Philosophy of Education}

The third subsidiary research question of this study was regarding the philosophical motivations for employing an alternative, non points-based grading system. All teacher participants were asked: "How does your educational philosophy or your philosophy of teaching align with your grading practices?" (see Appendix A, 8). Some participants expounded upon their philosophies to greater lengths than others. Brandi neatly summed up her philosophy by stating:

Teaching and learning is all about what do you want [students] to be able to know and do, and how are you going to know that they've learned it or that they can do it? I just feel like the standards-based grading gives a more clear picture of whether they know it or whether they're able to demonstrate that skill than just assigning a point value to whether or not they've completed it, because they could have completed it but still have no real understanding about what they did, or it might not be their own work.

This was the only instance where Brandi referred to her grading as "standardsbased." She typically described her grading system as "proficiency-based grading." 
Regardless of her semantics, it is clear that her grading practices are in line with her beliefs about education. When speaking of her philosophy of education, she also cited the gradual release of responsibility (GRR) model of teaching (Pearson \& Gallagher, 1983), and stated how using that instructional model was aligned with her beliefs about teaching and learning.

Many of the participants seemed entirely forthcoming when speaking of their philosophies of education, but there was a decided difference in the tone and feeling of their responses when speaking philosophically. Due to their body language when responding to questions related to their philosophies of education, it almost felt to me as if these teachers may not engage in discussions relating to their beliefs about teaching and learning very often.

Titus was suddenly contemplative when attempting to relate his philosophy of teaching and learning. He discussed his desire to get students to be "as good as they can be," and to "create a desire" and a "pride in what they can do, or pride in their capabilities," but then he began to address some ways that we may demotivate students:

The whole goal would be that they learn. You know, that's it. And all we're doing, in some ways, sometimes, is putting up barriers that stop people $\ldots$ and we've lost our whole goal, our whole mission. And it's funny, you know, in that it's ridiculously stupid here, but our title is: Teacher. We're just supposed to teach. And, I think we complicate it maybe sometimes.

When initially asked about the philosophical attributes of his grading, Simon stated, "That gets into a lot of stuff. I mean, that cuts into my motivation for being a teacher in general." He went on to convey his personal ideology and prevailing 
philosophy at great length, which he exercises throughout his daily life. However, in relating it back to education and specifically his grading he stated:

What I'm trying to do with the grading practices is to best align those practices with my philosophy within the institution that I'm embedded. It's impossible for me to fully align my practices with my personal philosophy within this institution—it's impossible. The institution as a whole doesn't have the same goals as me. So there's a discrepancy, and there's a disconnect there.

The grading system that Simon uses in his classrooms is almost a cocoon, or a safe haven, within an institution with which he is philosophically at odds. "This grading system is an attempt to try to have some sort of cohesion with my philosophy within the confines," he said. "This institution is very obtuse. And so, the grading system itself is a critique of the institution, I think, and it says that we can do things different and better if we think a little more critically." He went on to explain that:

I'm slowly but deliberately—-thoughtfully—-trying to make the environment of the classes I teach more democratic and more free. I'm trying to make my classroom more democratic, and [give] my students a share of the power in our relationship, and give them more freedom, because I think power should be shared, society should be democratic, and we should be free.

Similar to Simon, Titus also elaborated on the connection between his personal philosophy of teaching and learning to his grading:

In my grading, I guess - and I hate how this sounds, because it sounds like nonsense — but my philosophy is that everybody matters. And that we all matter the same, you know? And not that there aren't important people and unimportant 
people, and not that we're all not guilty of valuing self over others and things, but ideally my hope would be that kids come into my room and they would [say], "You know, he's not my uncle and I'm not calling him for ice cream, but he cares about me." And if each one-if they all walked out with that, then I've done a good job.

He went on to address his students' potential motivation for doing coursework, and whether it was related to their positive opinion of him, or not, it was irrelevant because, as Titus put it:

This kid's going to walk out the door here with a degree, or with a diploma—or without a diploma — and they're going to live in our world and need to work in our world and be a part of it, and we've got to make that happen. We've got to help make that happen. We can't do it all, you know. There are too many bad things going on right now that hurt kids, but my big philosophy is I want them to learn as much as they can and feel valued.

Christine, again, related that it was more the nature of traditional points-based grading systems that prevented a harmony between her educational philosophy and her teaching practices within the classroom:

My whole philosophy on education or whole purpose being a teacher is to help my students become self-regulated at the end of the day, and so a points system didn't match up with that thought in my head. When I'm asking students to be able to correct their thinking and correct what they're doing on a daily basis and be able to really process what they're doing and be reflective, that's not-you can't put points on that. 
She elaborated upon how a non points-based grading system is more in line with her beliefs about education and her ultimate goals for what she wants her students to accomplish:

I think this type of system definitely lends itself to what I want for my kids. I can't assign points and percentages and calculations to the way that I want them to think and the way that I want them to do things, it just... they were very conflicting.

Everett's comments about his philosophy related to his grading practices were somewhat unique in that he described how drastically his philosophy of teaching and learning had changed over the years. Once upon a time, Everett would have never even considered adopting an alternative grading system, but he described at length how his beliefs had changed and detailed some of the factors that inspired that change.

He described initially being "very, very black and white" in his thinking about assessment and grading. "I mean, I thought that you had to treat every kid the exact same way or it's unfair to some of them. And I guess I just wasn't taking into account where everybody starts from," he said.

Once he began to realize the disparity of resources - or lack of resources - from which students in low SES have to draw upon, Everett's beliefs about education, and grading in particular, began to change:

When you come to art and you have to bring supplies, there's such an unlevel playing field that I realized I've got to bring it up level before I start assessing it. I used to be very, “You do it or you don't do it. Here's the due date. Everyone's got the same due date and it's perfectly fair." And then I realized that a lot of kids 
don't have the advantages... These kids go home and there's nobody home. I mean, they're by themselves the whole time. I realized I've got to treat every kid on an individual basis and do what I can do for him to try to ensure that he's successful in the classroom.

Everett went on to state that while he once thought of himself as "just a reporter", he now approaches it from the vantage point that "it's not really fair to those kids who don't have the advantages." Therefore, Everett parcels out his time to intentionally give more of it to students who may lack the support structures from other places. "I have found that the kids that have the support and have had the listening skills coming in and the focus, they learn despite less attention. And the other kids benefit from the additional attention."

Everett went on to mention that his views began to change several years back when he had conversations with an old wrestling buddy from college who is now a principal in a different high school in Illinois. Everett's friend explained some of the changes he was making within his school that were based largely upon the work of Wormeli (2006), and Everett initially took issue with it:

I argued with him all night. I said, "That's great in theory, but practically it's not gonna work." Before he left he said, "Hey, I'm going to send you a book and I just want you to read it.” And I said, "Okay." So I got this book called Fair Isn't Always Equal by Rick Wormeli [2006] and I read it. And I reread it. And I finally called him up and said, "You know what, man? This makes sense. You're right. I agree with what you're saying now. I didn't think of it from that perspective and 
now I do." And so he sent me another couple of books and I read them, and I was hooked after that. Then I was changing what I was doing in the classroom.

Titus also admitted to changing the way he grades, and the way he thinks about grading, over time. He admits to being "guilty" if we go back "10 years ago," of simply providing students with an assignment, checking it off the list, putting it in the gradebook, and moving on. He said, "If there was a poor performance, we'd write that off as "you didn't do what you were supposed to," and we'd move on to the next thing."

Everett stated that this change — a change in the way teachers think about their grading practices - is a key first step to reforming one's grading practices. Once teachers begin to metacognitively examine their grading, then they may be able to arrive at a place where they might consider altering some of their traditional instructional and grading practices. He said that teachers "have to change the way that they think about grading before they can change the way that they grade." He encourages his colleagues around him to question what the grades for their students represent - what they truly mean. "I get all kinds of answers," he said, "but the bottom line that we always come back to: it should show their mastery of the content. Period."

During the online focus group, the teachers spent some time discussing whether or not they, as teachers who employ alternative grading practices within their classes, should advocate for alternative grading — whether or not they should encourage others to use some of these grading systems that they have adopted. Once again the issue of belief in the prevailing philosophy arose. Simon said:

You really have to believe in the system. You have to believe in the process. You have to believe in the underlying principles and the philosophy. I think it would 
be beautiful if everybody got rid of points and letters, but even if they did, if they didn't really believe in it, then it wouldn't be effective."

Brandi concurred with Simon that before other teachers can attempt to switch to more alternative forms of grading, they need to have a good understanding of their "success criteria," and a good understanding of "what they really want their students to know and be able to do." If not, she argued:

“They're just going to be putting a number-or a Meets or Exceeds—at the top of a paper, and it's not going to give students feedback. They have to be at a place [where] they're able to explain what it is they expect the students to do and what they expect them to know. Or else they're just using the points system.

Christine, while in similar agreement with Brandi and Simon, did express a certain amount of optimism during the focus group that other teachers may have a growing interest in alternative grading. She said, "I find myself having conversations with other teachers in my district and there are quite a few people who are interested that I've talked to about it and I think that it's more about just getting the word out there." Although Titus and Everett were not privy to this conversation in the online focus group, it is clear from their other statements that they spend a certain amount of time and effort speaking with other colleagues from their school and encouraging members of their faculty to analyze their own grading practices. To this end, in his initial interview Everett said he encourages other teachers by saying, "You don't have to change the way you teach, just change the way it's recorded in your gradebook. And a lot of them struggle with that because they've been doing it for 25 years. That's how they learned it." However, he holds fast to the beliefs supporting his style of alternative grading: 
I tell teachers that if you can come up with a reason that this doesn't make sense to you without using the phrase, "Because it makes it harder for me"-because it's not about you — then I'd like to hear it. And they can't. They cannot. Now, some are offended that I would even say something like that to them, as if: "I don't work hard." I don't say you don't work hard. I'm just saying this is about getting information to kids so that they can get to the next level.

However alternative grading is advertised, discussed, or adopted, it is clear from the comments of these teacher participants that their underlying and foundational beliefs about the nature of education and their philosophies of teaching and learning were central to adopting alternative grading systems. Whether their beliefs stemmed from clear and consistent instructional practices, whether they were derived from personal worldviews relating to social justice and democracy, or whether they were forged over years on the front lines of classrooms grappling with teaching theory as it relates to practice, the decision to alter their grading practices was deeply and passionately rooted in their philosophies of education related to teaching and learning.

\section{Invariant Qualities, Horizon Clusters, or Themes}

Through the process of horizonalization, all data were analyzed according to delineated horizons, which related back to the subsidiary research questions of this study. Throughout that analysis, some common themes or invariant qualities - qualities which appear to be essential to the nature of the experience (Moustakas, 1994)-began to arise from the participants' statements and descriptions. These themes were organized into horizon clusters and considered independently as to their own inherent nature of the 
phenomenon of alternative grading. The invariant qualities identified were: Revision or Resubmission of Assignments; Student Learning; Students' Perceptions of "Being Done" or Being Satisfied with "Good Enough;” Practice; the Nature of Success; and the Nature or Purpose of Grading. An examination of each invariant quality will be presented below through the collective responses of all participants before offering both individual and composite textural and structural descriptions of the experience of grading alternatively in the secondary schools.

\section{Revision or Resubmission of Assignments}

One of the most common qualities that continually arose from the data was the fact that all teachers allowed some form of revision or resubmission of assignments. This is not too surprising in that all of these teachers had abandoned traditional grading to pursue grading practices that were more reflective of mastery learning. One essential aspect of mastery learning, as coined by Bloom (1968), is the use of correctives, whereby the teacher will offer feedback on students' initial submissions in order to move them to a level of proficiency or mastery of the content. This principle is embraced by all of these teachers, and as such it is an invariant quality of this experience. The allowance of resubmissions seems to then branch out into other aspects of this phenomenon, including student learning, the perception of "being done," and the nature of success.

Titus and Everett employ a grading system that is very open where students are allowed to revise any assignment, and based on their comments, they appear to be in a school community where their colleagues do not necessarily share those viewpoints. Everett neatly summarized his thoughts on the issue of allowing revisions saying: 
I would rather you turn in something that you are happy with, something you put the time in, you feel good about, than something you feel rushed to get in because you changed your mind halfway through, or because you were [absent] for a while. The important thing is that they learn it, not at what point in the unit that they learn it.

Everett reiterated that learning is the ultimate goal, regardless of when it occurs by stating that some students may not "get it" at the beginning of the semester, "but as long as they get it by the end, we're good."

Titus mentioned how this quality alone - being able to revise assignmentsseemed to contribute to a distinct change in the way students viewed the work in his class. In the mini-focus group he stated:

I think they've been so trained in the status quo that they just go along, and then when the light goes on, I think the big thing that they get is, "You mean I can fix this? I can learn this—I can go back and learn this?” That's the part that they get - that they can continue to show their progress.

Of course, to Titus this was an incredibly positive outcome of his grading system, but it wasn't the only one. Titus also stated how he anticipates that this aspect of being able to revise assignments will inspire a feeling of hope among his students where they may not have had any previously:

I do think what we'll see towards the end of the year: kids will have hope that won't have hope in other classes. Because they'll know, "If I put the work in now, I can salvage this.” ... So the kid that's failing math and the kid that's failing science, and then the kid who's failing Speech for me, well he's going to get to 
the point where mathematically, he doesn't have a chance. And that's going to cause less learning even that last four or five weeks, and a complete shutdown, and behavior issues, and everything else, but the kid with me will always be reminded that it's your choice...

Titus allotted that this type of a revision allotment could account for more grading on behalf of himself, the teacher, but that was a sacrifice that he seemed willing to make in the interest of continued engagement through the end of the term, a chance for increased student learning, and the chance to offer students a sense of hope.

Brandi spoke about how the revisions process in her class has worked to enhance student engagement. In her initial interview, she said, "Students really are much more engaged in working toward achieving this skill or the learning target rather than just completing the item. They will redo things, whereas before they just take the B or the C, and that was good enough. Now they'll redo it because they want their skill to improve." Christine made a similar statement in her debrief interview when speaking about how her grading system has motivated her students' to continually engage with content, even after receiving an initial score for an assignment. She said:

After you assign them a point score, I felt like their knowledge and their growth really truly did shut off because they didn't sit there and ask themselves, "How can I improve this?" And I didn't ask them to. I did tell them, "You can turn in anything whenever you want to," but there was no drive for them to do that because they already had their points.

It was related to this quality of allowing resubmissions of assignments when many of these teachers spoke of their grading as an "ongoing process," as Brandi stated, that 
students' learning doesn't just stop because an assignment has been completed. In their estimations, neither should the grading.

In a similar vein, Everett took specific issue with the common practice of students receiving a zero in the traditional gradebook for failing to complete an assignment, especially a performance assessment. He equated the process of awarding a zero with assessing the student's work and giving them $0 \%$. In the gradebook, that means the same, even though he passionately stated that "there's been no assessment done at all," calling it a non-assessment. He lamented that teachers may tend to "use grades as punitive tools" and riled that, "too many teachers that just throw the zeroes in [the gradebook] and they don't put enough effort into actually getting formative [assignments] done and getting any feedback to the kid."

Everett stated that the grades he reports should only be indicative of what a student knows and can demonstrate, and should never be punitive in nature, and that the resubmission of assignments is essential to creating that sort of environment:

If they didn't turn [an assignment] in, then they haven't learned something, or they haven't demonstrated that they have learned something, or some part of it. Here's another chance. Demonstrate that you've learned it. That's all I'm concerned with: the end game.

Although it seems apparent from their comments that Titus and Everett work in close proximity to teachers who may not believe in allowing students the opportunity to revise their assignments, it is clear that all of the teacher participants in this study view resubmissions of assignments to be an essential quality of their grading systems. This element of revision opportunities seems rooted in some of their educational philosophies, 
as described earlier, and also spills over into other invariant qualities, such as student learning and the nature of success.

\section{Student Learning}

Another invariant quality that emerged in many of the teachers' comments regarding the notion of student learning. In one way or another, all of the teachers indicated that the primary objective of their classes and their teaching is to ensure that students learn, and they feel that their grading systems should accurately reflect the amount of student learning that has occurred. In their initial interviews, the participants made statements regarding how their alternative grading systems seemed to influence student learning. As documented previously, Simon related the story of his student who cynically criticized his instructional process, stating that they were "just doing this to learn," only to come around to truly valuing that process. He followed that up later in the interview by stating:

When you have students who enjoy it, first of all—-they enjoy learning and say things like, 'Oh, we're just doing this to learn," that's success to me. And you can't quantify that. And you can't track it with a [standardized] test. It's not going to show up on the ACT.

The participants' statements in the focus group sessions and the debrief interviews related back to student learning, as well. Brandi stated how the self-reflections she uses enhanced her students' learning, which was her ultimate goal. "There are some who are learning through reflection to improve what they do. I mean, we want students to learn." 
In the focus group, Brandi also commented on her perception of the improved quality of student work that she observed as a result of her switch to an alternative grading system: [One] thing that I wanted to mention was that the quality of my students' work has vastly improved from this type of grading over the points. They used to just say, "Well, I did it. Give me my points," and they were done. But now, the quality just isn't anything close to what they used to do. So I would never go back to using points.

Christine mentioned a similar aspect of the learning and quality of student work she observed as a result of employing a non points-based grading system:

It really did help because it didn't just shut [their learning] off. I would say at least half of the students I saw a significant improvement. Maybe because I was asking for more from them and maybe because I was grading harder, it required them to go further if they really wanted to have a good grade.

From the statements of Titus and Everett it was clear that student learning was the core element of their grading system, regardless of all other factors. In their mini-focus group, they discussed student learning through various angles. When speaking about unmotivated students, Everett recalled encouraging students to learn for learning's sake. He said, "That's a common thing that I hear, 'I don't even want to be in this class.' Well, you're in the class, so let's make the best of it. Let's get a credit. Let's work. Let's learn something!"

Titus concurred that this sentiment is naturally occurring within their grading system remarking that "there's no punishment for learning." Again, many of the 
opportunities for student learning in Titus and Everett's grading system are tied back to the opportunity for students to revise their assignments, but Titus continued:

There's a fear that you'll discourage learning in [some] by allowing learning for everyone, and so the thought is if we allow you to do it later, then you won't do it earlier, and you'll get behind. There's such a fear of that, and you've got to look at your ultimate goal. Your ultimate goal is for these kids to learn as much as possible. And the fear is unfounded because $\mathrm{X} \%$ of your class- $-50,60,70$, whatever you get an hour-they're pleasers. They have the support system and everything to play by the traditional rules and they're going to keep up to pace and they're going to do fine. It's your at-risk, needy kids, traditionally underserved, those are the ones that you then give them a chance to learn - that's really your target. And then the ones that were traditionally fine, they're going to learn even more. It is the true win-win.

It is clear that one of the most essential qualities of these teachers' alternative grading systems is the importance placed upon student learning, above all else. The teachers have taken measures to ensure that the grades they are reporting are truly indicative of the amount of learning that has taken place, at least in so far as the students are able to demonstrate that learning in their classes. According to this data, student learning is an invariant quality of alternative grading systems in that it is unchanging and readily apparent. 


\section{Students' Perceptions of "Being Done" or Being Satisfied with "Good Enough"}

Another interesting quality that arose from the statements of three of the teacher participants was students' notions of "being done"-either with an assignment, or activity, or the learning process itself. As this idea manifest itself in more than one teacher's statements, I felt it worthy of examination as an invariant quality of the alternative grading experience.

These teachers indicated that their students were approaching their assignments with completion in mind, in an effort to "be done" with them. Coupled closely to this approach was a mindset among students that several were satisfied with whatever level they individually deemed "good enough." It seemed that some teacher participants chose an alternative grading system precisely to challenge their students to do more, to go further, and to rise about a status quo when approaching their academic work. Christine commented that deciding "they're done" means that "a lot of them are okay with just meeting my expectations," but that, "some of them want to be the best and they want to exceed my expectations or a project's expectations."

She commented that her grading system, itself, is able to challenge her students to more real-world thinking and application. "I want them to be able to look at someone else's design and be able to get that eye for detail, to get that eye for design," she said. "I like that [the grading system] allows for more thought from [students] instead of me telling them what to do and them doing it, because that's not really always how it works in the real world." 
In a similar way, Brandi described her students as having previously sought out completion and the state of "being done" with her assignments, an attitude she has seen begin to change under her alternative grading system:

Before, when I said, "You can redo it," or "You need to practice it some more," well, they had already received their points and so they were done. Now with this— just the new vocabulary—-they aren't working for points anymore, they're working for the attainment of the skill or the knowledge.

However, she did point out that this new way of thinking about their academic assignments can be challenging for students, as well:

The biggest change is just how the students are reacting to that, because they don't see grades as being ongoing and that they can improve. They are used to thinking that, "This is my grade and I'm done," but now they're thinking where they can go back and they can increase their knowledge or increase their skill. And some choose to do that, and some choose not to, still.

Titus also commented how, as well as overcoming a sense of being satisfied with mediocrity, he related how alternative grading systems offer students a more concrete sense of ownership over their own academic achievement which empowers them, essentially, to rise to whatever level of learning they desire:

I also think ownership [is] a big part of this—resubmissions, and things like that — to know that, "Okay, I'm capable of more," and so they have the choice to do more. Once they've completed the summative [assessment], it's in the gradebook; I'm finished with it, but they don't have to be. They can take it from that $\mathrm{C}$ to a $\mathrm{B}$ to an $\mathrm{A}$, and so they're now- I don't know if empowered is the 
word that I'm going to keep using over and over-but they have the ability then to choose how much they want to learn and they're not limited by one snapshot on one day.

As it was indicated by more than one teacher participant, perhaps overcoming a mindset of "being done" or being satisfied with "good enough" is another unyielding quality essential to the experience of grading students through an alternative system.

\section{Practice}

Yet another quality that was mentioned by some, though not all, of the teacher participants was the idea of practice. In all cases, drawing a clear demarcation between formative and summative activities was essential, even to be able to analyze one's own activities to see whether they were formative or summative. However, many teachers phrased their formative activities as examples of "practice." Especially Brandi, who said, "Any worksheets, any projects, any activities—we just call that practice. So, they might say, 'I need to practice this more.' Much of the class time is used for them to practice." In her proficiency-based grading system, she set up daily formative activities which were explained as and regarded as practice for students. She said, "I allow a whole lot more time for practice, and, it's- I just use the word practice a lot more. Students are much more interested in practicing now than they were before."

Titus and Everett also distinctly differentiated between formative and summative assignments, and just as it takes practice to learn any other skill, they framed their formative activities as essentially practice. Titus said: 
We base everything on formative \{assessment being practice and preparation with skills and the content we're wanting to convey, and then the summative \{assessment\} demonstrates students' level of mastery with that content, and we allow resubmissions with everything that we do. There are no blended scores or averages. It's just this is the level of mastery that you've shown with this, and so that's what I want to report is the most accurate measure.

Everett followed suit in his initial interview stating that homework, being formative, is solely regarded as practice. Their recommendations, as such, would be that homework not be graded, especially as it is just practice.

We're recommending that homework not be graded — it be assessed and given back, but not entered into the gradebook; just graded for completion being that it's more practice. There are too many kids who are not performing on homework, but then they can show they understand it on a test, but the homework grade brings them down.

This notion is certainly in keeping with best practices as espoused by assessment experts (Stiggins et al., 1989; Guskey, 2001; Reeves, 2004), however, this is a notion that is somewhat controversial among teachers, especially those grading in traditional ways, as traditional teachers often view grading as their last true measure of autonomy in the classroom (Reeves, 2008).

\section{The Nature of Success}

The idea of success and what it means to be successful was a specific question from the initial interview (see Appendix A, 7), and as such all teachers in this study 
addressed it. Sometimes, success was described in relation to students and their own individuality. For instance, Christine stated that, "Success is going to be different for each kid." Simon extended this thought, embracing those differences by stating, "We all start at different places; we're all different people; we learn at different speeds, and have different interests"

Other teachers spoke of success and how it related to the academic achievement students are able to achieve. Titus succinctly pegged his definition of success saying, "I think success would be working as close to your capability as possible." He also stated that he uses his grading system to communicate to his students how highly he regards their success. He said, "I want to send the message that failure is not okay, and I'm not going to be okay with it... and I'm not going to let you be okay with it."

Some, like Brandi, spoke of success in relation to both student achievement as well as the barometer by which she would gauge her own classroom as being successful. She said:

I think success for students is when they're fully engaged in what they're learning and they're excited about what they're learning and they're looking for ways to go above and beyond, or apply that in different ways. I guess that would be the same success for my classroom, as well. I like seeing them all working on something different and not to a prescribed formula... based on what they've identified they need to know or they need to do. I mean there's certainly foundational information, but they'll learn those things at different rates and in different ways. 
Simon also described success in relation to how he viewed his own role as a teacher and an educator, and what type of success he might hope to achieve in a more holistic sense. He said, "If there's a couple of students that I can see- through their interactions with their peers or through conversation with me - who start to think differently and evolve and become more critical thinkers, that's successful to me." $\mathrm{He}$ then stated, half-jokingly, "And, maybe because my bar is so low, I think that I've had huge success."

He elaborated in all seriousness, however, stating:

I've only been doing this for not even two full years, and I already have a collection of letters from students who have taken my courses thanking me, and to me that's successful. I'm sure lots of teachers get that stuff, but, the types of letters I've been getting, they make me tear up sometimes. It's like: "I see the world differently now and I didn't think about all of these things before I took your class," and I can tell they're going to be good people, you know? You can't quantify that stuff... Consciousness is not quantifiable and we should stop trying to quantify things like that.

Whether from the perspective of students succeeding academically, or personally, or from a teacher's perception of being a successful educator or role model within the classroom, it is clear that the nature of success is instrumental to these teachers' experiences grading their students in non-traditional means. Despite their divergence from the mainstream grading practices, it is evident that they have taken an alternative path while keeping a very clear vision of success in mind for both their students and for themselves as teachers. 


\section{The Nature or Purpose of Grading}

As this study deals primarily with grading practices, the nature and purpose of grading was a theme that emerged in all of the participants' comments. Obviously, then, the nature or purpose of grading is an invariant quality related to alternative grading. In order for teachers to even arrive at a place to consider grading students in an alternative, non points-based fashion, they must first be willing to analyze and scrutinize their own grading practices, especially the question of: what do students' grades mean (Brookhart, 1993)?

Everett questioned the validity of including non academic achievement data in students' grades, items like extra credit, behavior, participation, effort, etc. (Brookhart, 1991; Stiggins et al., 1989). He encouraged fellow teachers:

Just ask yourself: does the grade reflect content? I mean, bringing a box of Kleenex for extra credit? Does that have anything to do with the content? You know, if this kid misbehaved in class, that's for discipline. That's for the office. That has nothing to do with: does he know his content or not? As previously mentioned, Everett feels that homework should be regarded as formative practice, and therefore, not recorded in the gradebook. However, he elaborated on just how misleading homework scores could be when attempting to report exactly what a student knows, as he reported the unfortunate truth of what goes on in the "library or student center" just before school, " you'll see kids furiously copying homework," he said. 
Thus, according to Everett, there was no way for teachers to genuinely validate that a student was actually the one doing the homework, despite getting full credit for it. He also cited social media and technology as proliferating the avenues students used to forge their assignments, and again pointed out that this further disadvantaged underserved students who do not have access to such luxuries, sardonically stating, "They don't get to cheat on their homework."

Ultimately, it came down to a misplaced emphasis. Everett viewed that emphasis as being placed on homework, "something that they can't even validate that the kid did it, as opposed to putting the emphasis on what they've taught and what [students] can demonstrate that they know on a test."

Other teachers became just as fiery when relating their perceptions of the nature or purpose of grades. Simon minced few words when he stated, "Grading...to me is like a necessary evil within the system. I just do it because I have to, really.” He continued, pontificating:

I'm not even convinced that "assessment," as we talk about it, is even necessary. I know that I should be because I'm a professional educator and I'm supposed to be socialized to accept all of these things that educators are supposed to believe in, but I don't. I don't even think that assessment is necessary... in a lot of ways. I do it because I have to.

Still, Simon related an instance of encouraging a colleague who was also interested in exploring alternative grading for his own class. Simon urged him to maintain his own level of individuality and personal comfort when adopting alternative grading. His advice to other teachers considering adopting an alternative grading system was that, 
"You don't have to be me to do this. You don't have to be an anarchist to believe that getting rid of points is a good idea. You don't have to believe that assessment is largely a smokescreen to believe that this is a good idea. That's the first thing: be yourself"

According to Brandi, the nature and purpose of grading boils down to, "just questioning what you do and why you do it." Christine corroborated this notion by offering suggestions that were in line with backwards design (Wiggins \& McTighe, 2005), "We kind of gotta start at the end," she said. "What types of things are you looking to assess from your students? Are you looking to assess skills? Are you looking to assess their learning? Are you looking to assess their effort?"

Speaking of how he might encourage fellow colleagues on where to begin to analyze their grading, Titus neatly surmised:

The first thing is I'd have them examine: what's the purpose of the grade? And so, when they look at what their grade should reflect, then I would ask them to do a little introspection: do their grades, under the traditional practices, do they do that?

Certainly, the nature and purpose behind grading and the meaning of grades was a central facet of being a teacher who employed an alternative, non points-based grading system. It was undoubtedly an invariant quality of this phenomenon. Based on this data, so, too, are the notions of the nature of success - what it meant to be successful as a student and as a teacher in a class that was alternatively graded — hopefully encouraging students to rise above being satisfied with completion of academic work that was merely "good enough." At the heart of the alternative grading experience, as suggested by this the experiences of these teacher participants, was the role of student learning. Finding 
ways to maximize student learning, especially by employing strategies like allowing students to revise or resubmit assignments — which contributed to their continued growth and development, and may possibly increase their own notions of empowerment and ownership over their academic experience-was essential to alternative, non points-based grading at the secondary level.

\section{Individual Textural Descriptions}

After analyzing the data through a phenomenological lens using the process of horizonalization, identifying delineated horizons of the data, and then organizing the emergent themes into horizon clusters of invariant qualities, I will now record the textural descriptions of the experiences at hand. Textural descriptions, according to Moustakas (1994), are the "what" of any given experience or phenomenon (p.78). As evidenced by the delineated horizons and horizon clusters of invariant qualities, the four cases of this multi-case phenomenology all share certain inherent commonalities even though they represent four different types of alternative grading. I will provide specific textural descriptions each of the following alternative grading systems: Christine's, Brandi's, Simon's, and Titus and Everett's, who share the same grading system.

\section{Case 1: Christine}

Christine describes her grading system as "a mastery type of focus rather than a points and completion focus." She said that the new grading system had a huge impact on the ways in which she planned her instruction, stating that she "definitely put way more thought into planning." 
Each year Christine records her courses' progress in her educational blog. Prior to the semester, she reviewed her blog and broke all of her assignments down into categories. This forced her to "really decide what was a mastery component and what was important."

This process forced her to cut out a lot of her previous material, as she ultimately felt like it was a rote assignment, just doing it for the sake of doing something and she felt like that wasn't in line with her purposes, so she "tried to cut out a lot of the fluff."

She stated that even as the new way of grading impacted her planning, it also in turn caused her to reassess not only her assignments for the course, but also her expectations of what was acceptable and what wasn't.

I found myself redesigning assignments, trying to decide what I wanted the kids to pull from it, and so I had to redesign my expectations. I had to redesign what it means to meet my expectations and I had to decide what it means to exceed them, instead of "What does it mean to get an A?" or "What does it mean to get an F?" What do I want the kids to tell me? How are they demonstrating their learning? Additionally, she tried to align her course redesign with the backwards design of learning (Wiggins \& McTighe, 2005). She questioned:

Where do I want them to end up? What do I want them to demonstrate? This grading system really lent itself to that, figuring [out] — kind of writing the rubric first. I went back into our curriculum map and I started writing my expectations instead of the assessment piece first, because that kind of has become the assessment. 
Christine said that one of the things she liked about grading in this fashion was how it affected her students' thought processes. She said that her alternative, non points based grading system caused the students to have to "think more about what they're doing. I like that it allows for more thought from them instead of me telling them what to do and them doing it, because that's not really always how it works in the real world."

In her grading system, the highest score possible, an Exceeds, was intentionally undefined in order to encourage creative thought among students. "I'm asking them to think outside the box and show me in a creative [way] — trying to get that type of thinking — and that's really the focus of this kind of class." She said:

I like them being able to think about what they're doing and think about ways that they can meet or exceed expectations instead of them making something yellow because it's on the rubric —or putting a certain number of objects on there because it's what they're supposed to do. They're not robots." Obviously, the switch to a new grading system affected the way that she graded her students, but possibly even more than she had originally anticipated. In her both her feedback analysis and her debrief interview, Christine mentioned how she initially went through a period of what she described as "grader's guilt."

At the beginning - I think that's the hardest part—-to feel like you're doing the right thing for your students and that it's working, and that you're having success, because as I mentioned in my reflection, I had a lot of guilt—graders guilt— because I was grading a lot harder than when it was a point system. I was really looking for more and asking for more from my students, and I felt bad for giving them a bad grade. 
However, despite her initial struggles in adjusting to a style of grading that was new and foreign to her, she reflected that she ultimately came to truly the value the way in which her grading system allowed her to provide students more authentic feedback, and how she viewed that process as entirely positive.

It definitely changed my grading a lot. I feel like I am not just putting a score on the paper. I'm really having to explain where I'm coming from to the kids and really make it very clear and visual for them to understand whether they're meeting or exceeding. So it's definitely a little bit more work on the grading end, but it's more fun, I guess-I don't know if that's the right word. I really get into my grading a lot more than just "check, check, plus, plus." I like it a lot better.

\section{Case 2: Brandi}

Brandi used what she refers to as a proficiency-based model of grading. She was introduced to the proficiency scales at a district assessment training. By that time, she had already grown dissatisfied with the traditional points-based system of grading. She said, "I was tired of hearing: 'I'm only going to do this if it's for points.' 'It's not worth enough points for me to do.' And so there was that constant struggle."

Within her proficiency-based grading, Brandi identified learning targets for each activity and built them into her rubrics. She stated that, "We'd already used rubrics; we just had to take the points off of the rubrics and put different headings on top. Probably the largest change was setting up the gradebook, which all had to be done by us."

Currently, Brandi and another one of her colleagues have been commissioned by her district to create and pilot a standards-based gradebook, which she has found rather 
cumbersome. "It wasn't something that was already done, so that was a huge time constraint."

This shift to a new style of grading affected her classroom practices. She reflected about the change in how instruction now operates in her classroom:

Since the focus is on mastering a skill or knowledge and not earning [points], we focus on opportunities for students to practice a skill, not just completing a worksheet or project. We provide students with a variety of opportunities to practice and they choose which ones they need. I do not assign worksheets as homework and then collect and assign points - they are practice opportunities. I will give and go over answers in class so they know how they did. No "grade" goes into the gradebook until the assessment is given over that learning target. Brandi's reliance upon the learning targets and proficiency standards had been very encouraging for her. In relating how her students are interacting with their academic work and her feedback she created a "proficiency scale for the students with all of the targets listed so that they could go along and assess themselves as to where they were at on each individual target as we went through the unit," which allowed her students to continually track their progress. "They were very aware of what the expectations werewhat they were supposed to learn," she said.

There was also an element of collaboration in Brandi's alternative grading as she allowed her student to score themselves on the rubric as well, and an assignment is not complete until the students do so. From there, Brandi said, "I score it and I hand it back to them, and then if they want to work on any particular area, they can redo that area." 
On the whole, she perceived that her alternative grading system had a positive effect on her both her students' quality of work, as mentioned earlier in the chapter, as well as their desire to learn:

After being in this for a full semester and the beginning of another semester, the students really are much more engaged in working toward achieving this skill or the learning target rather than just completing the item. They will redo things, whereas before, they wouldn't redo things - they would just take the B or the C [and] that was good enough. Now, they'll redo it because they want their skill to improve.

\section{Case 3: Simon}

Simon used the 3P Grading System, developed by Peha (1995). This alternative, non-points based grading system is divided into three categories: Progress, Participation, and Performance. Individual assignments are scored with either a check, a plus, or a minus. Simon described the criteria for the scores:

The minuses are me asking them to redo the assignment or to revise the assignment because they haven't done it in a satisfactory way. The checks mean things were fine-it was good. The pluses are the above and beyond assignments.

While that line of scoring seems consistent with, or at least similar to, some of the other alternative grading systems, the 3P system offers a collaborative meeting between teacher and student to finalize the grade for the course.

When it comes time to actually assign a letter grade for the quarter or for the semester, which I have to because I'm in the institution which requires it, they 
grade themselves. They write up a proposal for which grade they deserve in each of those categories, then I tell them what I think they deserve in each of those categories, and then we average the two together with some very simple math. We have a conference. We talk about it. So that's how we come to letter grades. And they supply evidence as well, in a mini-portfolio.

As previously documented, Simon felt this grading system was consistent with his desire to offer his students more of a share in the power of decision-making, as he attempted to structure his classroom in to more democratic fashion. He said, "I teach my students ways to have democratic discussions and try to reach consensus. I give them power to decide for themselves: the parameters and projects and who will do the assessing.”

In order to accomplish this, Simon had to restructure his instructional activities in such a way that allowed students to practice their conferences skills, writing rationales with supporting evidence in order to achieve a measure of consensus and more equitable distributions of authority:

Last semester we practiced with simple rationales and then we moved up to discussions or conferences without the rationales, and then, we did both. I wanted them to practice throughout the semester, so then by the time we came to the actual semester grade, they were prepared. They knew what the conference would be like and they knew what their rationales should be like. I didn't just expect them to go into it blindly at the end of the semester.

During the online focus group, several participants were impressed with Simon's grading system, particularly this aspect of allowing students a sense of authority in 
assessing, and grading, themselves. Both Brandi and Christine referred back to it in their debrief interviews. Christine stated how incorporating this element in to her grading system could help to "create more growth" on the part of her students. "In my system I ask my kids to reflect a lot, but I don't ever have them evaluate themselves," she said, "I think it would help them grow a lot more in the end."

Brandi agreed that having the students actually grade themselves would be something that she would be interested in adopting for her system. Reflecting back on the focus group, she said:

I've done something like that, I don't know if it would be similar, but having them give themselves a score, talking about whether they learned what they wanted to learn, or questions. Having the students evaluate themselves and reflect on their grade - I was interested in hearing more about that, and how that can be adapted to what I'm doing.

Ultimately, Simon's use of the 3P Grading system allowed him to instruct his classrooms from a more democratic platform that encouraged students towards critical thinking and freedom:

I think that because it's open and it's more free, and because the grading system itself is a challenge and a critique of the institution that we're in, it leads them to think — the grading system itself leads to critical thinking.

This also freed him, as the teacher, from the bonds of traditional points-based grading, which was something that he experienced tangibly. He stated:

Last year when I was doing the points system, I definitely caught myself doing some things just so that we could get some points in to the computer. It's like, 
“Oh, we don't have any points yet. I gotta get some points. Their parents are going to look their grades up and there's not going to be any points." So, that affected what I did last year. This year, I don't have that hanging over me so everything we do is intentional and done thoughtfully.

\section{Case 4: Titus and Everett}

As Titus and Everett were regarded together as one singular case as they both employed the same grading system, one of their own unique design. Cases were bound by the alternative grading systems rather than the individual teachers, although in this instance it is allotted that Titus and Everett may have their own unique experiences with the same system. The grading system they used was alternative and certainly nontraditional, although not necessarily non-points based. It certainly could have been run in a non-points fashion, but that was not a requirement. Unlike Brandi, who was officially piloting a standards-based gradebook for her district (and to some extent her proficiencybased grading system), Everett and Titus were unofficially commissioned of their own volition — encouraging their colleagues within their own school (and district) in a grassroots effort to have teachers analyze their own grading practices, at the very least, and possibly to adopt their grading system if possible.

The design of their grading system was one that clearly distinguished assignments as either formative or summative in nature, and while they valued formative assignments, especially meaningful assignments that work to develop skills, they regarded formative strictly as practice, and not something which should have a significant weight in the gradebook. They ascribed a minimal percentage to it, somewhere between $15-30 \%$. They 
felt that non achievement data, such as behavior, attendance, effort, and extra credit, ultimately had no place being factored into the students' grades at all. The primary factor that should account for the majority of students' grades were their summative scores, because, in their line of thinking, that was the clearest measure of what the student knows and is able to demonstrate. Titus outlined it saying:

What we do is we set up two categories, formative assessment and summative assessment—we are still tweaking that trying to find the right percentages that I think will work best—and we base everything on formative being practice and preparation with skills and the content we're wanting to convey; and the summative then demonstrates students' level of mastery with that content, and... we allow resubmissions with everything that we do.

Everett provided further detail about his perceptions of this system, especially the role of homework as formative assignments that was purely practice, and the essential importance of assessing the summative:

Homework [should] be assessed and given back, but not entered into the gradebook - just graded for completion being that it's more practice. There are too many kids who are not performing on homework, but then they can show they understand it on a test, but the homework grade brings them down. And:

We're recommending [that] all tests be allowed to be made up, in fact, all summative assessments have to be made up, or it goes down as an incomplete. You can't assess a kid on what he's done if he hasn't taken the assessment, and 
just throwing a zero in there doesn't help anything. So we're saying that all summative assessment has to be made up, all those tests have to be taken. One key aspect of their system is the teacher's clear understanding of the nature and purpose of formative versus summative assignments. Titus elaborated saying: You could have 3-15 summative assessments throughout a semester if you're doing good formative work to build to those summative assessments. We require that to be eligible to pass a course, you must have completed all of the summative assessments in that class, that's why the number has to be manageable. I mean, this week's daily quiz is not a summative assessment. These are projects; they should be multiple different types of measurements, you know, maybe it's oral this time, maybe it's a written test, project, presentation. So, you have to finish all of those summative assessments because that's the only way that we really know what you know. And then that grade, whatever that is, that percentage, your grade in the class cannot be lower than that grade - because this is what I know. We then blend it with the formative to give you an overall grade, but if your formative were to bring that summative score down, the summative override kicks in and the summative grade is your grade for the course.

Based on their comments and statements, they appeared to be meeting with mixed reactions within their school. They did have a pilot group of teachers who were prepared to adopt this style of grading next fall, but it was also apparent that they had colleagues who were resisting stepping outside of traditional grading norms. In their mini focus group, Titus blamed tradition for this resistance: 
It probably all comes back to how teachers have been judged for years: "How many kids are sitting straight up in their seats?" "How many are focused on the teacher?" "This is how we do it." "This is the right way."

He also described how the element of time, itself, is a prohibitive component of traditional grading:

Even how parents are judged: children are supposed to be seen not heard. We want that compliance, and every assignment in traditional grading is based on time. You know, I determine - regardless of how well I tell it, regardless of what's going on in your world - that in X number of days, every kid should be the same and master to whatever level, and that's all that I want them to learn, because, by golly, I'm going to teach them to follow these rules, and so really, we're grading rule following. Instead, through their system, they have designed it in such a way to continually offer students a sense of hope, an opportunity to learn regardless of any other factors. Everett related his experience tutoring students in his spare time:

There's a few kids that I mentor and - [when] we get into the second half of the semester - if they get far enough behind, or by the time that I get them they're far enough behind, and these teachers don't allow retakes - at that point we cut that class loose and concentrate on the ones that you do have a chance to pass. Had [those teachers] adopted [our grading system], the kid would still have a shot. I mean we could still get him to do the work, we could still get him caught up, we could learn! You know, they're not encouraging learning by doing what they're doing. 
Both of them expressed not only confidence in their grading system as being just and fair, but they also felt that it will eventually be adopted and mandated by their district. Titus stated:

Ultimately, [my] personal opinion, is that it has to be mandated because the disservice that we do across the board with the random policies in different classrooms, and the absurdity of the variety of practices in those rooms, and so many of which — it's not too strong to say — can be pretty harmful to kids. Once it is agreed upon there are certain things that are good for kids that have to happen, or what our mission is, then it's got to be. That it's set in stone.

Everett concurred that he believed their grading system will be mandated, but also that he anticipated a certain amount of backlash. "Anytime you mandate anything that goes counter to what they're doing there's going to be backlash," he said. But they remain undaunted. Titus definitively stated:

We're not afraid at all. Because if it's the right thing to do, that's what you do. And until someone comes in and poses a concern that we can't answer, then I absolutely think this is the only way that it should go.

\section{Individual Structural Descriptions}

According to Moustakas (1994) structural descriptions in phenomenology are essentially the "how" of an experience (p. 78). After analyzing this data through horizonalization and comparing both the delineated horizons and the invariant qualities of the phenomenon of grading in an alternative fashion, not only do the textural qualities of the experience begin to arise, but so, too, do the structural qualities. In most instances, 
"how" the teachers have been able to implement these systems is largely based upon their own incentives, but a close examination reveals that other factors have also played a role in how these systems have come to be. The following sections will detail individual structural descriptions of each case in this study.

\section{Case 1: Christine}

Certainly, Christine's implementation of the No Points System was due largely to her dissatisfaction with points in traditional grading formats, as well as her initiative to seek out a different system that was more in line with the type of learning environment she wished to provide for her students in her classroom. Additionally, she then needed to redesign, or at least restructure, her entire curriculum in order to incorporate the new style of grading being implemented.

However, Christine also went to lengths to describe the support structure and encouragement that she has felt from her colleagues and her superiors within her school, but also even at the district level. She said:

In our district, our administrators are on the forefront of things and on the forefront of educational thinking - they're definitely very supportive. Right from the get-go I went to our Assistant Superintendent and basically asked for permission to do this and asked what his thoughts were on it, and he was all about different types of grading especially when it's a mastery type of focus rather than a points and completion type of focus. They're trying to move things in that direction in our district, so yeah, they're absolutely supportive. 
Certainly, this type of buy in from the highest levels of the district s encouraging in order to create a space for teachers to attempt to experiment with alternative grading measures. Still, Christine related that she even has support among several of her colleagues within her school:

I've had a few people, including members of my department and our surrounding department, ask about the system because I think a lot of them, including my husband (who also teaches at Easton), are really thinking about how they're assessing their students and what that means. Are we assessing effort? Are we assessing mastery? Are we just wanting them to get the work done? I mean what are we truly looking for? We have these conversations all the time at school so whenever I jump in with my system and [am] telling them that it's mastery-focus and that it's more about expectations, not about doing this assignment because I need to get this number of points to get this grade. It's more about the skills they're walking out the door with—what they've learned.

Clearly, Christine's individual efforts contributed greatly to this alternative grading system coming to fruition, but it was apparent that she also benefitted from a supportive school faculty, as well as district administration that bought into these principles - or at least her exploration of them — which also assisted in making the No Points Grading System a reality at Easton High School.

\section{Case 2: Brandi}

Likewise, Brandi took her own initiative to make her grading system a reality. Especially when introduced to the proficiency scales during a district training and 
realized that they harmonized with her own beliefs of what classroom practices should truly be, she had the confidence to act upon them.

From there, her district created a Core Assessment Team, of which she quickly became a member. That her district was willing to spend the resources to at least investigate this type of grading and how it might be incorporated on a wider scale was telling. Additionally, they were willing to give her a position of leadership regarding how it was initially implemented in the schools, which no doubt aided in the generation of the proficiency-based grading system that she employed.

Furthermore, she described taking comfort in having another teacher colleague who was also piloting this system with her. "My counterpart at Weston was on board with me," she stated, "so we have been traveling this road together."

To be able to have a confidant, especially when stepping outside of the traditional norms of any experience, is hugely reassuring. No doubt, this collaborative leadership venture has contributed to the structural designs of Brandi's grading system.

\section{Case 3: Simon}

Simon's use of his the 3Ps grading system was in keeping with his philosophical outlook on education and life as a whole. While he may not have benefited from the same type of encouragement and support from those around him professionally, he related how he found support from his administration as he continued to push the envelope of traditional educational norms for his classroom. "The administration is supportive, surprisingly," he said. He then expounded upon navigating his administration's approval, as well as relating an anecdote of their support of him: 
The more radical shit that I try to get away with, the more they like me, which is weird. So to them, I don't say: “Hey, I have this radical philosophy and I want to try these radical things," it's just like: "Oh I'm trying different stuff," and it's “interesting pedagogy." But they just think I'm doing interesting things, and they love it.

He related this story:

Our building principal recently was at a district meeting where the high-ups at the district gave all of the administrators these books about best teaching practicespeople always talk about "best practices,"-I mean, (Mimicking) "Best practice! You've got to be using best practice!" And one of the highest ranked best practices was: Assessment that is student driven and doesn't involve points (Laughs). And so my principal said to me in a meeting, "You know, when you told me you wanted to do this, I sort of instinctively thought that it was a good idea, but now there is evidence that I can point to that the district has shared," and so he was saying, if you ever get flak from parents or from anybody you can say [that] you have this evidence... So yeah, they're fully supportive of it. Even though he was admittedly attempting to push the envelope of his instructional practices to make them even more closely aligned with his personal ideology, some of which may be at odds with the prevailing normative institutional structures - he even referred to himself as a "Trojan horse"-Simon remained in his administration's good graces, which certainly benefited him in these efforts toward alternative, non points-based grading. 


\section{Case 4: Titus and Everett}

There are many factors which led to the structural development of Everett and Titus' grading system. The first of which was the theoretical examination of their own practices related to instruction and grading. Both teachers mentioned how they had previously operated very differently in the classroom than they do now. Everett even related how his educational philosophy had entirely changed from when he began his career. This reversal of mindset was inspired through conversation with other educators and friends, as well as with each other.

Titus mentioned that they worked together to arrive at a consensus between the two of them regarding what this grading system should entail and how it should operate. Titus stated that:

This school year has been the first year [to] actually put it thoroughly into practice. It actually came up, really started about 18 months ago, 24 months ago. A lot of the components of this I had been doing, but formalizing it, really thinking it through, working with [Everett]—-kinda worked around some of the edges on it, and still letting it evolve as need be as we work through it.

Like Brandi, the two of them expressed a sense of solidarity in that they felt they were in this experience together, and not all alone. Still, it was apparent that they felt like they had the support of their administration, although they described it as a distanced support, and not because their administration didn't want to associate with it, but because they didn't want to appear to be forcing it from the top down. Instead, according to the way that both Titus and Everett related this support, their administration was content to 
sit back and allow Titus and Everett to grow support for this type of alternative grading from the ground up as a more grassroots endeavor. Titus said:

They've supported us all the way. They would like this — what we're doing, or something similar to what we're doing - to be more widespread throughout the building. They just have exhibited a kind of path where they don't want to be involved in any mandates because they're afraid that they won't get a buy-in and it will cause conflict with the staff.

With all of the things that are coming down now, with RTI and Rising Stars and PARCC and all the Common Core work that has to be done, and how that goes into our evaluation, any more things they're saying you must do, especially when there's not a clear answer that you can package buy from someplace... They've really supported - they would be thrilled if what we were doing was school-wide in the future, but as of now I think they want everything to be kind of grassroots. Even from a distance, to know that they have the blessing of their administration to continue encouraging their colleagues to analyze their own grading practices was comforting. Like some of the other teachers, that zone of support had been instrumental in bringing their grading system into the realm of possibility for themselves and other teachers within their building.

\section{Composite Textural Descriptions}

The composite textural descriptions of the experience are those which arise in all of the given cases and overlap. There were many invariant qualities that were shared by several, although not all, participants, such as the use of points, for instance. While points 
were viewed as detrimental to teaching and learning by several participants - even being cited as a motivating factor for abandoning traditional grading-Titus and Everett found ways to grade alternatively, and authentically, regardless of whether or not points were used. However, in describing the composite textural descriptions of this experience, there were certain traits which appeared to be essential across the board with all participants, specifically: a primary focus on student learning, allowing revisions or resubmissions of assignments, and an alignment among these teachers between their educational philosophy and their instructional practices within the classroom.

In every instance, these teachers seemed motivated to alter their grading systems in an effort to foster and engender student learning. Some of them related that student learning more along the lines of critical thinking or creative thinking; some related it to real world skills that could be applicable to their future job market; and others described it solely related to academic achievement at the secondary level. Regardless, increasing student learning seemed to be at the heart of abandoning traditional grading norms and employing a version of alternative grading.

Additionally, allowing students to revise and resubmit work appeared to be consistent across the board with all teachers. Often, this seemed to be an outcropping or natural extension of the first quality — that by allowing the resubmissions, student learning was fostered and developed, as opposed to "cutting that learning off" in favor of a fixed time constraint. None of these teachers favor reporting a student's grade at an arbitrary cut-off date - not until the semester or class was completed. Instead, they described grading, just like learning, as an ongoing process that is fluid and not bound by time. 
Finally, all of these teachers appeared to have taken action in an effort to align their instructional practices in the classroom with their educational philosophy or their beliefs about teaching and learning, or what is best for kids. Especially in an educational climate that is fraught with standardization of assessment, rote learning practices, and scripted curriculums, holding fast to educational beliefs or to act upon theoretical whims is not easy for teachers to do (Feiman-Nemser \& Buchmann, 1985). However, according to Richardson et al. (1991):

Genuine changes will come about when teachers think differently about what is going on in their classrooms, and are provided with the practices to match the different ways of thinking. The provision of practices without theory may lead to misimplementation or no implementation at all, unless teachers' beliefs are congruent with the theoretical assumptions of the practice. (p. 579)

\section{Composite Structural Descriptions}

In the same way that the composite textural descriptions relate the shared nature of the experiences of all participants, so do the composite structural descriptions relate the essential structural features among all participants in this experience. Largely, that appears to be support from the teachers' colleagues, administrators, and district officials.

It may seem obvious to say that administrators who are not in favor of alternative grading measures would not allow them to occur within their schools or districts.

However, there is still a large of uncertainty regarding alternative grading. To have an administration that is wholly on board is remote, although that can be very beneficial. Rather, having an administration that is at least open to the possibility of examining 
alternative grading, or has the capacity to place an amount of trust in teachers to practice their craft and to grade their students in a way that they, the teachers, deem beneficial to their students' learning, growth, and development is essential.

Additionally, it appears to be very helpful to have a local support structure, either a colleague or a confidant who is sharing this experience in order to make it tangible. At the very least, to have a community of teachers or a department that is supportive of these endeavors may be just enough of a support system to allow alternative grading systems to flourish within the current structure of secondary schools.

\section{Synthesis of Meaning: The Essence of Alternative Grading}

The final step in Moustakas' (1994) Transcendental-Phenomenological Reduction is the synthesis between textural and structural elements of a given experience or phenomenon. Synthesizing textural and structural elements in this way will lead phenomenological researchers to arrive at the true essences of the experience at hand.

Having thoroughly analyzed delineated horizons, horizon clusters of invariant qualities, individual textural and structural descriptions, and composite textural and structural descriptions of four select cases of alternative grading systems, I am now at a place to synthesize these elements to arrive at the essence of grading in an alternative, non points-based fashion.

As seen from both the individual and structural descriptions, teaching in a school that is supportive of alternative grading to varying degrees is an essential structural aspect of the experience. Obviously, were one in a school climate that was rooted exclusively in 
traditional forms of assessment and grading, it would likely be very difficult—although not impossible - to grade in an alternative, non points-based manner.

Even so, not all environments that are conducive to alternative grading are the same. Through the experiences of these teacher participants, we have observed various administrative reactions to this phenomenon. We have seen district-level administrations that are on the "forefront of educational thinking and progressive pedagogy," local administrations who are piloting standards-based gradebooks for examination and possible implementation. We have seen school administrations that appear to be currently awakening to "interesting pedagogies and new ways of doing things," and still others who show a veiled support, unwilling to throw much weight behind the effort, possibly for fear of creating a divided school faculty.

Whatever the level of support, in order to effectively employ an alternative, non points-based grading system, having administrative backing is crucial to its success. Furthermore, it is also beneficial to have a measure of support from teacher colleagues, preferably if two or more colleagues are voyaging ahead on the alternative, non pointsbased path together. The teachers in this study were able to share this experience with a confidant along the way have benefitted greatly, and all teachers who participated in this study's online focus group felt a measure of shared purpose and camaraderie.

Essentially, teachers who employ alternative grading systems must be willing to be intensely self-reflective and critically examine their instructional practices as they relate to the end goal of student learning. Many of these teacher participants offered suggestions for how to begin this self-reflective examination: What do the students' 
grades in my class mean? What do I want my students to be able to demonstrate or do? How will they show me that they have learned what I have taught them?

For these teacher participants, it was apparent that their self-reflective capacities stemmed from deeply rooted philosophies of education pertaining to teaching and learning, about and to which they were steadfastly passionate and dedicated. In keeping with the essential nature of the phenomenon of alternative grading, a central theme in all of their educational beliefs was the importance of student learning above all else. These teachers went to great lengths to engender student learning, allowing students opportunities for revisions and resubmissions of work, and sometimes overhauling their entire courses and grading systems to more accurately assess whether or not students genuinely learned in their classes.

When all the qualities and textural and structural elements are boiled down, it is clear that fostering an authentic and much more intrinsic path for student learning is at the heart of alternative, non points-based grading. Perhaps Simon's student related it the best saying, "It seems like we are just doing this to learn."

\section{Chapter Overview}

This chapter has documented the data collection process, the method of data analysis according to phenomenological principles. Following Moustakas' (1994) model, all data has been analyzed through the Transcendental-Phenomenological Reduction, horizonalization, and presented via a synthesis of textural and structural elements in order to arrive at the essence of the experience of grading in an alternative, non points-based fashion. In the concluding Chapter VI, I will summarize the study and outline limitations, 
offer suggestions for future studies related to alternative grading, and discuss this study's implications for the field of education. 


\section{CHAPTER VI}

\section{SUMMARY}

Adhering to the methodological framework of a multi-case phenomenology, having analyzed the data with a fresh and novel perspective after bracketing my own experiences in the Epoche, and having synthesized textural and structural elements to uncover the true essence of an experience, it is important for phenomenological researchers to reflect upon the nature of their research as a whole. To this end, chapter six will summarize this study, discuss the findings - especially related to the relevant literature, as well as examine implications this study has to offer the field of education and possible future studies related to alternative grading.

\section{Summary of the Study in Brief}

In chapter one, I introduce the concept of alternative, non points-based grading, especially in relation to more traditional and commonly accepted forms of grading. I state the problem, namely: that the American educational system is becoming increasingly standardized, especially in its forms of assessment, which is largely consequential to the way in which teachers grade (Briscoe, 1994; Wood, 1994; Shepard, 1999; Stiggins, 2002). I also present my primary and subsidiary research questions in chapter one and define some key terms that are specific to my study, especially: alternative assessment, traditional grading systems, alternative, non points-based grading systems, and 
instructional practices. I then describe the study itself, as well as offer some perspective of the study's significance. Chapter one concludes with a brief overview, and a description of the study's limitations.

In chapter two, I outline my theoretical framework, which has been built upon a constructivist foundation and informed by several researchers invested in alternative assessment and grading practices for decades, namely: Guskey (1999, 2004, 2006, 2010), Popham (1993), Reeves (2004, 2008), Stiggins (1989, 2002), Wiggins (2012), Wiggins \& McTighe (2005), and Wormeli (2006). I then examine the relevant literature beginning with the historical implications of grading and assessment and investigate the way in which grading practices have evolved in this country over the past century, culminating with the very uniform and standardized shape they take in schools today, largely due to the growth of standardized testing and the standards movement. I also detail grading practices themselves, and highlight specific examples of several types of grading models, both traditional and alternative. Chapter two concludes with an investigation of the relevant literature regarding the meaning of scholastic grades, and the findings related to whether or not grades are able to encapsulate what students actually know and can do.

Chapter three outlines the prevailing methodology of this study, and how it is reflected in my research questions, as well as the data collection procedures. This chapter also describes the research design and the emergence of my blended and somewhat complex methodological framework, a multi-case phenomenology. Both of these methodologies are discussed, especially the process of transcendental-phenomenological reduction, in order to frame this study, as well as the way in which I combine these methodological elements. Finally, the chapter concludes with the profiles of the study's 
teacher participants and a breakdown of the four cases based on the four unique alternative grading systems.

The fourth chapter is The Epoche, an account of my own personal history and previous experience with the phenomenon of alternative, non-points based grading. The Epoche is an essential element for phenomenological researchers, as it allows them to state their own perceptions and biases of a phenomenon, and to lay them aside $-\mathrm{a}$ process Husserl (1931) termed as "bracketing” (p. 98). The Epoche allows phenomenologists the ability to analyze the data in a way that is fresh and new, completely clear of their previously held ideas related to a given experience (Moustakas, 1994).

In chapter five, I present the data. After a brief summary of the data collection, I describe the process of analysis, namely the transcendental-phenomenological reduction as outlined by Moustakas (1994), and the process of horizonalization, analyzing the data based on the delineated horizons of: Motivation, Feedback, and Philosophy of Education, from which several themes or invariant qualities emerged: Revision or Resubmission of Assignments; Student Learning; Students' Perceptions of "Being Done” or Being Satisfied with "Good Enough;" Practice; the Nature of Success; and the Nature or Purpose of Grading. I present both individual and composite textural descriptions of each of the four unique cases, and then relate the same process with the structural components, individual and composite structural descriptions. Finally, the textural and structural elements are synthesized in the summary of meanings in order to arrive at the essences of alternative, non points-based grading, as experienced in the four separate cases by these teacher participants. 


\section{Restating the Research Questions}

In the same way that Peshkin (1985) frequently revisited his thoughts as they changed and evolved throughout the course of his study, it is beneficial for qualitative researchers to revisit their initial questions at various points, especially at the final write up stage. In Peshkin's experience, he was sometimes quite a distance away from the initial question with which he started. Therefore, as a way to bring this study full circle and refocus on its origin, the research questions are restated here:

\section{Primary Research Question}

1. How does the use of an alternative, non points-based grading system influence teachers' instructional practices in their classrooms?

\section{Subsidiary Research Questions}

a. What are the motivating factors behind teachers' decisions to implement an alternative, non points-based grading system?

b. How does the use of an alternative, non points-based grading system influence the type of feedback that teachers provide to their students?

c. How does the use of an alternative, non points-based grading system relate to a teacher's educational philosophy regarding student assessment and grading? 


\section{Answering the Primary Research Question}

\section{How Does the Use of an Alternative, Non Points-Based Grading System Influence Teachers' Instructional Practices in their Classrooms?}

When asked directly how alternative grading had influenced their instructional practices, most of these teachers said they had changed very little. Some potential reasons for this may have been that either these teachers had been grading in this way for some time - or grading in a style that was similar, or they taught in such a way that was very conducive for a switch to alternative grading so they did not need to alter their instructional practices very dramatically.

However, it was apparent that the implementation of an alternative, no pointsbased grading system did have some influence on these teachers' instructional practices. One such area was that these teachers were forced to analyze the nature of their assignments, especially distinguishing between formative and summative assessments in their classes. Certainly, Titus and Everett had a clear understanding of formative and summative work, as the entire design of their grading system was predicated upon a thorough understanding of that system. Titus even offered by way of encouragement to any potential teachers who might be considering moving to alternative grading to first make sure they have a clear understanding of the differences between formative and summative assessments, and how best to use each one.

This formative versus summative understanding manifested itself throughout the term for Christine as well, as she indicated that grading in this way forced her to analyze the nature of her assignments, what she wanted her students to actually be able to do. She stated that she realized some of her formative assignments were actually summative in 
nature, and she had to revise her assignment categories. To that end, Christine also stated that this change to an alternative, non points-based grading system caused her to redesign her assignments, her expectations for those assignments, and forced her to do put much more thought into the way that she planned the semester.

Additionally, the transcendent phenomenological reduction of the data analysis revealed that including resubmissions or revisions of student work was one of the essential elements of alternative, non points-based grading. Although these teachers may not have seen this as a specific change to what they were doing, it was certainly one way that the grading system influenced their instructional practices. All five of these teacher participants mentioned including resubmissions or revisions of student work, which aligned with Bloom's (1968) concept of mastery learning. These teachers indicated that their practice of allowing resubmissions was born out of a desire to maximize student learning - allowing students to turn in work they were happy with, as Everett said, and to instill in them a sense of hope, as Titus mentioned, that they can take their work and improve upon it.

Another important aspect of allowing revisions, one that Brandi mentioned, was to make it clear to students that learning, much like their grading, is a fluid process, and that it is not fixed by a certain time limit, and that it is never over. Furthermore, it was clear that all of these teachers' instructional practices were in place solely to foster student learning above all else, the grading system among them. These teachers strongly felt that grades should be a true reflection of students' abilities, and did not feel that grades should be used punitively. 
The essences of how employing alternative grading systems influenced these teachers' instructional practices resulted primarily through an intensive self-reflection in order to analyze what their students' grades truly meant, and whether they were an accurate reflection of student learning. Ultimately, these teachers altered grading practices related to their instructional practices to engender student learning above all else, while also noting the importance of having administrative and collegial support.

\section{Answering the Subsidiary Research Questions}

\section{What Are the Motivating Factors Behind}

Teachers' Decisions to Implement an Alternative, Non Points-Based Grading System?

The motivation for these teachers to implement alternative, non points-based grading systems was very important. As one of the subsidiary research questions, the interview protocols dealt with motivation specifically (see Appendix A), and as such, motivation served as a delineated horizons in analyzing the data.

One of the biggest motivations for these teachers employing alternative, non points-based grading systems was their feelings that this type of grading was a better representation of what students know and can do. When asked, Brandi stated so directly, but others, like Titus and Everett, indicated that they had a strong desire for the grades they reported to accurately reflect their students' abilities.

Another motivating factor for these teachers in grading this way was to attempt to foster a sense of "self-regulation" among their students, as Christine stated. She wanted her students to begin to employ the skills from her content area to get them to "think like a designer" and to give them some "real world" practicality. Brandi also noted that her 
motivation for switching to this type of grading system was to make her class more "student driven" and to "empower them" to "eventually come up with criteria and things on their own."

Finally, the notion of equity among students, especially those coming from low SES played a large role in these teachers' motivations for grading alternatively. Titus and Everett stated specifically how their experiences tutoring students individually gave them a glimpse at the inequities faced by "traditionally underserved" students. Titus said, "We wanted to make sure that students' weren't being impacted by their address."

The motivations for switching to an alternative, non points-based grading system did not occur overnight for these teachers, but rather came about after serious reflection of their instructional practices, four of whom had several years of classroom experience to draw upon. The major factors they cited for the switch was a desire to report grades that were a more complete representation of their students' abilities, to instill in their students a greater sense of self-direction and responsibility, and to provide a system that was equitable and fair for all students regardless of socioeconomic conditions.

\section{How Does the Use of an Alternative, Non Points-Based Grading System Influence the Type of Feedback that Teachers Provide to their Students?}

The nature of feedback that teachers provide their students was a major focus of this study: the teacher participants were asked about it directly in the initial interview (see Appendix A); in the focus group (see Appendix B), three of the five submitted reflections of their own feedback self-analyses; and the concept of feedback served as a delineated horizon for data analysis procedures in that it was s subsidiary research question. 
The teachers who submitted reflections of their own self-analysis reported that the activity of analyzing and coding their own feedback was very enlightening and made them even more "conscious" about the feedback they provided, as Simon said in his debrief interview. Christine also stated how completing the feedback self-analysis allowed her to see some types of feedback that were more effective than others. Ultimately, she found that feedback given in-person seemed to resonate with her students more than with feedback submitted electronically, as she was surprised to find that students sometimes didn't even bother to open the electronic feedback documents.

Furthermore, these teachers described how the bulk of their feedback was largely informal, and came as a result of informally assessing students' work, and then giving them verbal suggestions, criticism, or encouragements. Many of these teachers described their feedback as conversational, with the ultimate goal being for students to produce a higher quality of work.

\section{How Does the Use of an Alternative, Non Points-Based Grading System Relate to a Teacher's Educational Philosophy Regarding Student Assessment and Grading?}

The teachers in this study were very forthcoming when describing their educational philosophies, especially Simon, who detailed specifically how his personal ideologies are woven into his instructional practices, but even his grading system. He stated that his intentions with the grading system were to "best align those practices with my philosophy within the institution that I'm embedded." As he mentioned that his philosophy does not always match up with that institution, he saw his grading system 
itself as a "challenge and a critique of the institution that we're in," and he credited the grading system for leading his students to "think more critically."

Brandi brought her philosophy back to a succinct definition of teaching and learning as being, "all about what you want students to be able to know and do," to which she felt alternative, non points-based grading better suited than traditional grading. Christine also stated, "I can't assign points and percentages to the way that I want [students] to think," which was philosophically problematic in that she sought to develop more independent thinking among her students.

One teacher, Everett, described how his educational philosophy had changed entirely since he entered the profession, especially after getting an up close and personal view of some of the disadvantages faced by his underserved students. His new outlook on education, one built upon equity and a "level playing field," was very conducive for his switch to alternative grading.

Whether motivated by prevailing personal ideology, beliefs about best practices regarding teaching and learning, a desire to encourage skill development among students, or a belief in equitable learning conditions for all, it is clear that these teachers' philosophies related to education. Teaching and learning played a significant role in their implementation of an alternative, non-points based grading system.

\section{Implications of Alternative Grading}

Several of the revelations from this work hold key implications for the field of education and the teaching profession specifically. First and foremost, that alternative, non-points based grading systems are a viable option, one with which these teacher 
participants have had great success. All of them expressed their intentions to continue to use their alternative grading systems in the future, some adamantly refusing to grade in a traditional points-based system ever again. Largely, this was done to align their classroom practices more closely with their beliefs about education and the nature of teaching and learning, and to foster improved student learning, especially by allowing revisions or resubmissions of assignments and providing timely, thorough feedback.

It is also beneficial for teachers employing alternative grading systems to have the support of their colleagues, and ideally a confidant who is simultaneously grading in an alternative fashion. This type of collegial support can be very valuable, especially as opposed to those teachers without the support of anyone around them who may feel as if they are grading alone in the darkness and questioning their own beliefs and if what they are doing is truly in their students' best interests.

\section{Implications for Teachers}

Perhaps the biggest implications of this study are those that relate directly to teachers. Research has shown that most teachers grade in the same ways that they themselves were graded (Reeves, 2008), but that does not necessarily mean that is the most effective manner of grading. Rather, this study would implicate that teachers examine the nature of the grading systems they employ to see if they are reflective of genuine student learning.

As has been documented, allowing resubmissions of assignments is an essential element of alternative grading, one which is intended to improve student learning. Regardless of the type of grading system, other teachers might be encouraged to adopt 
this practice to demonstrate to their students, as these teacher participants indicated, that the process of learning is ongoing and fluid.

Furthermore, other teachers may stand to benefit from analysis the nature of the feedback they provide to students, just as these teacher participants did. There may be discrepancies between their perception of their feedback - what it is designed to accomplished and what it is accomplishing — and what is actually being perceived by their students. Just as Christine discovered, other teachers may gain an understanding of how to offer their feedback through different channels in order to maximize its effectiveness.

Finally, other teachers might benefit from the experiences of these teacher participants and the ways in which they aligned their practices with their beliefs about education, and teaching and learning. These participants were critical and self-reflexive in evaluating their own practices, and many have made significant changes that were not necessarily easy, but ones that they deemed to be in the best interests of students. Other teachers would do well to reflect on their own practices and attempt to bring them into harmony with their own educational philosophies, as much as possible, in order to do what is best for their students.

\section{Implications for Administrators}

Besides the importance this study holds for teachers, it similarly holds many implications for administrators. As the structural descriptions of the experience of alternative grading have shown, varying degrees of administrative support is vital to these endeavors. Whether on the forefront of progressive thinking, like Christine's district, or 
whether more distantly tolerant, like Titus and Everett's district, it is essential for local and/or district administrations to be a support structure for teachers to analyze what their students' grades actually mean and how they might refine them in a more authentic capacity to ensure that grades are indeed fulfilling curricular aims.

Furthermore, as the literature suggests (McMillan, 2001), and as these teacher participants have corroborated, it could be potentially harmful for students to have multiple types of grading systems for every different teacher they have. Therefore, administrators should carefully examine the nature of the grading systems employed in their schools and districts, and whether or not those grading systems are in the best interests of their students' learning and development. As Titus said, "Once it is agreed upon that there are certain things that are good for kids, then it has to be [mandated]."

However, alternative grading practices are not something to be rushed into blindly. Even as some school districts like Adams County (CO) and Excelsior Springs (MO) have adopted standards-based grading across the board, other districts, like Osseo Area School District of Maple Grove (MN) are now backtracking due to lack of support from multiple stakeholders including teachers, students, parents, and community members (Young, 2012). Administrators should carefully assess their needs (Hall and Hord, 1987) in light of their grading practices in order to adopt policies regarding grading practices that can do the most good for the most of their teachers and students.

\section{Implications for Students}

Although this study did not attempt to examine student perceptions of alternative grading systems, several of the teacher participants noted how their students reacted to 
them. Some mentioned their students were confused initially, although both Christine and Simon described how their students eventually came to either prefer this grading system, or at least to understand the purpose behind it.

Either way, Brandi cautioned against sending "mixed messages" (McMillan, 2001, p.31) to students. She did not feel that it is in students' best interests to be graded in different ways for different teachers that they may have throughout the day. Titus agreed with her, stating that just such a scenario could be potentially harmful for students. His solution was for administrations to mandate the types of grading systems that are known to be in the best interests of students, not necessarily the ones with which they are most familiar.

\section{Implications for Teacher Preparation}

This study holds certain implications for those in teacher preparation programs, as well as pre-service teachers, themselves. As the literature has demonstrated, teachers typically grade in the manner in which they themselves were graded (Reeves, 2008). It is possible that pre-service teachers may be preparing to enter the field in the same way, intending to grade their students in the same ways in which they were graded, without actually analyzing the meaning behind students' grades. Pre-service teachers would do well to consider their grading practices and those implications.

Additionally, this study stands to benefit pre-service teachers by encouraging them to analyze the ways in which their grading influences their instructional practices. One major example of this is whether or not to allow resubmissions or revisions of assignments. As the teacher participants in this study have shown, accepting 
resubmissions or revisions of assignments is an essential element of alternative grading, and one which they all do in order to foster student learning.

Furthermore, teacher educators would do well to expose pre-service teachers to various types of grading systems, if nothing else to provide them with options of various grading styles and to offer them alternatives to solely grading in the same fashion in which they themselves were graded. Instructors in higher education may also be encouraged to adopt alternative, non points-based grading systems of their own, especially as they typically enjoy somewhat more autonomy in their courses than at the secondary level, but also modeling an alternative grading system for their teacher candidates could prove beneficial.

\section{Implications for Parents or Community Members}

As with the implications for students, this study is not about parental perceptions of alternative grading, although it does hold some important implications for parents and the community at large. None of the teacher participants mentioned receiving any type of negative feedback from parents regarding their grading systems. Titus alluded to the fact that parents don't really attempt to- nor do they need to - understand how the grading system works, their only concern is with what their student needs to do in order to receive the grade they want. Perhaps this study could encourage parents to begin to change that perception by shifting their own focus so strongly from the final grade earned more towards supporting student learning above all else, as alternative grading practices essentially seek to do. 
Furthermore, all of these teachers mentioned civil responsibility to some degree or another. Whether it was in preparation for real-world skill development and application, like Brandi and Christine described, or whether it was in efforts to produce citizens who are productive members of society, as Titus and Everett stated, or whether it was instilling a critical awareness of their role in the governing social nuances around them, as Simon sought to do, all of these teachers mentioned their grading as a way to foster community development in a positive way. Perhaps alternative, non points-based grading can be expanded to incorporate even more authentic outcroppings of civic engagement.

\section{Findings in Relation to the Literature}

The findings from this study seem interestingly situated in relation to the literature reviewed in chapter two. Certainly, Wormeli's (2006) work has been instrumental. In one case, a teacher participant, Everett, cited Fair Isn't Always Equal (Wormeli, 2006) as one of the main motivators behind the entire reversal of his philosophy of teaching and learning, and which ultimately prompted his switch to an alternatively based grading system. In this case, both Titus and Everett mentioned notions of fairness and equality, especially in relation to socioeconomic discrepancies, as being integral to their rationale for their implementation of an alternative grading system.

In another case, Brandi mentioned the work of Marzano (2000) as having been instrumental to her implementation of proficiency-based grading, learning targets, and her piloting of a standards-based gradebook. It is apparent that these teachers are not making changes on a whim, nor are they being strictly critical of their own practices 
without perspective, but rather they are reflecting upon what they do and the way in which they grade their students in relation to current research in the field.

However, the most telling aspect of the literature that relates to these teacher participants' experiences may be the meaning of grades, and what elements teachers feel students' grade should be comprised of. Just as Brookhart (1991) identified "nonachievement data," i.e., behavior, effort, participation, etc., that many teachers insisted on including in students grades, these teacher participants largely felt that those factors had no place in students' grades. Like the findings of Stiggins et al. (1989) related to best practices, these alternatively grading teacher participants felt that grades should be reflective solely of what the students know are able to do, and many said so directly.

Titus and Everett went further, asserting that even achievement data that is formative in nature, such as homework, daily in-class work, and quizzes, should have minimal to no inclusion in a students' grade, but instead, students grades should be comprised either largely or entirely on students' summative assessments. As Titus stated, "That's the only way we know what we know."

Even among the participants who did not draw such heavily distinct lines between formative and summative assignments, they still spent time reflecting upon the meaning of grades, and attempting to ensure that the grades they reported for their students were more specifically indicative of those students' ability levels.

Another important insight of this study in relation to the literature is the nature of feedback these teachers explored. Three of the five teachers were able to examine their own feedback by taking samples of it and coding their feedback thematically. They then analyzed it in whichever way they deemed to be important, and shared a written 
reflection of their analysis with me. All who submitted feedback analyses mentioned how worthwhile this activity was for them. As Simon stated in his debrief interview, he now makes a "much more conscious effort to be thorough in his feedback as a result of this study, which is good." And not only good, but also in line with the literature, specifically Wiggins (2012) who stated, "research shows that less teaching plus more feedback is the key to achieving greater learning," and that "'no time to give and use feedback' actually means "no time to cause learning"' (p. 16).

As the synthesis of textural and structural descriptions reveled, one of the essences of alternative grading is the emphasis upon student learning as being centrally important. According to the literature (Wiggins, 2011; 2012), student learning is also tied closely to the effective implementation of teacher feedback, which these participants have been able to explore.

Finally, it is also evident that the decision and motivation for these teacher participants to actually change their grading to alternative, non points-based formats was deeply rooted and consistent with their own educational philosophies and beliefs about teaching and learning. This is both consistent with best practices as outlined by assessment experts (Stiggins et al., 1989; Cox, 2011; Campbell, 2012), but it is also a rarity among current teachers, as many teachers experience a disconnect between their beliefs and the practices within the classroom (Fang, 1996). If there is a consistency between beliefs and practice, it often seems to be teachers constructing a philosophy that validates their classroom practices (Simmons et al., 1999). However, these teacher participants did just the opposite: changing their classroom and instructional practices to 
more harmoniously align with their educational beliefs and all to foster an increase in student learning.

\section{Future Studies}

This study has revealed the real possibilities of future research studies based upon and related to the topic of alternative grading in general, and no point-based grading specifically. One potential study would be to investigate the students' perceptions of alternative, non points-based grading, and their experiences of what it is like to be in classes that are graded in such ways. It would be interesting to see their accounts of the difference between being graded in alternative, non points-based fashions compared with more traditional formats, especially over time. Whether students have the same perceptions of alternative grading at the end of a term as they did at the beginning of it might be telling as to the effectiveness of the grading system in accomplishing its essential goal of developing student learning.

Beyond just their perceptions of alternative grading, another worthwhile effort would be to study whether or not being graded in an alternative, non points-based grading system had any impact over students' whole concept of school and the purpose of education in general. In analyzing students' own self-reflections as to the purpose of school itself and their primary reasons for attending school, it could shed light on whether or not the way in which they are graded in a class, either alternatively or traditionally, has any relationship to their purpose and sense of being.

Besides just students' perceptions, studying parental perceptions of alternative, non points-based grading. It might be a worthy endeavor to examine whether parents are 
concerned more with the means or the end when it comes to their students' grades and learning in school. Everett and Titus mentioned their perception of parental opinions during their mini focus group, but found that interaction to be minimal at best, potentially misunderstood at times, and quite possibly ultimately irrelevant to a large degree. Whether parents are aware of the intricacies of alternative grading may not be essential to the practice itself. Still, a study of parental perceptions of alternative grading might be useful to uncover whether parents perceive a difference in the way in which their student is learning, or even engaging in school in general due to the way in which they are graded.

Another intriguing extension of this study would be to analyze the nature of students' performance in alternatively graded, non points-based classes. Perhaps compared with traditionally graded classes, but even stronger still may be to analyze their performances standing alone, independent of any kind of comparison. The beauty of this type of alternative grading is being able to assess in a more authentic and qualitative fashion. Even this study itself — rooted in qualitative methodology and adhering to the principles of phenomenology gives it a power to examine what is, independent of outside pressures or perspectives. So, too, by studying student performance in alternatively graded settings, and potentially assessing or evaluating that performance from a more holistic and authentic vantage could be both rewarding and powerful.

\section{In Closing}

This alternative, non points-based grading journey has been an epic adventure for me, one that began with my own personal desire to alter the way in which I graded my 
students to instill in them a more authentic motivation to learn and to push them to excel far beyond the minutia that commonly satisfied them. That system has been tried and revised, analyzed and honed, evolved and extrapolated, and has now blossomed into the full-blown pursuit of my doctoral experience.

It is markedly encouraging to me — besides that the realization that this work is not finished, but only just begun — to know that this research is ripe with extensions for further study and the possibility of even greater implementation of alternative non pointsbased grading at the secondary level. The nature of the topic is timely; it has revealed a hunger among teachers for even more authentic forms of assessment and grading simultaneously able to motivate and stimulate learning — all of which alternative grading has been shown to be able to do, although it largely requires great effort on behalf of the teachers to remain committed to providing timely, thorough feedback, and it also comes at the expense of sacrificing and breaking away from points, percentages, and other empty quantitative measures of evaluation and assessment.

This study has given me hope that there are more teachers in the field who desire increased student engagement, teachers who are similarly dissatisfied with the rigid structures and confinements of traditional grading. Like Christine mentioned in her debrief interview when reflecting back on the focus group, "It's nice to know that there are other teachers out there that are trying this and that I'm not crazy, or that I'm not that far off...”

She is not that far off, indeed. But she has been an early adopter, one of the first to act and to lend her voice to a cause that is one part hopeful optimism, one part terrifyingly undefined terrain, one part intensely concentrated hard work, and one part 
rewarding vindication in the realization of student potential. In reflecting upon Sartre's (1965) notion of being and nothingness, Morris (1966) said, "To understand what it means for something 'to be' is to understand what it means for that thing 'not to be'" (p. 22). As far as alternative grading is concerned, we have a century's worth of knowledge of what it is not, but through studies like this one- that touches the essence of the pointless grading experience — and through those future studies yet to come, perhaps we can begin to visualize the nature of what alternative grading truly can be. 


\section{CHAPTER VII}

\section{AFTERWARD}

\section{Return to the Epoche}

Reflecting back on the course of this study, it has been both meaningful and vindicating. Yet, through the guidance of my dissertation committee, I have realized that it is expressly necessary to revisit the nature and process of the Epoche more completely, and to describe my own continual challenge throughout in "bracketing" my prior experiences with alternative grading (Husserl, 1931, p. 98). As I mentioned in chapter four, my own experience with alternative, non points-based grading is rather lengthy and setting those experiences aside in order to encounter the phenomenon of alternative grading in a fresh and new way was both difficult and enlightening (Moustakas, 1994).

As this was my maiden attempt conducting a phenomenological study, there were times when I certainly felt my own novice inexperience rearing its head. I had never previously performed the exercise of the Epoche - nor bracketing - and the execution of it was certainly educational. As I mentioned in chapter four, the initial process of stating my prior experience, performing an intentionally self-reflective purging almostdeclaring my preconception — was very unique. It was at once both meditative and therapeutic, as I was able to clearly realize my own biases and presuppositions regarding alternative, non points-based grading. Moustakas (1994) describes the Epoche as a 
clearing process, and I definitely felt that. With my own prior assumptions lifted from my consciousness, although not entirely removed. I can attest that this process benefitted me greatly during the data collection process, as I truly did perceive to be examining the collective cases in a fresh and new light.

Still, once my own experiences were bracketed and set aside, keeping them shelved throughout proved challenging. Perhaps because of my own inexperience as a phenomenologist, or perhaps in a more subconscious manner due to human nature, I fear my own preconceived ideas could have subtly leaked back in to the findings of this study, despite my attempt to prevent them from doing so.

One such instance - possibly the most obvious - is the case of Christine, who implemented my own No Points Grading System at the outset of the 2013-14 school year. After she was put in contact with me by one of my committee members, she was eager to adopt the No Points Grading System, as well as to participate in this study. As I know first-hand the challenges that face teachers who employ alternative grading in their classrooms, I continued to provide support for her related to her grading and her implementation of the No Points Grading System, specifically. My fear is that I may have unintentionally given her a certain measure of preference in describing the findings and implications from her case. Bracketing all of my previous experiences with a grading system with which I am so intrinsically connected was one thing, but keeping those predispositions consciously at bay may have proved to be another.

Another instance when the bracketing of my prior experiences was challenged was with the case of Titus and Everett. As I was both fascinated and encouraged by much of what they were attempting to do, we maintained a running communication and 
dialogue regarding grading practices. At some point, it was difficult for me to discern exactly where my role changed from researcher to fellow collaborator and alternative grader. Even after data collection sessions with the two of them, we would go round and round discussing alternative grading at length in a collegial way that was full of energy, excitement, and passion. I fear that my bracketed preconceptions may have possibly slid back into my description of their case.

Another reason for this fear was throughout our post data collection discussions, it was clear that there were elements of grading and alternative grading about which we disagreed. Even a statement as admittedly powerful as Everett's belief that teachers need not change the way that they teach, only the way that it is recorded in their gradebook-I am not convinced that I agree with that. Regardless, I hope that my personal leanings and my own beliefs - that the way in which a teacher grades creates a specific structure and framework for the class that colors the way in which he or she imparts instruction-did not intrude upon the discussion of the data analysis. Although, I certainly appreciate Everett's view as both powerful and potentially enlightening for teachers who grade using traditional means to begin to analyze their grading practices and to possibly move towards alternative grading.

While there may have been moments where I disagreed with my participants, and they with me, we certainly maintained a healthy and professional association throughout this study. Although it was challenging to bracket an experience in which I have invested so much, like alternative grading, it was simultaneously unique and rewarding. As Crotty (1998) details, phenomenology is designed to be the most objective of all methodologies, one that stands in contrast to the "rampant subjectivism" that abounds (p. 48). Being able 
to successfully bracket one's preconceptions regarding a phenomenon is a key step in the process of maintaining a harmonious duality between subject and objectivity.

I have attempted to do this to the best of my ability, although I allot that there may be times when my former understandings may unwittingly and subconsciously reappear. However, according to Crotty (1998), phenomenologists are commissioned to bracket their experiences to the best of their ability, and no more. Furthermore, he notes that this process is far from a "presuppositionless description" of a phenomenon, and more of a reconstruction of new meaning. He said, "It will be as much a construction as the sense we have laid aside, but as a reinterpretation - as new meaning, or fuller meaning, or renewed meaning — it is precisely what we as phenomenologists are after" (p. 82).

Feeling very much an emergent phenomenologist, myself, and realizing the huge benefit that phenomenology holds for the field of educational research, I endeavor to continue to use this methodology in further studies, either another blended methodological design, or simply as a purely phenomenological design outright. I am eager to hone and refine my own bracketing skills in the future to be able to divine the essence of additional phenomena in an increasingly clear and transparent fashion. 


\section{REFERENCES}

Adams 12 Five Star Schools (n.d.) Standards-based grading informational brochure. Retrieved from http://www.adams12.org/files/learning_services/SBG_Brochure.pdf

Anderson, L. W. \& Krathwohl, D. R. (2001). A taxonomy for learning, teaching and assessing: A revision of Bloom's taxonomy. New York, NY: Longman Publishing.

Anderson, R. S. (1998). Why talk about different ways to grade? The shift from traditional assessment to alternative assessment. New directions for Teaching and Learning, 1998(74), 5-16.

Au, W. (2011). Teaching under the new Taylorism: High-stakes testing and the standardization of the 21st century curriculum. Journal of Curriculum Studies, 43(1), 25-45.

Ayllon, T. \& Azrin, N. (1968) The token economy; A motivational system for therapy and rehabilitation. New York, NY: Appleton-Century-Crofts

Becker, W. E., \& Rosen, S. (1992). The learning effect of assessment and evaluation in high school. Economics of Education Review, 11(2), 107-118.

Bloom, B. S. (1968). Learning for mastery. Evaluation Comment, 1(2). 1-12.

Bloom, B. S. (1982). The Master Teachers. Phi Delta Kappan, 63(10), 664-68.

Bloom, B. S., Engelhart, M. D., Furst, E. J., Hill, W. H., \& Krathwohl, D. R. (1956). Taxonomy of educational objectives: Handbook I: Cognitive domain. New York, NY: David McKay.

Bobbitt, J. F. (1918). The curriculum. Boston, MA: Houghton Mifflin Company.

Bower, J. (2010, February 16). Replacing grading. Retrieved from http://www.joebower.org/2010/02/replacing-grading.html

Bower, J. (2010, March 10). Detoxing students from grade-use. Retrieved from http://www.joebower.org/2010/03/detoxing-students-from-grade-use.html 
Brilleslyper, M., Ghrist, M., Holcomb, T., Schaubroeck, B., Warner, B., \& Williams, S. (2012). What's the point? The benefits of grading without points. Primus, 22(5), 411-17; 427.

Briscoe, C. (1994). Making the Grade: Perspectives on a Teacher's Assessment Practices. Mid-Western Educational Researcher, 7(4), 14-16.

Brookhart, S. M. (1991). Grading practices and validity. Educational Measurement: Issues and Practice, 10(1), 35-36.

Brookhart, S. M. (1993). Teachers' grading practices: Meaning and values. Journal of Educational Measurement, 30(2), 123-142.

Brookhart, S. M. (1994). Teachers' grading: Practice and theory. Applied Measurement in Education, 7(4), 279-301.

Brookhart, S. M. (2011). Starting the conversation about grading. Educational Leadership, 69(3), 10-14.

Brown, A. S., \& Brown, L. L. (2007). What are science and math test scores really telling us? The Bent of Tau Beta Pi, (Winter), 13-17.

Bruner, J. S. (1966). Towards a theory of instruction. Cambridge, MA: Harvard University Press.

Campbell, C. (2012). Learning-centered grading practices. Leadership, 41(5), 30-4; 33.

Carey, T. \& Carifio, J. (2012). The minimum grading controversy: Results of a quantitative study of seven years of grading data from an urban high school. Educational Researcher, 41(6), 201-8; 208.

Carifio, J. \& Carey, T. (2009). A critical examination of current minimum grading policy recommendations. The High School Journal, 93(1), 23-37.

Carroll, J. (1963). A model of school learning. The Teachers College Record, 64(8), 723723.

Casner-Lotto, J., \& Barrington, L. (2006). Are they really ready to work? Employers' perspectives on the basic knowledge and applied skills of new entrants to the $21 \mathrm{st}$ century U.S. workforce. The Conference Board, Inc., the Partnership for 21st Skills, Corporate Voices for Working Families, and the Society for Human Resource Management.

Chapman, H., \& Ashbaugh, E. J. (1925). Report cards in American cities. Educational Research Bulletin, 4, 289-293. 
Cherepinsky, V. (2011). Self-reflective grading: Getting students to learn from their mistakes. Primus, 21(3), 294-8; 301.

Cizek, G. J., Fitzgerald, S. M., \& Rachor, R. A. (1995). Teachers' assessment practices: Preparation, isolation, and the kitchen sink. Educational assessment, 3(2), 159179.

Conley, D. T. (2000). Who is proficient: The relationship between proficiency scores and grades. Paper presented at the Annual Meeting of the American Education Research Association, New Orleans, LA.

Cox, C. H., \& Bloom, B. S. (1980). Basic skills through mastery learning: An interview with Benjamin S. Bloom. Curriculum Review, 19(1), 10-14.

Cox, K. B. (2011). Putting classroom grading on the table: A reform in progress. American Secondary Education, 40(1), 67-87.

Creswell, J. W. (2007). Qualitative inquiry \& research design: choosing among five approaches. Thousand Oaks, CA: Sage Publications.

Cross, L. H., \& Frary, R. B. (1999). Hodgepodge grading: Endorsed by students and teachers alike. Applied Measurement in Education, 12(1), 53-72.

Crotty, M. (1996). Phenomenology and nursing research. London: Churchill Livingstone.

Crotty, M. (1998). The foundations of social research: Meaning and perspective in the research process. Thousand Oaks, CA: Sage Publications.

De Leonibus, N., \& Thomson, S. (1977). Alternative grading systems. The Practitioner $3(3), 13-17$.

Dewey, J. (1904). The educational situation. Chicago, IL: The University of Chicago Press.

Diegelman-Parente, A. (2011). The use of mastery learning with competency-based grading in an organic chemistry course. Journal of College Science Teaching, 40(5), 50-9; 58.

Dweck, C. S. (2006). Mindset: the new psychology of success. New York, NY: Random House.

Eisner, E. W. (1994). The educational imagination: On the design and evaluation of school programs. Upper Saddle River, NJ: Prentice Hall. 
Erickson, J. A. (2011a). A call to action: Transforming grading practices. Principal Leadership, 11(6), 42-5; 46.

Erickson, J. A. (2011b). How grading reform changed our school. Educational Leadership, 69(3), 66-5; 70.

Excelsior Springs School District 40. (2011). Assessment and grading handbook. Retrieved from http://www.essd40.com/userfiles/3/AssessmentGrading\%20Handbook\%2010\%2019\%2011\%20Final.pdf

Fagan, P. (1999). How broken families rob children of their chances for future prosperity. Backgrounder, 1283.

Fang, Z. (1996). A review of research on teacher beliefs and practices. Educational research, 38(1), 47-65.

Feiman-Nemser, S., \& Buchmann, M. (1985). Pitfalls of experience in teacher preparation. The Teachers College Record, 87(1), 53-65.

Feldman, A., Kropf, A., \& Alibrandi, M. (1996, April). Making grades: How high school science teachers determine report card grades. Paper presented at the Annual Meeting of the American Educational Research Association, New York, NY.

Feyerick, D. and Garrett, D. (2011). School teaches by ability, not grade level. CNN.com. Retrieved from http://www.cnn.com/2011/US/05/14/education.gradeless/index.html

Freire, P. (1972). Pedagogy of the oppressed (M. B. Ramos, Trans). New York, NY: Herder and Herder.

Fried, R. L. (2005). The game of school: Why we all play it, how it hurts kids, and what it will take to change it. San Francisco: Jossey-Bass.

Gagné, R. M. (1965). The conditions of learning. New York, NY: Holt, Rinehart and Winston.

Gagné, R. M., Briggs, L. J. (1974) Principles of instructional design. New York, NY: Holt, Rinehart and Winston.

Gewertz, C. (2012). N.H. schools focus on competency. Education Week, 31(20), 1-2.

Good, W. (1937). Should grades be abolished? Education Digest, 4(2), 7-9

Greenstein, L. (2012). Assessing 21st century skills: a guide to evaluating mastery and authentic learning. Thousand Oaks, CA: Corwin Press. 
Guskey, T. R. (1994). Making the grade: What benefits the student. Educational Leadership, 52(2), 14-20.

Guskey, T. R. (2000). Grading policies that work against standards... and how to fix them. NASSP Bulletin, 84(620), 20-29.

Guskey, T. R. (2001). Helping standards make the grade. Educational Leadership, 59(1), 20-27.

Guskey, T. R. (2004). 0 Alternatives. Principal Leadership, 5(2), 49-53.

Guskey, T. R. (2006). Making high school grades meaningful. Phi Delta Kappan, 87(9), 670.

Guskey, T. R. (2010). Lessons of mastery learning. Educational Leadership, 68(2), 5257.

Guskey, T. R., \& Bailey, J. M. (2001). Developing grading and reporting systems for student learning. Thousand Oaks, CA: Corwin.

Guskey, T. R., Swan, G. M., \& Jung, L. A. (2011). Grades that mean something: Kentucky develops standards-based report cards. Phi Delta Kappan, 93(2), 52-57.

Hall, G. E., and Hord, S. M. (1987) Change in schools: Facilitating the process. Albany, NY: State University of New York Press.

Hawley, P. (1993). Being Bright Is Not Enough. The Unwritten Rules of Doctoral Study. Springfield, IL: Charles C. Thomas, Publisher.

Heidegger, M. (1988). The basic problems of phenomenology (A. Hofstadter, Trans.). Bloomington, IN: Indiana University Press.

Hendrickson, J. \& Gable, P. (1997). Collaborative assessment of students with diverse needs: Equitable, accountable, and effective grading. Preventing School Failure: Alternative Education for Children and Youth, 4l(4), 159-163.

Hout, M., Elliott, S., \& Frueh, S. (2012). Do high-stakes tests improve learning? Issues in Science and Technology, 29(1), 33.

Huhn, C. (2005). How many points is this worth? Educational Leadership, 63(3), 81-82.

Hunt, L. H. (Ed.). (2008). Grade inflation: Academic standards in higher education. New York, NY: SUNY Press.

Husserl, E. (1931). Ideas: general introduction to pure phenomenology (W. R. B. Gibson, Trans.). Oxford, England: Macmillan Company. 
Jung, L. A., \& Guskey, T. R. (2011). Grading exceptional and struggling learners. Thousand Oaks, CA: Corwin.

Kant, I. (1881). Critique of pure reason: In commemoration of the century of its first publication (2). Oxford, England: Macmillan Company.

Kazdin, A. E. (1982). The token economy: A decade later. Journal of Applied Behavior Analysis, 15(3), 431-445.

Kirschenbaum, H., Simon, S., \& Napier, R. (1971). Wad-ja-get? The grading game in American education. New York, NY: Hart Publishing Co.

Kliebard, H. M. (2004). The struggle for the American curriculum, 1893-1958. New York: RoutledgeFalmer.

Kohn, A. (1999). From degrading to de-grading. High School Magazine, 6(5), 38-43.

Kohn, A. (2004). Test today, privatize tomorrow: Using accountability to "reform" public schools to death. Phi Delta Kappan, 85(8), 568-577.

Kohn, A. (2011). The case against grades. Educational Leadership, 69(3), 28-33.

Lalley, J. P., \& Gentile, J. R. (2009). Classroom assessment and grading to assure mastery. Theory into Practice, 48(1), 28-8; 35.

Leather, P.K., \& Yocum, M. (March 29, 2012). Beyond seat time requirements. Education Week Webinar. Retrieved from: http://www.edweek.org/media/beyondseattime.pdf

Lichtman, M. (2013). Qualitative research in education: A user's guide. Thousand Oaks, CA: Sage Publications.

Malehorn, H. (1994). Ten measures better than grading. Clearing House, 67(6), 323-324.

Marchionda, D. (2010). Point by point: Adding up motivation. Teaching English in the Two-Year College, 37(4), 408-13; 420.

Marvell, A. (1992) To his coy mistress. In W. Harmon (Ed.), The top 500 poems (pp. 229-230). New York, NY: Columbia University Press.

Marzano, R. J. (2000). Transforming classroom grading. Alexandria, VA: Association for Supervision and Curriculum Development.

Marzano, R. J., \& Heflebower, T. (2011). Grades that show what students know. Educational Leadership, 69(3), 34-39. 
McMillan, J. H. (2001). Secondary teachers' classroom assessment and grading practices. Educational Measurement: Issues and Practice, 20(1), 20-32.

Merriam, S. B. (2009). Qualitative research: a guide to design and implementation. San Francisco, CA: Jossey-Bass.

Messick, S. (1989). Meaning and values in test validation: The science and ethics of assessment. Educational Researcher, 18(2), 5-11.

Moran, D. (2005). Edmund Husserl: Founder of phenomenology. Cambridge, UK: Polity Press.

Morris, V. C. (1966). Existentialism in education. New York, NY: Harper \& Row.

Morrison, H. (1926). The practice of teaching in the secondary school. Chicago, IL: University of Chicago Press.

Moustakas, C. (1994). Phenomenological research methods. Thousand Oaks, CA: Sage Publications.

Norlyk, A., \& Harder, I. (2010). What makes a phenomenological study phenomenological? An analysis of peer-reviewed empirical nursing studies. Qualitative Health Research, 20(3), 420-431.

O'Connor, K. (1999). How to grade for learning. Thousand Oaks, CA: Corwin.

Pearson, P. D., \& Gallagher, M. C. (1983). The instruction of reading comprehension. Contemporary educational psychology, 8(3), 317-344.

Peha, S. (1995). The 3ps grading system: A faster, easier, better way to grade. Teaching That Makes Sense. Retrieved from www.ttms.org.

Percell, J. C. (2013). The value of a pointless education. Educational Leadership, 71(4). Retrieved from http://www.ascd.org/publications/educationalleadership/dec13/vol71/num04/The-Value-of-a-Pointless-Education.aspx

Peshkin, A. (1985). From Title to Title: The Evolution of Perspective in Naturalistic Inquiry. Anthropology \& Education Quarterly, 16(3), 214-224.

Peshkin, A. (1988). In search of subjectivity: One's own. Educational Researcher, (7), $17-21$.

Pink, D. H. (2009). Drive: The surprising truth about what motivates us. New York, NY: Riverhead Books. 
Pink, D. H. (2011) Dan Pink on the surprising science of motivation. TED: Ideas worth spreading. Retrieved from http://www. ted. com/talks/dan_pink_on_motivation.

Popham, W. J. (1993). Educational testing in America: What's right, what's wrong? A criterion-referenced perspective. Educational Measurement: Issues and Practice, 12(1), 11-14.

Reeves, D. B. (2001). Standards make a difference: The influence of standards on classroom assessment. NASSP Bulletin, 85(621), 5-12.

Reeves, D. B. (2004). The case against the zero. Phi Delta Kappan, 86(4), 324-325.

Reeves, D. B. (2008). Effective grading practices. Educational Leadership, 65(5), 85.

Richardson, V., Anders, P., Tidwell, D., \& Lloyd, C. (1991). The relationship between teachers' beliefs and practices in reading comprehension instruction. American Educational Research Journal, 28(3), 559-586.

Robertson, J. (2012). An education revolution beckons the digital age. The Kansas City Star. Retrieved from http://www.kansascity.com/2012/04/16/3559348/educationrevolution-beckons-in.html

Rugg, H. O. (1918). Teachers' marks and the reconstruction of the marking system. The Elementary School Journal, 18(9), 701-719.

Sartre, J. (1969). Being and nothingness: An essay in phenomenological ontology. Secaucus, NJ: Citadel Press.

Scriffiny, P. L. (2008). Standards-based grading. Educational Leadership, 66(2), 70-74

Sen, M. (1998). Alternate assessments in a high school geometry class: Portfolios. Thresholds in Education, 24(3), 30-35.

Shepard, L. A. (1989). Why we need better assessments. Educational Leadership, 46(7), 4.

Shepard, L. A. (2010). What the marketplace has brought us: Item-by-item teaching with little instructional insight. Peabody Journal of Education, 85(2), 246-257.

Silver, J. (Producer), Wachowski, A. (Director), \& Wachowski, L. (Director). (1999). The matrix [Motion Picture]. USA: Warner Brothers.

Skinner, B. F. (1954). The science of learning and the art of teaching. Harvard Educational Review, 24, 86-97. 
Spenser, J. (2010, October 26). Why my district missed it on standards-based grading. Retrieved from http:/www.educationrethink.com/2010/10/why-my-districtmisses-it-on-standards.html.

Stake, R. E. (1995). The art of case study research. Thousand Oaks, CA: Sage Publications.

Stake, R. E. (Ed.). (2004). Standards-based and responsive evaluation. Thousand Oaks, CA: Sage.

Starch, D., \& Elliott, E. C. (1912). Reliability of the grading of high-school work in English. The School Review, 20(7), 442-457.

Starch, D., \& Elliott, E. C. (1913a). Reliability of grading work in mathematics. The School Review, 21(4), 254-259.

Starch, D., \& Elliott, E. C. (1913b). Reliability of grading work in history. The School Review, 21(10), 676-681.

Steadman, L. C. (2010a). How well does the standards movement measure up? An analysis of achievement trends and student learning, changes in curriculum and school culture, and the impact of no child left behind. Critical Education 1(10), 141 .

Stedman, L. C. (2010b). Why the standards movement failed: An educational and political diagnosis of its failure and the implications for school reform. Critical Education, 2(1).

Stiggins, R. J. (2002). Assessment crisis: The absence of assessment for learning. Phi Delta Kappan, 83(10), 758-765.

Stiggins, R. J. (2004). New assessment beliefs for a new school mission. Phi Delta Kappan, 86(1), 22-27.

Stiggins, R. J., Frisbie, D. A., \& Griswold, P. A. (1989). Inside high school grading practices: Building a research agenda. Educational Measurement: Issues and Practice, 8(2), 5-14.

Tierney, R. D., Simon, M., \& Charland, J. (2011). Being Fair: Teachers' Interpretations of Principles for Standards-Based Grading. In The Educational Forum (Vol. 75, No. 3, pp. 210-227).

Van Manen, M. (1990). Researching lived experience: Human science for an action sensitive pedagogy. Albany, N.Y: State University of New York Press. 
Weimer, M. (2011). Grading practices: Liabilities of the points system. Faculty Focus: The Teaching Professor Blog. Retrieved from http://www.facultyfocus.com/articles/teaching-professor-blog/grading-practicesliabilities-of-the-points-system/

Wiggins, G. (1989). A true test: toward more authentic and equitable assessment. Phi Delta Kappan, 70(9), 703-713.

Wiggins, G. (2011). Giving students a voice: The power of feedback to improve teaching. Educational Horizons, 89(3), 23-26.

Wiggins, G. (1991). Standards, not standardization: Evoking quality student work. Educational Leadership, 48(5), 18.

Wiggins, G. (2012). 7 keys to effective feedback. Educational Leadership, 70(1), 10.

Wiggins, G. P., \& McTighe, J. A. (2005). Understanding by design. Alexandria, VA: Association of Supervision and Curriculum Development.

Willis, P. (1999). Looking for what it's really like: Phenomenology in reflective practice. Studies in Continuing Education, 21(1), 91-112.

Wood, L. A. (1994). An unintended impact of one grading practice. Urban Education, 29(2), 188-201.

Wormeli, R. (2006). Fair isn't always equal. Portland, ME: Stenhouse Publishers.

Yell, M, \& Drasgow, E. (2005). No child left behind: A guide for professionals. New Jersey: Pearson.

Young, J. (2012, November 8). Standards-based grading isn't measuring up. Press and News. Retrieved from pressnews.com/2012/11/08/standards-based-grading-isntmeasuring-up/

Zhao, Y. (2009). Comments on the common core standards initiative. AASA Journal of Scholarship \& Practice, 6(3), 46-54. 
APPENDIX A

TEACHER PARTICIPANT INTERVIEW PROTOCOL 
Research Title: Essentially Point-Less: The Influence of Alternative, Non Points Based Grading on Teachers' Instructional Practices Researchers: Mr. Jay C. Percell, Dr. Robyn Seglem

IRB Protocol \#2013-0308

Name (Pseudonym)

Date

1. Tell me about the way in which you grade your students.

a. How long have you graded this way?

b. What is your motivation for grading in this manner?

2. Have you always graded with this system?

a. If not, why did you change?

3. Is your administration supportive of your grading methods?

a. Are your colleagues in your department/school supportive of your grading methods?

4. At the beginning of the semester, how did your grading system affect your planning for the upcoming semester/year?

a. How does it affect your lesson planning on a daily basis?

5. How does your grading system affect your instructional practices?

a. How does your grading system relate to your students' specific learning needs?

b. How does your grading system facilitate your ultimate instructional goals for your students? 
i. Do you provide any "interventions" or "correctives" in order to assist students in reaching these goals?

6. In your grading system, what types of feedback do you typically provide to your students?

a. What is the feedback that you provide to your students designed to accomplish?

b. At what point in the instructional process do you provide feedback?

c. How often do you provide feedback? Multiple times per unit? Per assignment? Per day?

7. How do you define success?

a. For your students?

b. In your class?

8. How does your educational philosophy or your philosophy of teaching align with your grading practices?

a. How is your philosophy of education or teaching and learning manifested your instructional designs?

b. Are there ways in which you feel your instructional practices are disconnected with your philosophy of education or teaching?

9. Would you consider using this type of grading system again in the future? Why or why not?

a. How might you modify this grading system to maximize the quality of your students' performance and production? 
10. Would you recommend this style of grading to your colleagues or other educators?

a. What tips or suggestions would you offer to other educators who are willing to switch from traditional grading systems to non points-based grading? 
APPENDIX B

FOCUS GROUP INTERVIEW PROTOCOL 
Research Title: Essentially Point-Less: The Influence of Alternative, Non Points Based

\author{
Grading on Teachers' Instructional Practices \\ Researchers: Mr. Jay C. Percell, Dr. Robyn Seglem
}

IRB Protocol \#2013-0308

The Focus Group will be conducted online video conference session (to be recorded) that will consist of all teacher participants and will be facilitated by the CoPrincipal Investigator. The specific questions for the Focus Group will be derived from the themes that emerge from the participants' initial interviews, but it is anticipated that these may be potential questions asked:

1. Hello everyone! Thank you so much for taking the time to participate in this focus group. Please introduce yourself to the group using only your pseudonym, and tell us the level and subject that you teach (but not the specific name of your school, please).

2. Great. Now please describe for us the grading system that you currently use in your classroom?

3. What are some of the features that you particularly like about the grading system you use?

4. Are there any aspects of your grading system that you find lacking?

5. What prompted you to employ this type of a grading system as opposed to a traditional grading system? What was your thought process like?

6. How does your grading system influence your instructional practices? 
7. How does your grading system influence the type of feedback that you provide to students? What does that feedback look like?

8. What are your perceptions of the ways in which your students are responding to this type of assessment, feedback, and grading?

9. How are you beliefs or philosophy about education and assessment reflected in this type of a grading system?

Do you ever encounter resistance or push back from parents? Administrators?

Colleagues? Do you have a support system to assist you in this type of grading endeavor? 
APPENDIX C

DEBREIF INTERVIEW PROTOCOL 
Research Title: Essentially Point-Less: The Influence of Alternative, Non Points Based

\author{
Grading on Teachers' Instructional Practices \\ Researchers: Mr. Jay C. Percell, Dr. Robyn Seglem
}

IRB Protocol \#2013-0308

Each teacher will participate in a Focus Group debriefing interview that will be conducted after the online Focus Group at the individual teacher's school sites. The specific questions for the debrief interview will be derived from the themes that emerge from the online Focus Group, but it is anticipated that these may be potential questions asked:

1. What were some of your biggest epiphanies that emerged from the online Focus Group discussion?

2. How can the experiences of the other participants who are also grading without points inform your own grading practices?

3. How might the experiences of the other participants inform the way in which you provide feedback to your students?

4. Based on what you learned from the other participants, are there any ways that you plan to change your current grading practices?

5. Did the focus group provide you with a sense of collegiality or camaraderie to know that there are other high school teachers interested in grading in a similar fashion as yourself? If yes, how so? If not, why not?

6. Would you be interested in participating in further collaborative efforts where high school teachers analyze their own grading systems? 
7. Do you have any input regard what you might like to see in those kinds of collaborative ventures? 